NBSIR 79-1776 (R)

\title{
TRANSCRIPT OF PROCEEDINGS
}

\section{SYMPOSIUM ON \\ TEMPERATURE COMPENSATED \\ VOLUMES IN THE SALE OF \\ PETROLEUM PRODUCTS}

Sponsored By:

The National Conference on Weights and Measures

Date: April 3-4, 1979

Place: National Bureau of Standards

Gaithersburg, Maryland

Ofticial Reporters

\section{NORTH AMERICAN REPORTING}


FOREWORD

This symposium addressed selected aspects of the impact on the sale of petroleum products by temperature compensated volumes. Speakers discussed the technical and economic effects, avallable technology and its performance capabilities, petroleum measurement tables, test methods and equipment, and weights and measures laws and regulations.

The papers and discussions as transcribed have been edited for clarity and conciseness.

The arrangements for the symposium program were made by $\mathrm{Mr}$. Otto $\mathrm{K}$. Warnlof, Manager, Technical Services, Office of Weights and Measures, National Bureau of Standards. 
PROGRAM

Tuesday, April 3, 1979

8:30 a.m. Registration at NBS

9:15 a.m. Session Chairman - Kendrick Simila, Chairman NCWM

Welcoming Remarks - Albert Tholen, Chief, OWM

Objectives - James Bird, Chairman, NCWM S\&T Committee

THE TEMPERATURE/VOLUME RELATIONSHIPS OF PETROLEUM PRODUCTS

Adin $\mathrm{Hall}$

Shell 011 Company and American Petroleum Institute

James R. Whetstone

Fluid Engineering Division, NBS

TEMPERATURE - MEASUREMENT ASSURANCE AND ACCURACY

Jacquelyn Wise

Temperature Measurement Division, NBS

MARKETING IN THE PETROLEUM INDUSTRY

Richard Southers

American Petroleum Institute

UNIFORM NATIONAI STANDARDS FOR AN EQUITABLE AND EFFICIENT MARKETPLACE

John G. Buckley

Northeast Petroleum Industries, Inc.

$1: 45 \mathrm{p} \cdot \mathrm{m}$.

DESIGN AND OPERATION OF MECHANICAL AUTOMATIC TEMPERATURE COMPENSATORS

Emmett Wehmann

Neptune Measurement Company and

Meter Manufacturers Technical Comnittee

PERFORMANCE CHARACTERISTICS OF MECHANICAL AUTOMATIC

TEMPERATURE COMPENSATORS

Howard Siebold

Liquid Controls Corporation and

Meter Manufacturers Technical Committee

PRACTICAL EXPERIENCES OF A RETAIL FUEL OIL MARKETER

Jay L. Dugan

Meenan Oil Company, Inc. 
Wednesday, April 4, 1979

9:00 a.m.

EVENTUALLY - WHY NOT NOW?

George Mattimoe

Division of Welghts and Measures, Hawa11

C. G. Bockus

Division of Welghts and Measures, Hawa11

ANALYSIS OF TEMPERATURE EFFECTS ON GASOLINE MARKETING OPERATIONS

Harold E. Harris

Exxon Corp. and American Petroleum Institute

AUTOMATIC TEMPERATURE COMPENSATION VOLUME OF LP-GAS MEASUREMENT

LeRoy Lindbloom

Northern Propane Gas Company and

National LP-Gas Association

VIEWPOINTS FROM THE FIELD OF WEIGHTS AND MEASURES

Darrell A. Guensler, Assistant Chief

California Welghts and Measures

Other Viewpoints

CONCLUSIONS

NCWM S\&T Committee 


\section{$P R D C E E D I N G S$}

Albert D. Tholen, Chief of the office of Weights and Measures at the Bureau of Standards welcomed the participants in the symposium and introduced Kendrick Simila, Chairman of the National Conference on Weights and Measures and Administrator. Weightsand Measures Division. Department of Agriculture, State of Oregon, as Chairman of the symposium.

Mr. Simila opened the symposium with remarks as follows:

I feel it is a distinct honor to be involved this year with the National Conference on Weights and Measures as Chairman, both of the coming conference in July and of this symposium.

I am sure there are many individuals here who will be contributing significantly to the sessions of the symposium-the discussions, the questions that are going to be raised, and some of the answers given. I look forward myself to learning a lot here on the issues involved in temperature compensation. From my own point of view, I would just like to say that this subject is one that I feel has been lying there dormant for some time. I think many of us have recognized that there are some unanswered questions that need to be addressed and I might just share with you what I believe are some of these issues. I certainly hope to come alyay after the next few days with some more insight into some of these.

What is it in terms of temperature compensation? We all think we know what we are talking about but I am not sure we are all looking at the subject with the same set of definitions or starting points in mind. That is one question I expect we will gain some insight into as we continue here.

Is it feasible, economically and technically? This is another issue to be dealt with here, to be raised, debated, and answered, hopefully, in some areas.

How do we do it in terms of hardware and softwara if it is economically and technically feasible? And finally, when do we do it in terms of various products and marketing levels obviously, it already has happened in some areas and marketing levels and in certain products. In certain types or transactions, temperature compensation has been with ws for some time.

So these are some of the issues that are on the ayenda of the sumposium that have been laid out and the expertise that is here will be sharing their views with us. I hope. personally, that we can come to grips with some of these things because the National Conference provides a gooj forum for such an activity where government and industry interact 
on a level where we are problem-solving in a non-threatening environment. Too much of government/industry interaction in other areas seems to be on an adversary basis.

At least it has been my experience in the time that I have been involved with the Conference that that is not the basis we operate on. So I feel that during the next two days you will have an opportunity to deal with some of these issues in a problem-solving fashion and gain perspective and insight into the subject. Hopefully, we can then come forward with some solutions in terms of recommendations that will give us an improved position in the petroleum measurement area.

At this time I would like to introduce the Chairman and members of the Specifications and Tolerances Committee of the National Conference which is the primary entity that is seeking the guidance of the experts we have here. We have four members of the Committee present this morning. Seated at the table on my right are: Gary Delano from the State of Montana, Frank Nagele, State of Michigan, and Lacy Degrange, State of Maryland. We have one member of the Committee yet to arrive, Mr. Darrell Guensler from California. It is a particular pleasure to introduce Mr. Jim Bird, State of New Jersey, who is the Chairman of the S\&T Committee of the National Conference for this coming year.

I often feel that out on the West coast we have a somewhat simpler type of life. We are a little closer to the frontier so that some of the big city problems and the techniques of discrepancy formulation in measurement, if you will, that are sometimesintroduced by less than straightforward individuals in making measurements have not yet arrived in our area. However, I often see Jim dealing with and solving problems that we have yet to tackle. I look to him as one of the people in the National Conference who has a wide range of experience to share and is certainly qualified to be involved in chairing a committee like the s\%T Committee. So at this time I would like to introduce Mr. James Bird, who will share with us his view of the objective of the symposium.

Mr. Bird described the objectives of the symposium $\exists s$ follows:

We hope to learn from many of you information that ran be coordinated and consolidated by the SiT Committee to maka proper reports or recommendations to the National Conferenca on Weighjts and Measures and to guide us in the future. Many times in the past the Conference and the various committees have responded to problems as they arose. We are now trying to turn this around and anticipate problems. We want to determine what avenues and alternatives are open to us down the road and which ones will be the best politically and economically, and as far as some of us are concarned, 
enforceable by weights and measures officials.

The 63rd Conference Report referenced the Sat Committee's concern about the problem of temperature compensation. Dur tentativapeport for this year will mentian that we are continuing to obtain information and data on the subject. We know that the various technologigs are hera. whether it is hardware, software, or test methods.

There are also political and legal problems that must be considered. Several states have contradistory opinions. In one state the Attorney General or the judicial system said that as long as it is not referenced (djsallowed) in Handbook 44, you can do it. Deher states said that unless it is referenced, you can't do it.

Technology must be balanced with cost effectiveness. For example, in some areas an aninistrator would say that if you have temperature compensation for a product, everybody is going to have to do it the same way. Is this really fair? For example, if we require everybody to have automatic temperature compensators on their measuring devices, this may not be the best way of doing it in all cases. You have, say, a large fleet, perhaps 50 or bo trucks, and it may be more appropriate to takg the temperature of the product at the last time that it is being delivered and make the temperature compensation by means of a computer in the office.

We also have to look at the test costs because if you require automatic temperature compensators on measuring devises, the length of the test is going to be extended. consequently the cost. Those of you who are involved in liquid petroleum testing realize that you have to take the regular test with the ATC discornected and then with it connected run more tests to determine in fact if that devise is accurate. Really you are testing two devices, it takes more time and it may take more equipment.

Then you have the political problem. In some areas of the west, it doesn't matter whether one stata has it or not because the merchandising system doesn't really cross the state 1 ine. But in the northeast, for example. New Jersey has to balance with Delaware; Delaware with Maryland, Pennsylvania and New Jersey. Pennsylvania with New Jersey, Delaware, Maryland, Ohio, West Virginia. New York with Pennsylvania, New jersey, Connecticut, Massachusetts, and Vermont, and so on. You have to determine the marketing patterns and everybody has to agree on a regional basis.

Reiterating what Ken said about the definitions, we have to define what the standards are. Quote, "What is a gross gallon and when is it and what is it?" Those things have to become standard. These are not only S\&T problems, they are L\&R problems, they are state statutory prodlems, they are also political problems because it also gets into the merchandising area of how you are gaing to convince the 
customer that this is the proper way to go.

We have a detailed agenda for the next two days. We have weights and measures people in the audience, we have industry people, we have marketing people, we have people from federal agencies.

I hope that, when we are done tomorrow night and the report is put together, the Sit Committee and others that are involved will have a much better concept of what the total problem is and what recommendations can be made to tha Conference.

We hope here to hear all points and to balance the factors of technology, legality, cost effectiveness, and any additional considerations that may arise.

Once the report is prepared from this meeting, then it will also be redigested by the people that are affected.

Ken also mentioned that a great deal of this information is already known. Through my experiences on the S\&T

Committee, I realize that many people in the meter industry are very well-versed in their aspect. The people in the scale industry are well-versed in their aspert. Similarly, with people in other areas. But seldom do all of us comprehend the whole problem of specifications and requirements for all equipment at any one time except a body of weights and measures people that deal with such problems.

It is our hope that maybe this meeting might be like Certo making jelly; you can't make the jelly without combining ingredients. If, as a result of this meeting, everybody better understands and comprehends the technical problems, the legal problems, the political problems, the cost problems, the enforcement problems, and all the other problems that are related, further down the road we are all going to be better off. Thank you. 


\title{
THE TEMPERATURE/VOLUME RELATIDNSHIPS
}

\section{OF PETROLEUM PRODUCTS}

\author{
Adin Hall \\ Shell Dil Company
}

and

American Petroleum Institute

My presentation this morning, in cooperation with Dr. James Whetstone, is to give you a revieww of the technical aspects of $t$ he thermal coafficient of expansion of petroleum. It is primarily an extract from a 9 th World Petroleum Congress paper entitled, "Investigations of Densities and Thermal Expansion Coefficients Applicable to Petroleun Measurement". Co-authorwith me on this paper were, James R. Whetstona, National Bureau of Standards, and John $A$. Simpson. National Buraau of Standards. If you should desire a copy of the complete paper, I believe that otto Warnlof can supply it.

The vast majority of bulk liquid petroleum is sols on the basis of volumes determined ty meter or by measurement in calibrated tanks. The gross volume obtained is corrected for impurities, if necessary, and because liquid petroleum has a relatively large change in volume with change in temperature, bulk volumes are usually stated at a standard temperature of to degrees Fahrenheit, or in some cases, 15 degrees, centigrade.

It is my understanding that 60 degrees Fahrenheit was chosen in the United States bacause it is very nearly the average ambienthemperature throughout the U.S. during the period of one year.

Measurements at standard temperature are seldom possible, so it is necessary t o convert volume at an observed temperature to volume at standard temperatura. Since measurements of density and temperature are readily obtaines under field or laboratory conditions, volume reduction factors or coefficients of expansion are correlated with density and temperature. Precise knowledge of the density and coefficiant of expansion of petroleum liquids with change in temperature is therefore required. Quantities of patroieum are sometimes expressed in weight units, but this is usually the result of a conversion from a volume measurement.

Petroleum crude oils and finisied products do not a: have the same thermal expansion coefficients. To be 
technically correct, therefore, each batch of material should have its own table for correcting volumes from observed tempéature to standard temperature. To provide such a table for each batch of petroleum material involved in commercial transactions would obviously be impossible. From a practical standpoint, therefore, data are secured for a range of petroleum materials and average values established. These average values can then be expressed as equations which may be used for the preparation of tables. The ASTMIP Petroleum Measurement Tables are the most widely used tables for reduction of volumes to standard conditions.

Obviously, a correction factor for temperatures above bo degrees Fahrenheit will be a number less than one while correction factors for temperatures below bo degrees will be greater than one.

This morning we are concerned with the basic work associated with density and thermal expansion of petroleum from which volume correction tables can be prepared. The investigations, which are the basic data for the API-ASTM-IP Petroleum Measurement Tables generally usad are the following.

1. Density anbd Thermal Expansion of American Petroleum Dils-- National Bureau of Standards Technologic Paper 77-1916.

Based on this investigation, two tables were published: United States Standard Tables for Petroleum Dils. National Bureau of Standards Circular 57-1916 and National Standard Petroleum Dil Tables-- National Bureau of Standards Cireular 154-1924.

Cir. 154 differs frgm Cir. 57 in the range of density and temperature covered ${ }^{1}$ ncludes API gravity rather than Baume. Circular 154 was approved by the American Petroleum Institute and the Bureau of Mines as well as the National Bureau of Standards.

2. (a) Thermal Expansion of Petroleum Dils in the range 0 degrees Centigrade to 300 degrees Centigrade--National Bureau of Standards RP244-1930.

(b) Thermal Expansion of Gasolines from O degrees Centigrade to 30 degrees Centigrade--National Bureau of Standards RP393-1931.

Following these investigations, National standard Petroleum Oil Tables, National Bureau of Standards Circular 410 was publishedin 1936. Financial assistance for these investigations was provided through the American Patroleum Institute. The tables were approved by the AfI, Bureau of Mines and the American Society for Testing and Materials (ASTM) as well as the National Bureau of Standards (NBS).

3. Expansion of Crude Petroleum, Petrolaum Products and Allied Substances-- Report of Instituta of Petraleum Sut-Committee J-- Sampling and Measurement-- 1941. 
The results of an investigation which compared a common factor calculated for approximately 200 oils in addition to those considered in Tachnologic Paper 77 are reported. Although not a laboratory work, it was an important contribution in affirming the data base of Circular 410 . Following this report. Tables for Measurement of Dil was published by the Institute of Petroleum in 1945. 4. The Density of the Liquified Petroleum Gas Hydrocarbons. Their Mixtures, and Three Natural Gasolines--Natural Gas ProcessorsAssociation--1942.

This investigation provided coefficient of expansion data for light hydrocarbons. It was a part of the thermodynamic work sponsored by the Gas Processors Association (formerly NGPA) on a continuing basis and provided the latest test results incorporated into the data base for the Petroleum Measurement Tabies published in 1952. APPLICATION OF PETROLEUM

\section{MEASUREMENT TABLES}

The calculation of a net volume of petroleum involves the accuracy of volume determination equipment such as meters or tarks, temperature measuring devices such as thermometers or thermistors, and specific gravity instruments such as hydrometers.

Perhaps the most important factor is the ability and carefulness of the person securing the data. Tables fur converting observed volumes to volumes at standard temperature are therefore only one step in the measurement chain. Such tables are not PVT data in the usual sense needed in process design but are tables needed for everyday commerce. This is not to imply that the tables should not be as accurate as possible, but to emphasize their application.

The Petroleum Measurement Tables have served well although individual cases have arisen wherein the coefficient of expansion of a particular oil has not followed the Petroleum Measurement Tables. In April of 1967. API's LP Gas Metering Subcommittee reported, as one of their projects, the preparation of standardised tables of meter adjustment fastors forpropane and normal butane to be based on Tabla 24 and revised compressibility data. Early in 1968. IP, ASTM, and API were studying a means of computer programming so that equivalence would be given to quantities calculated manually from the Tables. A survey, completed in Fabruary 1958, of API's Committee on Petroleum Measurement revealed that the members favored a revision of the Petroleum Measurement Tables so they would be more applicable to computer usage. In October 1968. Berridge and Linsell attributed a possible $105 s$ of 0.2 percent of the Bill of Lading cargo quantity to errors in the Petroleum Measurement Tables. Mr. F. Dribbell, 
Chairman. IP Panel ST-AG Measurement Calculations and Tables Panel answered in January 1969, that it was possible for differences in aromatic content, naphthene content and possibly sulfur content to cause errors in corrected volume equivalent to those attributed to volume correction tables by Berridge and Linsel1. The letter concludes with a request that any information on thermal properties of crude oil would be welcomed.

A similar request for additional data from industry was made by the Chairman. API Committee on Manual Measurement to the Committee on Petroleum Measurement in April 1969. During 1969-1972, considerable effort was devoted by the API Committee on Petroleum Measurement's Working Group on Physical Property Data in connection with computer programming of certain tables. During this period contacts were maintained with representatives of IP and ASTM to ensure uniformity of application. A subroutine for Table 6 , Volume Reduction to 60 degrees Fahrenheit, was made available by API on June $26,1973$.

In early 1972, Messrs. L. Downer and F. A. Inkley carried out an experimetal program to measure the thermal expansion coefficientof crude oils and finished products having a wide range of specific gravities. Their findings were reported to the API Committee on Static Measurement in May, 1972 and were published in the Dil \& Gas Journal, June 19, 1972. It was their conclusion that the Petroleum Measurement Tables were satisfactory for finished products but that new tables were needed specifically for crude oils. It was also their opinion that if additional work was necessary "the required manpower and expensefieed not be too great".

In view of the various questions which had arisen concerning petroleum physical properties, Mr. T. L. Hillburn, Vise-Chairman of the Committee on Static Measurement and Chairman of its Working Group on Physical Property Data recommended to the Committee on Petroleum Measurement on September 14, 1972 that "API turn to the National Bureau of Standards and request that they review original physical property data for both thermal expansion and liquid compressibility within the ranges generally of interest to tha industry. It should not be assumed that the current tables are necessarily wrong, only that data originally supplied by NBS has not been reviewed for 55 years and that during that time we have new and different crudes and products and improved techniques for testing them.

The recommendation was favorably accepted by the Committea on Petroleum Measurament and contact was established with the National Bureau of Standsrds. Following discussions between representatives of API and NBS, a report was made to members of API Physical Propertias Working Group on july 23,1973 . The conclusions were as follows: 
1. The Petroleum Measurement Tables data, base may not be represantative of modern crudes.

2. The values determined by Bearce and Peffer accurately represent the crudes available to them.

3. T he values determined by Downer and Inkley accurately represent the crudes availabie to them.

4. The doninant variance in the data rapresents the actual variation in the samples of petroleum tested.

5. Only minor improvements in the accuracy of density measurements can be expected. Since it is the sample variation which is the dominant variable, no sirable improvement in overall curve fit to existing data can be expected.

\section{AMERICAN PETROLEUM INSTITUTE}

NATIONAL BUREAU OF STANDARDS

\section{PRQJECT}

On April 24, 1973, the Committee on Petroleum Measurement authorized continuation of discussions with the NBS. In view of the conclusions in the report to the physical Properties Working Group, and the fact that the data base consisted of work by sevaral different researchers, it was concluded that an entirely new data base should be generated using present day technology. Accordingly, funds for the project were approved by the API and a formal agreenent betwsen API and NBS was signed on 14 May 1974.

The agreement contained the following provision:

"In accordance with the terms and conditions of this Agreement. NBS agrees to undertake a program of research (herein called the Program) to establish expanded physical property data for Table 6, "Volume Reduction Factors' (API Stant. 2540. ASTM D 1250, IP 200. ANSI 211.8, ISO R91) which will be based on a modern uniform data base and modern understanding of physics of petroleum, and which will reflect current and anticipated economically important sources of hydrocarbon raw materials and finished products. Further, NBS and API agree that the Program will be documented in accordance with generally accepted scientific standards.

It was further agreed that samples would be tested in a liquid state at atmospheric pressure. Temperature range would be from 0 degrees to 70 degrees Centigrade but tests would be discontinued when vapor pressure exceeded atmospheric pressure or when thelsample under test approached a non-liquid state. It is believed that these conditions most nearly represent the state in which raw materials and finished products are tested for commercial transartions. With the signing of the contract, the wrok was turned over to the Bureau of Standards. Dr. Whetstore, who was 
PAGE 10

responsible for their work will pick it up from here. 


\section{THE TEMPERATURE/VOLUME RELATIONSHIPS}

\section{DF PETROLEUM PRODUCTS}

Dr. James R. Whetstone

Fluid Engineering Diviston, NBS

Before discussing the data, I would like to give sort of a review of some of the mathematical background related to the thermal expansion

properties of some petroleums.

I say some in that, of course, it is impossible to test ell available petroleums, but what we have been successful in doing is running tests on approximately 120 or so crude oils and about 250 refined products.

These products, as you will see when I show some of the data, are pretty closely grouped into three types. The first are fuel_oils. generallyy $\$ 2$ fuel oils either for the purposes of home heating or in the form of the second

are various types of jet fuels, mostly commercial grade jet fuel; and the thirdfre gasolines. The latter included most types of gasolines, and one or two gasoline blending storks.

One defines thermodyramically the thermat expansion coefficient, alpha, as the fractional change in volume, $V$, or density, rho, with change in temperature, $T$ :

$$
d=1 / v \text { dVi:l } T=-1 / 0 \text { ed } P / d T
$$

It is interesting to note that one can measure the thermal expansion coefficient in one of two ways, either by observing the change in volume with temperature or the change in density with temperature, the only difference being in the sign.

We chose to measure density change as a function of temperature. These data were collected and ware fitted to the following representation, that is that the density at some temperature of measurement, $t$, is equated to the density at 15. 56 degrees $C$, which of course is 60 degrees $F$. plus an expansion coefficient A times whatever the temperature difference is, and an expansion coefficient 3 times the difference in temperature squared.

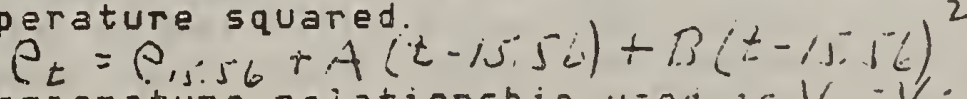

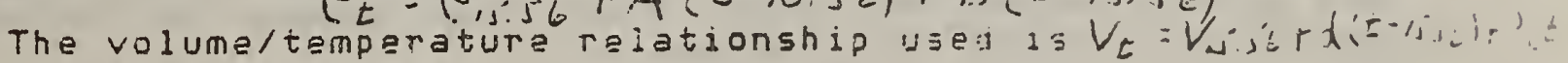
There are others which do not vary substantially. and 
I don't want to give the impression that there is only one.

There may be several, all of which in certain cases may be equivalent.

Here alpha is the linear expansion coefficient, that coefficient which gives the greatest change in volume with tempera- ture change, and then beta is a quadratic volume expansion coefficient, which gives a somewhat smaller change in volume with temperature although as one gets further away from bo degrees or whatever the reference temperature may be - in this case I have used 60, then that becomes more important.

What is commonly referred to as volume reduction factor, VR, is derived from the previous relationship, the volume - temperature relationship, in a very straightforward manner. It is the ratio of the volume at the reference temperature, so degreesF, or 15.56 degrees $C$, to the measured volume.

$V R=V_{b u} / V_{t}=\left[1+\alpha(t-60)+\beta(t-t c)^{2}\right]^{-1}$

These values are tabulated in the tables that Adin Hall was referring to. They are tabulated in this way because all that is required to compute the equivalent volume at 60 degrees $F$. is measured volume at a particular temperature, enter the tables by knowing the measured temperature and measured density, and come out with a volume reduction factor. Multiplication of that factor by the measured volumethen gives you the equivalent volume at the reference temperature.

So the problem becomes one of determining values for the coefficients alpha and beta.

As Adin Hall indicated earlier, Bearce and Peffer published data in 1916 which we have no reasan to disbelieve, and that data is plotted here. This is a representation of the data that they published in NBS Technical Note 77.

The thermal expansion coefficient is expressed in units of per degrees of fahrenheit and the density expressed in units of API gravity.

There are more products than crude oils. The central curve is a least squares fit through. thesa points that represents an average curve which can be quantified. There are unique values for alpha. From those values one can make any $k$ ind of table that is desired. 
COEFF. THERMAL EXPANSION (1OF)

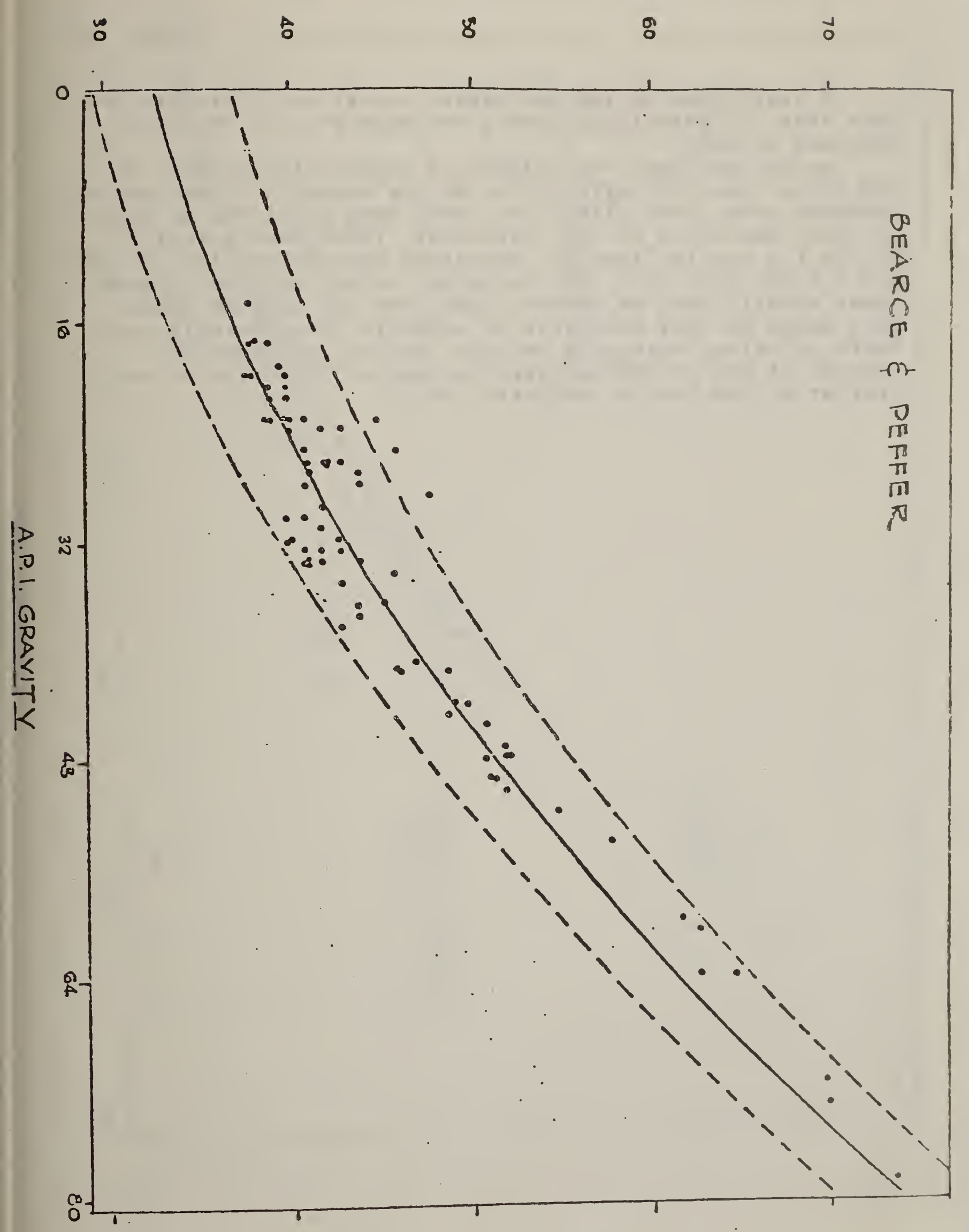


I have drawn in the two dashed curves to illustrate the fact that all petroleums aren't the same even if they have the same density.

As you can see, the scatter is rather significant. In the higher density region it is on the order of 10 percent or somewhat more. They didn't have very many gasolines up around . 7i they had three or four gasolines. Those four points a little bit heavier than.6, represent pentane samples. So one has a curve like this. One has also, as Mr. Hall said, some lower density data on natural gasolines and some LP gases were added to this data base to generate the presently used table of volume reduction factors. Now one comes to the results of the API/NBS physical property. This plot is very similar to the Bearce and Peffer data. 
COEFF. OF THERMALL EXPANSION $(/ O F)$

म के के के

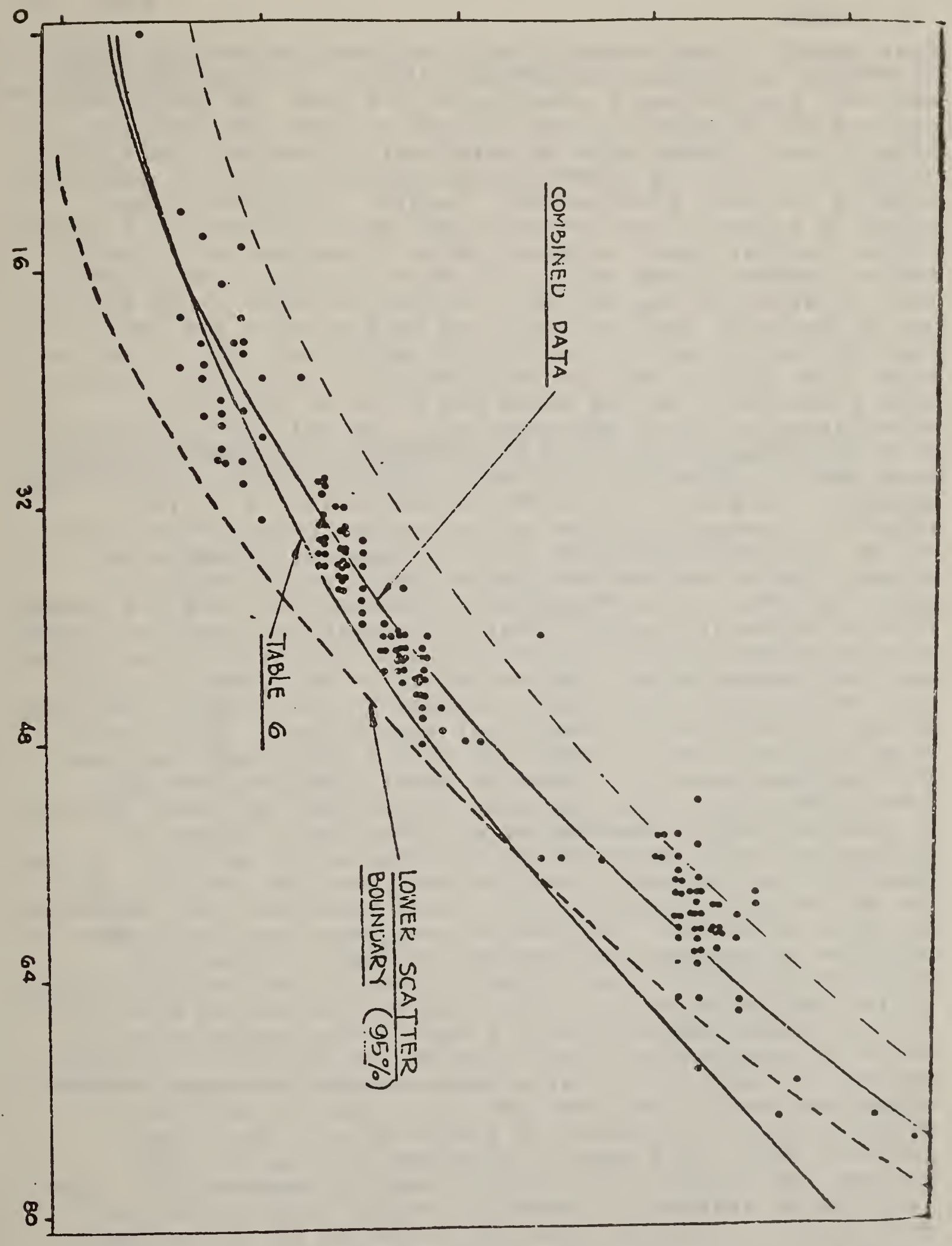


Once again, I have drawn through the data an average curve. There are two scatter bounds associated with it. As I said earlier, you can see a grouping of the data. At around 60 degrees API Gravity you see a clump of data which almost totally constitutes data on gasolines of various types. This includes all of the commercially available types of gasoline, that is no-lead, premium, and regular, plus one or two blending stocks which generally are not available on a retail basis. Further down, at about 36 to 40 degrees API, there begins another clump which is rather extensive and extends down to about 20 degrees API. In this extended clump are, on the higher end, the jet fuels and on the lower end, \#2 heating fuel primarily, along with \#2 diesel. Of course, we have crude oil plotted on this particular plot too, and as I said previously, we had about 250 products and only approximately 110 or 120 crude oil. The bulk of all the data then is product data which is, of course, of more interest here than is crude oil. The next question is how do all these compare. The Bearce and Peffer curve, which is closely related to any sort of tables or factors which are used for volume reduction purposes. lies systematicaliy below the product curve that we have gotten and I would emphasize again, as Adin has already said, that we feel that the reason it lies below is the fact that the samples of petroleum that have been measured and which generally constitute that curve may vary rather widely and certainly in 55 years the crude oils and products which were refined at the Bureau from those crude oils are not of commercial significance. So I don't find it particularly surprising at all that these new data lie somewhat above old data, in particular/since refining techniques have vastly improved in the last 50 years and one is able to obtain somewhat more controlled mintures of substances which might be generically called gasoline. So the question now becomes, given the fact that we can get values for the expansion coefficients, then what does that mean when you plug those back into the volume/temperature relationship relative to measured volumes and volumes at reference temperatures? What I am trying to show in tha following table is the magnitude of the correction that should be made for fuel oils and gasolines over a temperature range which is normally encountered, that is 20 to 100 degraes F. You can see in the case of fuel oils which have a somewhat smaller expansion coefficient than gasoline, that at 20 or 100 degrees one is approaching a discrepancy of about two percent, and in the case of gasoline it is about three percent. Of course, as one goes lower in temperature tiat is below bo degreas F., then the volume delivard in the transaction is greater than the volume at bo. and whenaver yo:s are above so, of course, the volume dalivared is 1 es than so. This gives some order of magnitude as to the amount 
of discrepancy. If there are any questions, I would be happy to entertain them.

Temperature

20
30
40
50
60
70
80
90
100

Volumetric change $(\%)$

$$
\text { Heating Oil Gasoline }
$$

$-1.8$

$-1.4$

$-.9$

$-.5$

0

$+.5$

$+.9$

$+1.4$

$+1.8$

$$
\begin{array}{r}
-2.7 \\
-2.0 \\
-1.4 \\
-.7 \\
.0 \\
+.7 \\
+1.4 \\
+2.0 \\
+2.7
\end{array}
$$

Positive values indicate expansion. 
MR. THOLEN: Jim, it might be well to add that the data that have been produced here at the Bureau are now being examined by API and ASTM people. It is possible that there may be a number of curves or sets of data, so at the present time we simply do not know what form that will take.

MR. HINE: On the equations that you were presenting, we had a representation on the $V$ at 15.56 times a quantity, then you went to VR equations. What is the exponent?

MR. WHETSTONE: I think the question you are dealing with is the volume reduction factor and that is going to be equal to the inverse of the brackets. Is that your question? Is that the answer to your question?

MR. HINE: Yes, the slide showed VR being $V$ at 15.56 over Vt.

MR. WHETSTONE: Whenever you divide by Vt and bring it to the other side, then you get an inverse.

QUESTION: Jim, you had a curve up there of coefficient of thermal expansion and density.

MR. WHETSTONE: YES.

QUESTION: What was the magnitude of the scatter of points at any one density? You mentioned 10 percent. Is it plus or minus 10 percent as the whole scatter?

MR. WHETSTONE: Plus or minus 10 percent. That is on the thermal expansion coefficient.

QUESTION: Right.

MR. WHETSTONE: So that doesn't mean that there is a scatter of 10 percent in the volume reduction factor. product?

QUESTION: How big were your samples for each type of

MR. WHETSTONE: Typically, the submitters were requested to send in two, one-quart samples.

QUESTION: Dne quart representing a lot, say a billion gallons, of crude, or it didn't matter what size?

MR. WHETSTONE: The only guideline that was given

relative to what $k$ ind of product that would be submitted was thir those products had the greatest volume. It was "please send us three products. "What happened was, as I said, we got fuel oil, jet fuel, and gasoline. That was almost universally true. Before that request went out, we had two companies send in a broad spectrum of $a 11$ their products, which included various kinds of lubricating oils and that is where some of the blend stocks came in.

QUESTION: Were there any crude in the samples?

MR. WHETSTONE: Oh, sure. As I said we had values on 120 or 130 crude oils. We got about 220 or 230 srude oils but ine were unable to make measurements on all of them generally because they were oither so gasey that we couldn't get a reproducible measurement at atmospheric pressure, or they were on the other end of the spectrum in which they were 50 
viscous that we could not introduce the material into the densimeter in such a way that we could believe the results.

QUESTION: I could give you a sample like that. Let's say you and I went out to take a sample arid we had a 10,000 barrel tank we had to take the sample from. Let's say you took a quart of sample from that tank. Is it generaliy known that the product is homogeneous enough? Wikl we get a representative physical sampling?

MR. WHETSTONE: The answer is no. I don't think generally whether it is in the field of petroleum or any field in which you are trying to sample bulk material, that is a question that you can always ask and argue about and you can continue to argue about forever without coming up with a very satisfactory answer.

QUESTION: I would appreciata your opinion.

MR. WHETSFONE: My opinion is that the samples ware collected in a way which was consisasent with the practice within the industry. That is to say that we generated a sampling document and we sent it out to pepple along with a request for samples. I have no information about whether or not that document was followed. The document itsel $\hat{f}$ was in the most part derived from standardized procedures that are used within the petroleum industry. I believe API has a sampling standard That was drawn upon heavily. I think there were some additions to that in detail but not in substance. QUESTION: What kind of a variance in the volume reduction factor resuits from the 10 percent scatter?

MR. WHETSTONE: We 11, of course, that is temperature-dependent, so at about, say 100 degrees, it gets big enough that it matters; you begin to look at a few tenths of a percent, that is for a 95 percent type of scatter boundry. That is not to say that the distribution is normal or anything else, just if it is assumed to be normal, then it is a few tenths of a percent at 95 percent confidence.

QUESTION: When you said fuel oil, do you mean distillate heating oil as opposed to residual oil?

MR. WHETSTONE: The way that samples came in was that somebody would send in a sample and it was labelled, generally something like "furnace oil" or "auto diesel," "\#2 fuel oil, "things of that type. So generally they were the light fuel oils, essentialy) fuel oil, they were not the heavy residwals although we did have some. Down in the lower end when you look at that graph at lower API gravities, you will find some points down there that are \#b oil andthings of that type.

QUESTION: Are these volume correction tables genaraily an industry standard?

MR. WHETSTONE: I think Mr. Hall should answer that

QUESTION: Which leads me to ask then if it is an industry standard, is there any prohibition against anyone 
else using them?

MR. WHETSTONE: I would think not. That would depend on whether they wanted to use them. That would be a decigion that they should make.

MR. HALL: The standard as generally used has five logo's as I recall. One is the Institute of Petroleum in England; American Socity for Testing and Materialsi International standards Organization; API; and ANSI. So these tables are available to anybody's use.

QUESTION: That is what I am getting to, they are voluntary standards then?

MR. WHETSTONE: Yes, I think that is true.

QUESTION: In other words, I couldn't go, say, to buy oil from Arabia and say. "Wait a minute, I have got a different set of tables, let's use mine instead."

MR. WHETSTONE: If you can make a contract with the Saudi's to do that, that is up to you. Goddluck.

QUESTION: But generally it wouldn't be done.

MR. WHETSTONE: I really don't know how the commercial transactions are set up.

QUESTION: I just wondered if, for instance, I went into a wholesaler and bought 1,000 gallons of API gasoline and I wanted him to volume correct it, would I be referred to a certain table?

MR. WHETSTONE: That would probably be the case but it doesn't have to be.

QUESTION: I don't think there are any other volume correction tables floating around the country.

MR. WHETSTONE: True, I think you are right. Your first point was that anybody could use them. That is true, anybody can. By the same token, anybody can use anything they want to.

QUESTION: Jim, as I understand it the decision has not been made yet to use the NBS research as a basis for new tables that would be adopted by API/COPM.

MR. WHETSTONE: As it stands right now, the data have been released to the API Committee on Petroleum Measurement and anyone else who would like it. As far as I know, and $I$ am certainly not speaking for the API/COPM, they have not come to a decision although they recently had a meeting and the upshot of that may shed some light on the derision or it may not. 


\title{
TEMPERATURE--MEASUREMENT ASSURANCE AND ACCURACY
}

\author{
Jacquelyn Wise \\ Temperature Measurement Division, NBS
}

If you choose to sell petroleum products by temperatura compensating volumes, you are going to need an accurate temperature measuring device.

There are many such devices on the market today. Many of them consist of a probe containing a resistance element, a thermocouple, a thermistor, or a quartz crystal. These probes are attached with electrical wire to some type of an electronic device. Many times the device has a digital display making it very easy to read. You simply put the probe in a container and take a reading. These digital thermometers can be rather costly and, in some cases, especially in the field, they could be inconvenient to use.

We have not done a great deal of work with digital type thermometers at the National Bureau of Standards. We have seen a few of them; mostly the clinical type used to measure body temperature. We have seen in some of these digital thermometers the readings becoming incorrect as the batteries weaken. Also, electronic components can age and cause errors. So a digital type thermometer, an elecironic thermometer, should be recalibrated often.

The thermometer that you would probably choose to use as a standard for temperature measurerment in a laboratory or even in the field would be the liquid-in-glass thermometer. It is rather inexpensive, extremely easy to use, and very easy to recalibrate. Their behavior is quite pradictable. We have a great amount of history on liquid-in-glass

thermometers and the calibrations will last a lifetime. The correction curves will tend to shift, either up or down,

reflecting a change in the bulb volumes, but once

thermometers have been calibrated ice point checks are all that is necessary to determine this shift, producing useful current salibrations.

There are many different types of liquid-in-glass thermometers, but they all are included in three categories. These categories are determined by the way the thermometers are to be used.

The first way a liquid-in-glass thermomter can be used is at complete immersion. By complete immersion we mean the entire thermometer is submerged in the liquid or medium being measured. If you are going to use a thermometer in this way. there are tuo requirements that must be met. You must have a container with a window, anabling you to see into tine fluld 
where the thermometer is placed, and secondly, the fluid must be clear so -that you can look through it. and read, the thermometer. In the petroleum industry, this is probabiy not possiblei therefore, you would not use a liquid-in-glass thermometer at complete immersion. Also, they are simply not made in this country to be used in this way. A very, very small percentage of thermometers, if any at all, are made by manufacturers for use at complete immersioni therefore, we will rule out this type of thermometer.

Perhaps 50 percent of thermometers manufactured are for use at total immersion. By total immersion we mean the bulb. which is at the bottom of the thermometer containing the. mercury,

and the portion of the stem containing the mercury are placed in the medium or bath whose temperature we are trying to measure. Consequently, with the total immersion thermomter, as the temperature increases you will have to continually push the thermometer down in order to keep it at total immersion. Therefore, the vessel must be deep enough to hold the mercury column when you are reading the temperature at the upper end of the scale.

The other 50 percent of thermometers manufactured are for use at partial immersion. By partial immersion we mean the bulb and only a specified portion of the stem is immersed in the liquid. With a partial immersion thermometer there is usually an immersion line or ring etched or placed around the bottom of the thermometer or the depth of immersion is marked on the back (example $76 \mathrm{~mm}$ ). With the partial immersion thermometer the rest of the stem, including a portion containing mercury, is at ambient temperature or the temperature prevailing above the medium being measured. Berause the temperature above that medium can vary, you will get slight differences in the readings on a partial immersion thermometer. This is not true with a total immersion thermometer because the stem is immersed in the medium and is at the same temperature as the bulb. Therefore, a total immersion thermometer is more accurate than a partial immersion thermometer.

It is very important that you use a liquid-in-glass thermomtar the way it was intended to be wsed. If it is a total immersion thermomter, it must be used at total immersion. It it is a partial immersion thermometer, it must be used at partial immersion. Otherwise, you could get a large error in the reading. This error will depend on the thermometer length in the incorrect temperatire environment and the temperature difference.

In ordar to emphasize this point, I would like to discuss an example. I am going to break an NBS rule and speak, as other speakers have, in degrees Fanrenheit and not degrees Celsius. The thermomters used in the example is one 
with a range of $3 z$ to 212 degrees $F$. This is a total immersion thermomter which will be used to measure a temperature at 200 degrees F. The thermometer, being total immersion, should be immersed near the 200 degree mark, with approximately $12 \mathrm{~mm}$ out of the bath so that the thermometer can be read. Let us say that this thermometer is only immersed to the 32 degree mark. Therefore, there will be 168 degrees ( 200 degrees F-BQ degrees Flemergent from the bath and at, let us say, 80 degrees instead of 200 degees $F$. If you insert these values into an appropriate equation, you wi 1 find that the error introduced by using this tharmometer incorrectly would be approximately 1.8 degrees F. Because you are using a thermometer incorrectly, you have introduced approximately a two degree error. Therefore, it is very important to use total immersion thermometers at total immersion and partial immersion thermometers at partial immersion.

Most thermometers contain mercury as the liquid. Mercury, if you will, is a dry liquid and when it retreats into the bulb nothing is left behind on the wall of the capil 1 ary.

You can also buy thermometers filled with organic liquid. This 1 iquid can be pentane, toluene, or alcohol, and usually contains a dye, which is generally red, making the thermometer easier to read. One problem associated with organic filled thermometers is that the liquid tends to wet the surface of the capillary. Therefore, adequate time must be given for the liquid to drain down into the lower portion of the thermometer when it is used to measure lower

temperatures. This can take as long as $15^{\circ}$ minutes to an hour for complete drainage. For this reason, thermometers having mercury as a liquid are more accurate than organic filled thermometers.

What is the accuracy of a liquid-in-glass thermometer? First of all, I want to define the accuracy as being the ability of a liquid-in-glass thermometer to reproduce temperature accurately when all factors are taken into account. In other words, all of the mercury is reunited, the thermometer has never been abused, it has never been heated beyond its top temperature, and you have a current set of corrections. When you use that thermometer and apply the correction, how good is that temperature determination? How accurate is that reading?

Here again we are going to discuss a thermometer with $a$ range of 32 to 212 degrees F. Let us begin by seaing how accurate a total immersion thermometer can be. The accuracy will depend on the graduation interval. Let us say you have a total immersion thermometer graduated in intervals of 0 . 2 or 0.1 degrees F. These are rather finely graduated thermomters If the thermometer is graduated in two-tenths there are five intervals for each degree, and if it is graduated in 
one-tenth there are ten intervals for each degree. A thermometer of this type, which is the most accurate liquid-in-glass thermometer for absolute temperature measurement in the Fahrenheit range, is capable of reproducing temperatures accurately within 0.02 to 0.05 degrees $F$. Dn another total immersion thermometer having the same range but graduated in intervals of 0.5 or one degree $F$, the accuracy will decrease to 0.1 to 0 . 2 degrees $F$. For a total immersion thermometer of the same range graduated in intervals of two degrees $F$ an accuracy of 0 . 2 to 0.5 degrees F will be realized.

A partial immersion thermometer having a range of 32 to 212 degrees $F$ and graduated in two degrees $F$, one degree $F$, or anything finer, is not improved by having finer graduationsi it is capable of measuring temperatures with an accuracy of 0.2 to 0.5 degrees $F$.

An organic filled total immersion thermometer of the same range, graduated in intervals of two degrees $F$, one degree $F$ or less, is accurate within 0.3 to 0.5 degrees $F$. The least accurate thermometer would be one that is organic filled, partial immersion, and graduated in intervals of two degrees $F$, one degree $F$ or lessi it would have an accuracy of only 0.8 to two degrees $F$.

Thus accuracy is going to depend on the type of liquid, mercury being more accurate than organic liquid; on the immersion, total immersion being more accurate than partial immersion; on the range; and on the graduation interval. The accuracy will decrease as the range and the value of the interval increase.

You may see liquid-in-glass thermometers that are graduated in intervals of 0.05 or 0.02 degrees $F$.

Thermometers graduated in intervals finer than 0.1 degrees $F$ are not recommended for absolute temperature measurement. The capillary is very small and the mercury will tend to cling to the wall. It will not move freely within the capillary and the meniscus could appear to move erratically. Considerable care must be taken when using this type of thermometer. A slight tap on the thermometer will help settle the meniscus at the correct position.

The choice of thermometer is going to be yours. Probably the biggest factor affecting the type of thermometer you choose is going to be the accuracy needed for tine test. you must then determine if you can use a total immersion thermometer or whether you have to use a partial immersion thermometer. If your vessels or baths are deap enough, tinen you would cartainly want to use a total immersion thermometar because it is more accurate. However, if jou have a shallow vessel, you would be compelled to use a partial immersion thermometer. Do you want one thermometer that covers the entire range of temperature measurement or should you select 
several thermometers each covering a shorter temperature range? If you have a shallow vessel, perhaps you could select three or four short total immersion thermometers. This would enable you to immerse the thermometer properly and have the higher accuracy of a total immersion thermometer. The graduation interval is another aspect to consider. The best accuracy is achieved if the thermometer is graduated in intervals of 0.2 degrees $F$ or 0.1 degrees F. However, as the interval gets smaller, a thermometer of the same range is going to get longer. Once you decide the accuracy range, interval, and actual physical dimensions required, you can then discuss the availability of such a thermometer with a manufacturer. Most reputable manufacturers in this country are listad in the Thomas Register. They may have in stock a thermometer you can use or they may be willing to design one if nothing is available to suit your purpose.

Whatever your choice of thermometer, you should never take it immediately from the mailing container and use it. You should examine it. At NBS we examine all thermometers under a 20-power microscope, looking for foreign material, mercury separation, and gas in the bulb. Mercury separation will occur in perhaps 60 percent of the thermometers you will receive because of rough handling in shipping. Most of the time you can see it with the eye unaided. All of the mercury must be reunited. Dccasionally droplets of mercury will collect at the top of the thermometer. These droplets can form because of mercury vaporization, even though the manufacturers insert a dry, inert gas under pressure above the mercury column. A microscope is used to detest the droplets, since you may not be able to see them with the eye unaided. These mercury droplets must also be reunited with the main column. Many times, because of rough handling during shipping, gas bubbles can form in the bulb. These gas bubbles must be removed. All of the mercury must be reunited and all of the gas must be removed from the bulb. If you don't do this, you could get an error of a degree or more.

Liquid-in-glass thermometers can be calibrated in two ways. The method used at NBS, and the one that will probably be used in your testing laboratories, would be to place the thermometer, making sure thatfall the mercury is joined, all the gas is removed, and no foreign material such as a glass chip, is in the capillary, in a calibration bath with a standard thermometer of some type. We use a standard platinum resistance thermometer at NBS. You may want to use an NBS calibrated liquid-in-glass thermometer or one that is traceable to NBS as your standard. Determine the tamperature of the bath medium when the thermometers being calibrated $a r e$ read and find corrections at various temperatures. Whar you usa a thermometer that has been calibrated, the correction must be applied to the thermometer reading to obtain an 
accurate temperature measurement within certain limits.

Some people we talk with who attend our seminars state that they cannot give a man in the field a liquid-in-glass thermometer with a set of corrections. Many times he either doesn't know what to do with the corrections, or he may apply them with the opposite sign and double the error. Therefore, the second method of calibration is used. The thermometers are placed in the calibration bath and compared with a standard. An accuracy needed when using the thermometers is established and we will assume it to be 0.5 degrees $F$. All those that fall within that 0.5 degrees $F$ tolerance are given to the men in the field, and all those that fall beyond that tolerance, that have corrections that exceed 0.5 degrees $F$, are rejected. The thermometers can now be used uithout applying any corrections and the people in the laboratories know that the temperature measurements will be within the tolerance that is required.

Liquid-in-glass thermometers are very easy to recalibrate. Once you have generated a calibration curve, all that is necessary is to check one of the calibration points and reposition the curve accordingly. Changes will occur in the bulb volume because of time and use. There is no way to prevent it.

The point that has been selected as the reference point on the liquid-in-glass thermometer is the ice point at 32 degrees $F$. This point should be plainly marked on any thermometer that you are thinking of purchasing or one that you might have designed. If a thermometer has been calibrated at several points, the ice point being one of them, and you have a set of corrections, all that is nesessary for recalibration is to check the ice point in an ice bath. An ice point calibration bath consists of a flask filled with ice made from distilled water, which has been shaved into small chips measuring 2 to $5 \mathrm{~mm}$, and distilled water. Pack the thermometer firmly in that ice bath. remove any excess water from the top of the ice, and take a reading. Any change you see in the ice point will be reflected in all of the other calibration points by the same amount and in the same direction. Therefore, in a period of three to five minutes you can recalibrate any liquid-in-glass thermometer that has an ica point calibration.

The ice point can also be used to determine if there is any mercury separation or gas in the bulb. If you observe an ice point correction that exceeds one scale division, it could be an indication that all the mercury is not joined or that gas is in the bulb. The ice point check should not be used as a roplacement for examining the thermometer under the microscope, but does offer an easy method for determining the inaccuracy of a thermometer reading due to rough handing in the field. 
If you are going to use liquid-in-glass thermometers in the laboratory, you will certainly want to read them with some type of telescope or magnifier. At NBS we use a 10-power telescope. This technique may not be necessary for reading thermometers used in the field. You can probably estimate to a half or even a quarter of a scale division with the eye unaided, but with an eyepiece the thermometer could probably be read unaided, but with an eyepiece the thermometer could probably be read to the nearest 0.1 of an interval. If an eyepiece is used it should be placedperpendicular to the thermometer to avoid any error due to paralax.

What I have tried to do in this short talk is to make you aware of the precautions that must be followed when making a temperature determination, especially if the instrument being used is a liquid-in-glass thermometer. If you need any help in any way on ...temperature measurement, feel free to contact the people here at NBS, especially the Temperature Measurements and Standards Division. We present an instructional temperature seminar twice a year in which we discuss in detail platinum resistance thermometry,

1 iquid-in-glass thermometry and thermocouple thermometry.

Does anyone have any questions? Yes, sir?

QUESTION: Have you done any temperature measurements on 1 iquid petroleum?

MS. WISE: No, none at all.

QUESTION: Any other particular medium other than liquid petroleum?

MS. WISE: No, what I do is calibrate thermometers under ideal conditions in calibration baths, comparing them to $a$ standard. I have rarely used or seen thermometers used or seen thermometers used in the field.

QUESTION: The reason I asked is that there are problems in the field about where, when, and how many temperature readings to take.

MS. WISE: We usually tell people they have to establish their own criteria. How many readings do you think are necessary?

QUESTION: What is the average frequency you have to have them calibrated? If I understand correctly, a thermometer that is used at lower temperatures, not exceeding the boiling point, does not present as much of a problem as a thermometer that is used at higher temperatures. Is that correct?

MS. WISE: That is true. The higher the temperatura: the more change you will see in the volume of the bulb. However, the bulb volume will change also while the thermometer sits on the shelf, and will change more rapidly when the

thermometer is new than it will after it has been in wse for several years.

Many people ask what the recalibration interval is for their thermometer. I tell them to recalibrata often when the 
thermometer is new. Since it is so easy to do, an ice point check can be made perhaps every other week. Once you see the ice point beginning to stahlize, you could extend that calibration interval. I would probably recalibrate my standard a minimum of twice a year, even if a change in bulb volume is not suspected.

QUESTION: Must 1 iquid-in-glass thermometers be used vertically?

MS. WISE: They should be used vertically. You can calibrate them horizontally, however, giving you corrections for thermometers used in the horizontal position. We do not calibrate horizontaliy at NBS.

QUESTION: What do you recommend to correct mercury separation?

MS. WISE: There are four ways to reunite the mercury column. This is one of the things that we discuss at length during the temperature seminar and I cannot discuss it in detail here.

The easiest way is to place half of the thermometer bulb in dry ice, causing all of the mercury, including the separated portion, to be drawn into the bulb. A slight tap on something soft like a rubber stopper will cause the separated portion to fall and reunite with the main column. You have to be very careful when doing this because the dry ice will freeze the mercury. If you freeze it solid and the bottom portion thaws before the top portion, the expanding mercury will cause the bulb to break.

QUESTION: After experiencing mercury separation, is it absolutely necessary to calibrate the thermometer again?

MS. WISE: No.

QUESTION: Do yu have a problem with stratification when you submerge the bulb at different depths?

MS. WISE: It is negligibl'en tevilibration equipment for measurements to 300 degrees F because of rapid bath circulation. When we calibrate above 300 degrees $F$ we have to correct for the error introduced because of a variation in temperature at the top of the oil bath.

QUESTION: You are probably working with a very small sampling.

MS. WISE: Yes. There is another question often asked concerning the gradients in the calibration bath. I know that they ara in my calibration baths and what the error is in my calibration equipment. You have to determine what it is in yours. It if is large, then you have to correct it; if it is small, forget it. 


\title{
MARKETING IN THE PETROLEUM INDUSTRY
}

\author{
Richard Southers \\ American Petroleum Institute
}

The purpose of my presentation will be to provide an insight into the workings of the marketing segment of the petroleum industry. The industry is generally considered to consist of five major components: Exploration, production, refining, transportation, and marketing.

The American Petroleum Institute is the largest trade association in the petroleum industry and the only one representing all the different segments. We have departments with assigned responsibilities in each of tha previously mentioned areas. I am a member of the Marketing Department. More specifically, I am concerned with the facilities utilized by marketers such as terminals, bulk plants, and service stations.

The chart which I have here is a graphic representation of the industry's marketing inter-relationships. You will note that there are two basic sources of supply for marketers; Major Refiner/Supplier and Independent Refiner/Supplier.

The middle men or wholesalers are known as: Branded Jobbers -- Independent businesses selling branded products, Commission Agent -- Company employee selling branded products, and Private-Branded Jobber -- Independent businesses selling private-branded products.

In some instances the jobber function is by-passed and the products flow directly to retail outlets from the refinet/suppliat.

Terminals are the primary distribution point and may oe located adjacent to or some distance from a refinery. Thay received their products by pipeline, ship or barge. Storage capacities at terminals vary considerably, dapending on tine market area to be served and the number of days storage reeded for the area. Marine terminals are zenerally tie largest from the standpoint of tank capacity.

Refiner/supplier-owned terminals with salaried personnel are the predominant mode of operations. Some terminals $3 r 2$ independently owned and are not affilisted with any refiners. Most of these are oriented primarily in the fuel oils.

Bulk plants are smaller than terminals and recalve tineir products by railroad tank car, or more frequantly by tojek transports. They store the produet in bulk for distrijution to servila stations, commercial accounts, farms and fi.l 011 accounts. 



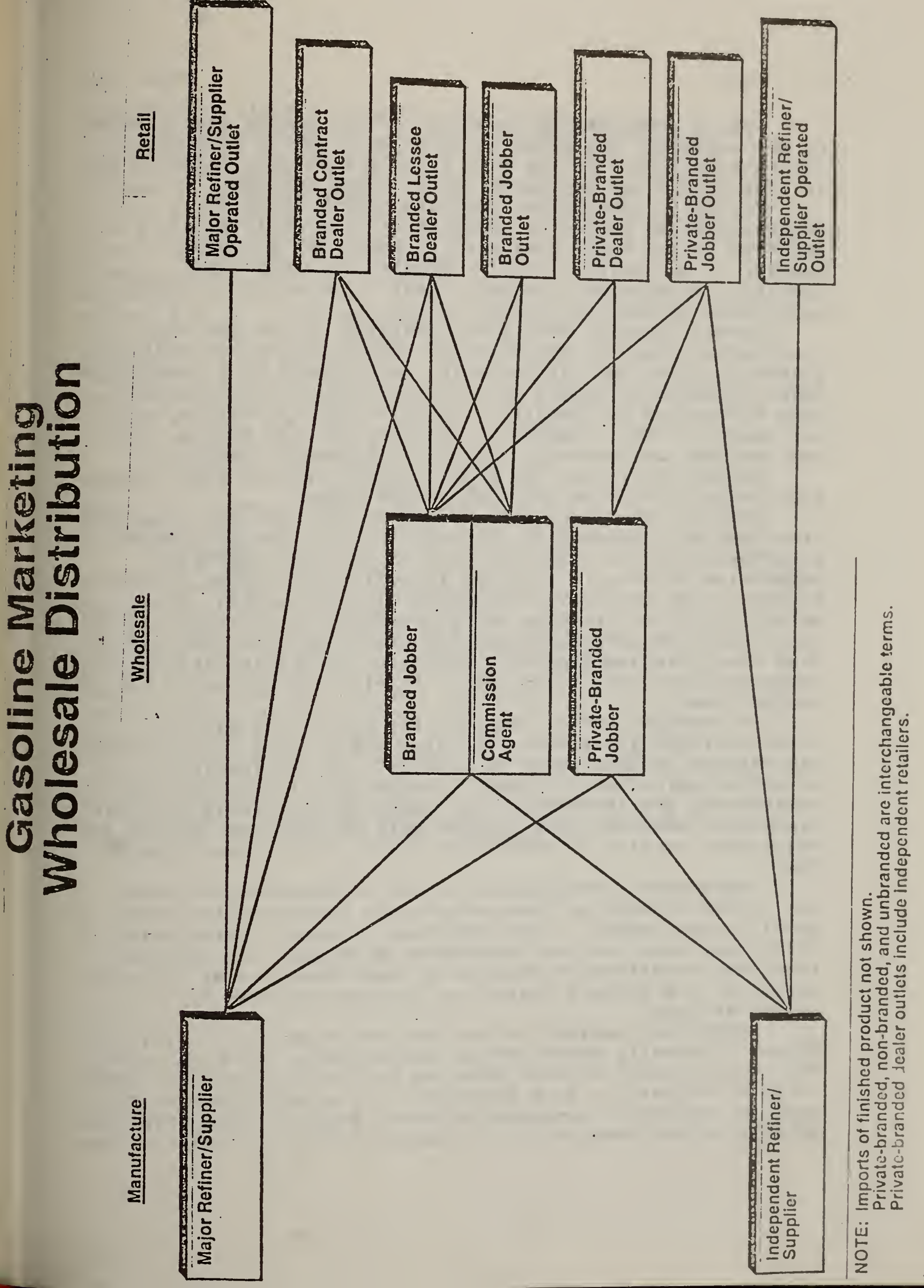


Trucks transporting supplies to bulk plants may be owned by the supplier, the plant operator or a common carrier.

Trucks hauling out of the bulk plant are usually referred to as tank wagons and are owned by the plant operator.

Typically, the jobber supplies name-branded or private-branded lessee or contract service stations in addition to any farm, home and/or commercial accounts. However, some jobbers are also engaged in the direct operation of service stations either by salaried personnel or by various contractual relationships.

Another type of bulk plant operator is the one who distributes products for a refiner/supplier and who receives a commission on each gallon sold. He is known as a commission agent. Commission agents"do not take title to the products they distribute and generally operate from facilities which are owned by their suppliers. They may own and supply their own stations and generally operate like small jobbers.

Refiner suppliers may also directly operate bulk plants. particularly in urban and high volume areas.

From the foregoing discussion, one can see that supplies flow from the refinery to the retail level through several different channels. Gasoline ends up at seven different categories of service stations in addition to other places of business such as convenience stores and car washes. This multiplicity of interests and channels of distribution is the reason for the varying viewpoints of the parties involved that precludes and "industry position" on the subject of this symposium. In today's language, "It all dependson where you're coming from."

In addition to the complexities of the industry's methods of doing business, one also has to take into account the effects of Government regulations and the supply situation which exists today. Because of all of this, when considering the ponderables of temperature compensation, the conference and individual states must be alert so that we do not become parties to creating a solution to a questionable need.

Temperature compensation or the adjustment of volumes due to the effects of temperature, has been used for many years in many areas of the petroleum industry. Where used, it has always been with an understanding between the parties involved, sometimes contractually and sometimes as accepted practice. The primary reason for its use has been for accountability.

Petroleum, whether in the form of crude oil or finisined produrt, normally makes several trips before it ends up at the retail level. It goes from the well to a gathering system -- to a refinery -- to a terminal - to a bulk plant -- to $\exists$ service atation or consuming account. Some of these trips are as long as half-way around the world. Practically all of them 
will involve different temperature zones. Without the use of temperature compensation it would be possible to have large differences, gallonage wise, between what was shipped and what was delivered. As an example, a tanker with a miliion gallons of gasoline aboard traveling through waters which produce a 5-degree $F$ change in the product temperature would have a volume change of 3,000 gallons. Percentagewise that is only three-tenths of a percent. If it were a one million barrel tanker, the change wuld be 126,000 gallons. There are 42 gallons to the barrel. It's still only three-tenths of a percent but it is 63,000 dollars at fifty cents per gallon wholesale. That same change would come to thirty-six thousandths of a gallon on a typical twelve gallon fill at the service station or amount to 1.8 cents to the dealer Dependent upon the dealers particular situation, it could be plus or minus. The retail customer receives exartly the volume indicated on the dispenser.

Temperature adjustment is also used for inventory control purposes at terminals and some bulk plants. Once again the factors remain the same but the multipliers get to be awfully big. So what can be a relatively insignificant loss factor can turn out to be a significant dollar amount.

I hope that from what I have said today you will have a better understanding of the petroleum industry and particularly the marketing segment. I also hope that you will see that the considerations of this symposium are entirely different from those which brought about the practice of temperature compensation within the industry. Thanks to Weights and Measures laws and regulations, accountability already exists at the retail level. Why, how, and when volume correction should be made or allowed in the market place is a most complex subject - one which should be better understood by the end of this symposium. To illustrate the complexity. the following 1 ist of factors to be considered was presented to the $S$ and $T$ Committee during the interim meeting of the National Conference on Weights and Measures. 


\section{FACTORS TO BE CONSIDERED}

\section{IN TEMPERATURE ADJUSTED}

\section{SALES OF PETROLEUM PRODUCTS}

1. Criteria for determining mandatory or optional adjustment of sales

(a). Mandatory--Which products; Wholesale; Retail

(b). Optional-- Buyer or Seller; Wholesalei Retail

2. Equipment Specifications

(a). Type approval

3. Testing Equipment

(a). Procedure--Equipment required

(b). Tolerance--Total test; Temperature Sensor

4. Manual Adjustment

(a). Determination of temperature

5. User Requirements

(a). Notice to Consumer

(b). Necessity for gross and/or net indications

6. Taxes

(a). Federal and state agreement

7. Equipment Availability and Cost

(a). Loading Rack

(b). Truck Meter

(c). Service Station Pump

8. Economic Impact

(a). Industry

(b) Consumer

QUESTION: Where does the consignee fit into your marketing arrangement? Is that the equivalent of the commission agent?

MR. SOUTHERS: Yes. A consignee is kind of a hybrid. Usually a consignee is an independent; he is not a company employee, but he is handling a company product that he does not take title to until he sells it. The company owns the product in the bulk plant. He pays for it when he sells it. This enables a man to get into business with not as mush capital as it would take if he was handling his own supply.

There are other factors. When you look at the different lines that go from onelsource to the other, it $100 \mathrm{ks}$ like $a$ tangled ball of twine. Wherever there has been a need. someone has tried to device a means of supplying that need and they have come up with new and different kinds of arrangements for doing this. But the consignea is one who does not own the product in storage; he pays for it as it is sold. There had been some of that at the service siation level in recent years. I don't know how much of it still 
exists. There was a surge of this at one time where even the product was carried clear to the service station and then the dealer paid for it as it was sold.

QUESTION: In terms of comparability in iniventory control, what level of agreement or disagreement would exist through, say a chain from the refiners to the jobber and then the next step to the retail level?

MR. SOUTHERS: It exists in some form all the way through. It is not a pattern type of thing. Generally speaking, the service station has not been receiving $a$ product on an adjusted basis.

Several of the companies have arrangements whereby the dealer can buy on an adjusted basis if he so desires, but he has to sign a one-year contract if he does it. Experience with this has been that many of these people at the end of the year say they came out about even and it wasn't worth the hassle of going through it so they don't renew the contract.

It is a matter of the contractual relationship. If the person wants it, he can bargain for it in his purchase contract, but it is not generally practiced at this level here. It is not even uniformly practiced after receipts to bulk plants, which you might think would be even more likely to get it but it is not uniformly practiced there either. Part of this is because when the practices within tine industry grew up, the product was much cheaper than it is today; operating losses could be absorbed because the product was so cheap. The product that was 10 cents a gallon 20 years ago may be 50 cents a gallon today. This is why people are saying, "What I used to do is not good enough toray. I have got to change. I can't stand that kind of losses."

Percentage-wise they still remain the same, but dollar-wise they have become much larger so people are saying that thelf have got to do something about it to recover their losses. QUESTION: I $a g r e e$ with you wholeheartedly on this accountability. If I understand it, there is accountability at the well-head, at the gathering system, at the refinery, and when it gets to the bulk plant, but thereafter it might not be down to the retail service agent, if what I understand you to say is correct. It seems to me that accountability is equally important all the way through the chain. You can't suddenly stop in the middle of the ball game and, for example, use..a different method of measuring when you get from the bulk p.lant to the motorist...

Let me-give-you an example of a problam. This was up. in vermont. The chap was buying his gasoline and he wondered where it was all going to in his underground tanks. For some reason it was.shrinking. One night he stuck his thermometer in and it read 50 degrees that night; he paid his taxas on the product; he dropped it into his underground tank. It sat there for days, and he measured the temperature. It had 
cooled 40 degrees. There was no way that he could resell the same volume that he bought. Even if it was temperature corrected from the truek, he certainly had no temperature correction going out of the pumpi now he had a little problem. He couldn't resell what he bought. He couldn't recollect the proper taxes upon what he bought, and he figured that he was paying out $\$ 500$ a year just because he could not account for his product resale. So I think you have got two problems here.

Another example of why I think accountability is important for resale. You and I drive into a station in LA, it is 80-degree product there. We buy 20 gallons of 58-degree API product. We have it/in the car. We really don't get 20 gallons when you temperature correct it; we get about $193 / 4$ gallons. At 80 cents a gallon, we have lost 20 cents each time we tank up for gasoline. Multiply that by millions.

I think that is a real problem and I think it could be solved. I agree with you on accountability, but I think it ought to go from the wellhead to the end.

MR. SOUTHERS: Let me go back to the accountability part of your question and answer that. A driller drills a well and then somebody operates the well and pumps it. You have several wells in an area so somebody creates a collection system, a gathering system that feeds into a pipeline. The crude is then picked up by a truck and moved out. We have, then, the pumper, the person who gathers and stores and then the person who transports to the refinery. All of the people are concerned with accountability.

Maybe I could better illustrate my point. I was at a pipeline meeting one time when the subject of how accurate the pipe- liners had to account for their product was discussed. One pipeliner says, "In the area that I serve, the way my pipeline flows, if they just let me have the difference, I would operate the pipeline for nothing. "That is where we need the accountability.

For example, the Federal Government buys F. O. B. They may have somebody haul a product for them. When they get it, they want to be able to determine whether the amount delivered agreed with the amount picked up at the refinery, whether it came by pipeline, ship, truck, whatever. That is what I am referring to as accountability.

It is a little bit different from accounting for why my inventory changed while I had it in storage. 


\section{UNIFDRM NATIONAL STANDARDS FOR AN \\ EQUITABLE AND EFFICIENT MARKETPLACE}

John G. Buekley

Northeast Petroleum Industries, Ins.

I am here today as a marketer and I recognize some of the marketing problems that action or lack of action by the Conference or by the states can have and is having.

I am going to be an advocate of temperature compensation for home heating fuels, basically home heating oil or \#2 fuel and kerosene or \#1 fuel; sometimes the two are mixed in the colder climates to get the right pour. I am not going to be an advocate for temperature compensation on gasoline because, very frankly, I think the cost of that kind of move would outweigh any possible benefits that could accrue to the person that counts, and that is the consumer.

Dur company buys gasoline by the tanker load and by the barge load, temperature corrected, from both major refiners and independent refiners. We resell that gasoline as wholesalers to independent, private brand retailers and retail it ourselves through our own private brand chain of stations.

We operate in the 5 ix New England states and that is certainly well within the frost belt, an area where you might consider that there is a need for temperature compensation on gasoline because it is coldup there in the wintertime. Yet we find that it is virtually a "wash" even though we buy temperature compensated and we do not temperature compensate when we sell. Our gains or losses are very minimal over the whole 12 months of the year. That is in Vermont, New Hampshire, Massachusetts, Maine, Connecticut, and Rhode Island. I don't see a strong case for temperature compensation if we come out evenand I suspect that tha consumer in the area comes out even, too, or very, very close to it. Certainly close enough to it, at lajst in the area of the country that I am familiar with, so that the additional cost of adding equipment on every truck that delivers gasoline to the station (and you are talking about a millior and half pumps just for starters) would be warranted. The investment by the petroleum industry in dispansing gasoline on the retail level and wholesale level would be much to large for the very minimal savings that might accrue to some consumers in some parts of the country.

But I am not here to talk gasoline. I am here to talk about heating oil berauseit is a product that has become 
affected very dramatically by the absence of a unified standard of measuring and temperature correcting throughout the system. Accordingly, this seminar is important and this issue is a very timely one.

In view of recent events here and abroad, I think there has become a very strong, almost an urgent need to take action to correct for temperatures throughout the system of distribution of home heating oil. One of the most significant problems that independent distributors or wholesalesspe this product have today is their inability to be competitive inith major integrated refiners in the sales of this product because the major integrated company, in its system, temperature compensates. When we buy from them or from the independent refiner, the product is temperature compensated, but when we resell in the colder climes, it is not temperature compensated.

When oil wholesaled at 12 cents a gallon (in 1973, not that long ago, that was the wholesale rack pricel it wasn't too significant an issue. You are talking about 6 or $7 / 100 s$ of a penny loss and that could be absorbed by an independent terminal operator.

But today, when that wholesale price has gone up more than fourfold in six short years, when you are talk about 6/10ths of a percent of the total product that is lost in parts of the country like ours, which translates to $3 / 10$ ths of a penny (and $3 / 10 t h s$ of a penny may not sound like much) I can tell you that in the distribution business at the wholesale level $3 / 10$ ths of a penny loss two years out of three is going to be more than your net profit on operations in selling this product all year long. So it is a very significant number.

I would like to expand a bit on the picture Southers painted of marketing, but I would like to focus strictly on home heating fuels, rather than gasoline, because a much simpler distribution scheme is involved and the players are more easily identifiable.

Before I do that, I would like to mention roughly where the product is sold so you can get a feel for who uses it in the country. It is only one of several home heating fuels. You can neat your home electrically, you can heat it with gas, you can heat it with propane, you can heat it with home heating oil. Because of the geography and tha way the pipelines are developed for natural gas, which has oesn under price controls, as you know, for 25 years, there are areas whare most of the homes usa one fuel or anotiner.

For home heating oil, the six New England states: Vermont, Maine, New Hampshire, Massachusetts, Rhode Island, and Connerticut, use among them about 20 persent of the $0 i$ usad in the country as home heating fual. Neis Yark State usas another 20 percent. If you add in New Jersey and 
Pennsylvania, you are getting very close to so percent of all the heating oil sold in the country. If you go down the rest of the east coast to warmer, more moderate climates, you add another 10 percent. So basically 70 percent of this preduct is sold on the east coast, and bo percent of it right in those nine northeast states. The balance is spread across the frost belt, through the miduest and even out to the 5 tat $\equiv$ of Washington. In most of those states it is a relatively minor home heating fuel, accounting for 10 to 20 percentof tie homes, compared to natural gas which will have most ôt tne balance. In certain regions it is the predominant fuel. Iir New England it is used in about 75 percent of 311 the riomes

Now you know where it is sold. What kind of a structure exists? You again have these three tiers of distribution. Yau have the refiner, the integrated refiner, who will sell as refiner in bulk to companies like ours, wholesalers, wno will sell at a rack to retailers, who delivers directly to tha home.

First, the refiner. Unlike gasoline, tha refinet whlle he has 100 percent of the supply has probably only 70 percent of the wholesale distribution system and less than 10 percen: of the retail business. So in a home heating fuel you ar? looking at an independent wholesale function, a termina! operator, who does nothing except buy home heating oil mostly under annual contracts with independent and major incezisted companies, and sells it to independent retailers. The independent wholesaler may market a bit on the retail level himself, but most of these independent terminal operators, and there are about 20 of them on the east cosst, fromiana to Florida and the Mississippi gulf are basically

wholesalersi 80 or 90 percent of all the cil they move, the heating ail, is as a wholesale operation.

That leaves then the independent retailer with about Es percent of the country. So 80 homes out of 100 that ara supplied with heating oil are supplied by tha indeparjen: sector; about 25 to 30 percent of all the wholesale hejting oil goes to the independent section, not allignad with $a$ major oil company or not affiliated with a major oil candir. That is the distribution system.

That independent wholesaler function, ayin, varles i region. It is 25 to 30 percent on the east coast where percent of the oil is sold, but around New rork Ci Island it is more 1 ike 40 percent. In New England it i between 45 and 50 percent. So it is a very signiticant marketing alement, particularly in soma of thos a nor states where the bulk of the product is sold

The independent retaiier lyill normally $\equiv$ dit his

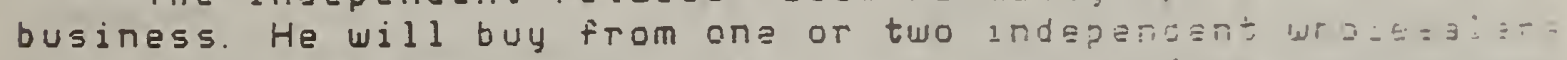
and he will also buy from one or two major ra: wholesale. They da this because it is a very jice 
competitive product. You will have 16 or 18 terminals in a harbor like Boston Harbor. So the independent retailer has a wide choice and if he buys from two or three, then he can swing his purchases if someone's price is a little high or someone else's is a little low, and take a little bit more of his monthly total from the low priced guy. It gives him $\exists$ little better feel for the price in the market if he deals with several companies; they like that competitive edge they have when they can price shop between two or three suppliers that they have contracts with.

In addition, of course, we have built up storage. Those 20 independent terminal operators that I talked about on the east coast have about $35 \mathrm{million}$ barrels of storage for home heating fuels, kerosene and \#2 fuel. That is a vital piece of hardware in the distribution system because it enables us to buy about 25 percent of our total annual volume during the summer months. Without that bulge when you go into winter, there is no way you can keep up with demand. The demand far outstrips U.S. refining capacity's ability to supply product in the middle of winter. You must fill those inventories. In addition, as part of the marketing strategy of the major companaies, a number of them that had very minor roles in some of the more remote areas of the country have in recent years done what they call rationalize their marketing system. They have withdrawn from areas where their penetration was slight. It used to be important for them to market in all 50 states. Now they look at where they can market profitably and where they are not marketing profitably they tend to pull out. Exxon has pulled out of retail heating oil distribution, for example, in the northeast in recent years. Shell has announced with-drawal from the wholesale market in heating oil this spring.

So some of the major companies are pulling back, are trying to rationalize, are trying to market only where they can market profitably rather than everywhere, and the independent terminal operator has filled in that gap and kept the essential product moving and we have done it, obviously, because we think we can market more efficiently than a major company because our entire focus is on marketing, on the storage of product, on the supply of product, at attractive prices, and selling it at competi-tive prices. When you tend to focus on one region and you tend to focus on one area, you tend to get better at it, or you should.

The key point to recognize here is that the independent terminal operatof in the absence of a policy is being hurt competitively at taday's price levels. When you buy product at 45 cents a gallon, cargo contract, temperature corrected, and you have to sell most of it in the wintertime not temperature compensated, our company which operatas in tiose New England states sees a six-tenths of one percent 
shrinkage. That is three-tenths of a penny at today's prices. If, by the absence of a policy, you put one of the competitive sectors at a three-tenths of a panny disadvantage, you are hurting them, you are hurting their competitive ability.

The integrated companies, get temperature compensation somewhere in their systemi either they temperature compensate at the refinery level, or they can have an inter-affiliate transfer accounting method, but one way or another they get it. They are not losing and we are, and it is a major item. So I think the single most important aspect or point I would like to leave with you today is that the absence of a unified standard on home heating fuels today gives an unfair competitive edge to the integrated refining company in the market distribution system.

If you believe that consumers benefit most when there is a fiercely competitive market serving them, then the Government must not be in a posture of giving one party to the competition an edge. Rather, the Government should create a neutral ground on which the competition takes place. But to provide that neutral groundlue need action from the conference and from the states because the continued lack of action is having a negative competitive effect.

I think we need uniform standards on a mandatory basis. I think we need them right through the system, right through the wholesaler and the retailer.

The wholesaler, obviously, is going to find it attractive. Dur company would find it attractive. We will make the investment. Industry-wide I would guess there probably would be a need at the rack for some 3,500 to 4,000 temperature compensation devices, not an enormous number to get rack business totally converted nationwide on a mandatory basis in a timely way.

Again, if the retailer could only do this by instailing a device on a truck, there would be a need for someuhere between 15,000 and 20,000 devices for trucks. However: I suspect that if this committee can come up with a table based on the tables that are already available (e.g., the ASTM tables and others), a simple table for a retailer to use, than the smaller retailers won't bother installing devices on trueks. They can simply make a manual adjustiment to tha bill for the temperature compensation by using the standard chart. The larger retailers, obviously, may prefer to go the route of having their trucks outfitted. You have a spaaker later on today who is going to talk about experience in that area of running 25 trucks for several years now with ineters. The other obvious alternate is building it into yuur computer runs on billing. Most retailers do have computer assistance an billing today in order to get billings out in a rimeis way berause one of our biggest singla problems rignt now ilin bi] 
cent and 65 cent product is cash flow. When you lay that product out in the consumer's tank, you need to be paid as quickly as possible because you have to pay for product when you bring it in by tanker. The longer that lag, the more difficult it is for you. So it is important to get bills out in a timely, day-by-day basis, and thus you could build up a coefficient into the computer to have those bills

temperature corrected by simply inserting into the computer the actual mean temperature of the day of delivery.

So there are at least three different ways you can do this; by hand, by computer, or with a machine on a truck. It doesn't seem to me to be a difficult task. The technology is certainly there and I think should be used.

While I said I think the key here is competitive impact that lack of action is having, there are a couple of other rather compelling reasons right now why it is urgent to take action in this area. One of those is certainly the issue of storage. You can't have enough storage. The reason you build storage is that you hope to buy a product that is used in the winter in the summertime when you can get it at a little better price, store it and then sell it hopefully in the winter when the price has gone up because the demand is high. You don't always succeed in making a profit on that storage but that is the reason you have it.

What you are doing by building in temperature correction through the whole independent wholesale and retail business is this: you are making it more attractive to build storage because you now you can buy in. July and August, have tha temperature compensation work for you and not fear losing three, four or five percent of that volume because you are buying it in July and seliing it in December. You don't have those big swings between the maximum high temperature in tha summer and. the minimum low temperature in the winter. You in effect can build storage and expect to get a return on that investment if you hava normal, seasonal swing in product prices. You are taking out of the business what is today a bit of a risk and promoting storage at these two leveis, wholesale and retail.

I mentioned that we have storage on the wholesale level of about 25 percent of our annual volume. If it were aasier to justify the economics of building more storage, obviously you would to take some of the seasonal swing out of this product and by swing I mean prica swing bacause you do gat rather dramatic swings in price for a product that has its high demand peak for only two or three months, and then for two or three other months have no demand at all. I think this is very important from the standpoint of the consumer.

If you go back to this last winter, in fact if you look at the last seven winters, you will sea that in four of those seven there were shortages. There were tight supplies, there 
were cash run up in prices. The first one was the winter of '72-'73 when we ran out of natural gas and the midwest cities had to shut their schools down, our heating oil was in very tight supply, and President Nixon in January of that year had to lift oil import quotas. Up until that time you couldn't bring in foreign products, we had a quota system. He lifted those quotas and the foreign product poured in and we got through the winter without running people out of oil.

The following winter, '73-'74, was the winter of the embargo. There you had not only weather and refinery constraints but decisions by political parties to not supply oil to this country. Again, a very difficult winter to get through, with a lot of foreign fuel coming in at a pretty high price and a consequent very fast price run up.

Then two years ago we had another winter where December and January throughout most of the frost belt was 25 percent colder than normal and where the U.S. refining industry, coupled with marine difficulties, ships and barges frozen in the harbors, was unable to meet that peak demand. There was an emergency entitlement program for two months under which if you brought in foreign heating oil, you got a five cent a gallon government subsidy offset entitlement payment in order to bring the price down and to enable you to stay competitive. During February and March of that year, the two months that that program worked, 700,000 barrels a day of heating oil came into this country.

Finally, we had the winter that we are just finishing where we not only had the bitter unprecedented cold weather in February which created marine difficulties, but we also had Iran going out of operation. Saudi Arabia placing limits on erude, resulting in not enough crude to run our domestic refineries, and a very difficult supply winter.

In each of those cases, the very dramatic seasonality of the product hurt us. In each of those cases there was high demand relative to storage. If the storage had been more adequate, you would have seen less of a prile swing and less risk of run outs and shortage. Just to give you an idea of what happened. In New York harbor, the price for cargo. tanker load, of heating oil went up. The first of January 1 t was running eight or nine cents above cargo contract prica, the firm price you sign for a year with the refinery. And then came Fabruary and that bitter weather and the spot price, if you had to go out and fill in an extra cargo here or there because someone was late in making a delivery to you or because demand was too high, the spot price in New York harbor was 20 cents a gallon higher than cargo contract. We went out and paid 55 and 58 cents a gallon for tankar loads of oil when we were selling it at the rack for 44 cents.

So you get these enormous swings. And to the extant ye can take some of the seasonality out of tinis produet by 
creating incentives to build storage at the wholesale level and at the retail level through this kind of a temperature compensation move. I think we are not only giving the consumer some supply protection that they don't now have, but we are also lessening the risk to the consumer of these wild gyrations and high swings in price, and of course the high swing always comes at a time of year when they need the product more and are buying more at that high price. So there is a legitimate consumer interest here in seaing more storage.

I could even argue that as part of the Department of Energy's program to try to promote conservation, homeowners are being encouraged to put larger tanks in when they build a home today. The typical tank home size, as you know, is 275 gallons but no one said that is all it should ever be. I happen to have a 2,000 gallon tank in my house and I buy oil in the summertime when the price is lower and I don't have to worry about snowstorms or anything else. I can fly through the winter and then buy again the next summer.

With temperature compensation coming to me, I am going to benefit as a homeowner because I an going to get a little more oil. It promotes that kind of activity at the home level, at the consumer level. Obviously, if the wholesaler, retailer, and consumer are adding storage, what you are doing for the country is making us less vulnerable to political cut offs, political action abroad which we have gone through

twice now in the last seven years, and I think that is a very - very dramatic and important reason why this kind of action should be looked at very seriously and with a stepped up timetable.

If there is any one time of year when this country is vulnerable to foreign supply cut offs, embargos, political unrest, and Lord knows we are vulnerable, it is in the wintertime. To the extent we can take some of the seasonality out of that and build more storage and have the incentives in the right direction to do that, as this move would do. I think that is a logical and integrated part of a sensible national energy plan. What you would be doing in effect would be blunting the swing of seasonality.

To be sure, we could do other things. For example, we could build more refineries in the country. As I said, the refining industry went all out last year and still came up short this winter, but there aren't incentives to build refineries right now. There have been price regulations on oil companies since 1971.

There is one subsidy for small refiners. If you look at the last six years, you will see that there have been 38 refineries built in the country, of which 37 average 10,000 barrels a day; highly inefficient, small teapots, but thæy got a $\$ 2$ a barrel subsidy. One big new one has been built. No 
large big ones are under construction today.

While Senator Johnson is going to start Senate hearing in April with the Senate Energy Committee, I think we are a year away from a bill in that area. You have got at least a five year lag time to build a new plant today. We have got to get through the next $5 i x$ years. Action inathe temperature compensation area, even in the absence of ${ }_{n} r e f i n e r y$ incentive program, will work more quickly to make us less vulnerable to foreign cut offs.

Finally, I might mention another conservation item. which results from the fact that many wholesalers are and have beenconsidering heating the product as a way to get their money back that they are losing. What do you do when you heat the product?You yeat it to 60 degrees F., the temperature at which you bought it. So you are now selling the same volume you bought. However, what do you do to heat? You put in boilers and you burn heating oil. This would be a wasteful use of energy that is in tight supply. But again, lack of action here in a more sensible direction will be promoting that kind of thing. Then where is the consumer? The retailer is buying cold product from one supplier, he is buying hot product from another supplier, and he is buying temperature corrected product from another supplier. It is not fair to the retailer and it certainlyfiot fair to the consumer who doesn't know what he is getting. You really need afunified national standard.

With a unified national standard, the entire industry, including the independent section that I belong to, will be better able to withstand the sudden interruptions caused by political decisions or sudden surges of demand in cold weather, or, as we had in this past winter, both. Because both trigger shortages and both causefvery rapid price run up. to the extent that you can mute that, you are going to help the independent section stay alive and viable and well, and you are going to help the consumer.

I think that national and international events this last six months have given a degree or urgency to this question that even warrants considering dropping your normal slow, deliberative, due process procedure that would not result in a unified national standard before January 1, 1981 . That is too long. You have a meeting here in July and ordinarily that meting would come to some conclusion, which wouldn't be finally adopted until the following July, and then you would set a date ahead $s i x$ months from there. I would like to see (and I think there is going to be some state urgency on this matter too) the July meeting come to some firm conclusions and recommendations and have the states do what they normally do in the next six months and get this program on the road January 1, 1980. I think it is too important for us to wait Now on top of everything else, we have tha Three Mile 
Is land problem in Pennsylvania. You have to know that with that nuclear plant in trouble and with five others down for earthquake inspection, the nuclear program over the nex: decade is not going to lend the kind of help we expected it to lend to our national energy picture. That throws the burden for all our economic growth right squarely back on our hydrocarbon, coal, natural gas, and oil, and a good chunk of it is going to have to be oil. Half of our oll is imported and it is growing.

Anything that we can do to promote conservation, compensate for seasonal surges by building more storage and keep a competitive industry, is going to be helpful in terins of national policy in the situation that we are living in today.

I would strongly recommend that the Conierence and the states move on this program, move on it with a sense ot urgency and national purpose, try to achieve both the competitive and national objectives that I have cutlined, and try to get it in place by Januarty 1, 1980. Thank you very much.

QUESTION: I think you pointed out quite well the value of an equitable measurement system. Is there anything now to prevent you from using the uniform national standard that is embodied in the tables that Jim Whetstone was talking about? What stops you from using that as your national standard? MR. BUCKLEY; While this winter if you had decided to do it you wouldn't have been hurt in the marketplace because product was short and prices were rising, in a more normal winter, if you are three or four-tenths of a penny above your competitor, you notice it imnediately in volume drop You are putting yourself in a position. if you do it and no cne else does, of being in a very poor competitive posture in terms of trying to build your business and develop ycar sales. It needs to be across the board. If everybody plays by the same rules, everybody is equal and starts equal from the gata.

QUESTION: I think it is called equity.

MR. BUCKLEY: That is correct. That was in the titia ai the speech. "equitable and efficient marketplaca."

QUESTION: As a former fuel oil buyer in Ney England ans

New Jersey, and I can remember I used to buy my oil at around 16 cents a gallon and I wasn't too concerned atout it However, if I vere a buyer up there today anja jesler was going to give me a manual adjustment or my bil! ior jome temperature and I had no way to know wrat it shojld ba. now could the consumer be protected on something ijke that?

MR. BUCKLEY: It is obvious that this kind of a program

has to $b$ announces with a certain amount of 7ationa: attention and thraugh statzenergy oftices and consuma: affairs off:ces ir each state so that the consumer xnous what 
is happening. The consumer in effect is being converted like industrial customers already are to buying BTUs, when and if they buy in the summer they are going to have a plus compensation, one to their advantage. Without temperature compensation. the consumer should be informed that the independent operator will be badly hurt competitively, and if that independent operator drops out and thera is lass competition year by year, the consumer at that point is $301 \pi g$ to be paying an auful lot higher prices. Whenever you have an absence of effective competition, you pay high picies. Whenever you have effective competition, the consumer gets the best deal. This is something that kind of guarantes the consumer there is going to be a competitive marketplace, competing for his business, and that if he takes certain actions, he can even get some rewards, and they happen to relate to storage and summer buying and things of that sort. QUESTIDN: How mush does temperature compensation mean to the average consumer?

MR. BUCKLEY: In Massachusetts, which is dead center in New England, what we are talking about, as I said, is three-tenths of a penny a gallon. The average account now has dropped over the last six years through various conservation efforts such as new burners, insulation, burning wood, et cetera; the average account now burns only about 1,000 gallons a year. At three-tenths of a penny, that is $\$ 3$. You are talking about an incremental cost maybe of $\$ 4$ in Minnesota and Maine, $\$ 3$ in Massachusetts and Rhode Island, and about $\$ 2$ here in the District. That is the net additional cost to the consumer of this kind of a program. That seems like a very small price for a consumer to pay to know that ha is aluays getting a unified measurement, he is juylng on a standard basis, and he is going to be buying in a competitive marketplace which might notbtherwise exist unless he does pay that $\$ 3$.

QUESTION: How do you keep the retail deliverer, I am talking about the inclement fuel oil dealer, hou do you keep him honest on a manual adjustment basis:

MR. BUCKLEY: The only answer I can give you is to ta!? you a little bit about the nature of the market in Meis England and elsewhere. In New England you have atout 2 , ju independent home heating oil dealers that hit thos 30 percent of the homes. The product is not controlled, there are no price or allocation controls on home heating o: a aris there haven't been since 1976, there'is nothing today :0 prevent him from raising his price 10 cents ir he wants to (never mind three- tenths of a penny for temparature correction), except the marketplace. He is go:ng to lose nis customer. People have become very price conscious. One of the things the embargo did was to let them learn that crar.cs don't mean anything. Heating oil is furgible product. ivo 
matter from whom you buy, you are getting the same thing. As a result, you see today a lot of customer movement year by year. We have seen it grow tenfold in our company. If we price too high, we lose accounts, measurable, significant number of accounts. So no one really can charge more than the market will bear for very long without suffering. The dealer is usually a person who lives in that town, he is usually on the Rotary, and he is usually a well respected businessman. Two thousand of them in that market isp lot of small businesses, but they are important, and well known, and recognized in their own hometown. The things that keep them honest now will keep them honest then.

QUESTION: If everybody is doing the same thing, whether it be temperature compensation or no temperature compensation, what difference is there for the consumer? Competition results in equity locally. What is the need for having to standardize through the whole U.S.?

MR. BUCKLEY: In the absence of a natiorial policy today the integrated sector is getting the benefit and the independent sector is not. That is where the competitive problem exists.

QUESTION: You said you were't competing with the integrated companies.

MR. BUCKLEY: Oh, yes we are, on the wholesale level. As I say, in New England we have between 40 and 50 percent of the market and they have the balance. We are almost even in New England. On Long Island it is about 40 percent, and on the entire east coast the independent terminal operator has 25 percent of the total wholesale volume and his competitor is a major integrated company. They have the advantage right now. It was a very miniscule advantage five years ago, but it suddenly loomed very important because, as I said, that three-tenths of a penny can be as large as or larger than the whole profit you make on selling heating oil all year long. It is a big number.

QUESTION: In your marketing area are any sales of middle distillates being made on a temperature compensated basis to reseller or retailers?

MR. BUCKLEY: Not that I know of, not in our market.

QUESTION: In your marketing area are any sales of iniddie distillates to commercial accounts being made on a temperature compensated basis?

MR. BUCUKLEY: No, I don't think so. You will see BTU contracts with industrial customers for residual fuel where they don't care how many barrels they get, yet they want to know what the BTU is. To commercial accounts, churches, hospitals, schools, people of that sort, small commercial accounts that use heating oil, we do not temperature compensate.

QUESTION: Justification for temperature compensation in 
LPG was originally stock controls, inventory controls, not marketing. Since marketing was competitive anyway, everybody had the same problem. Isn't fuel oil presently in the same situation?

MR. BUCKLEY: There is far less temperature compensation needed in fuel oil. The swings aren't so great as they are in the lighter products. Those swings are so dramatic in the products you are talking about that they can't be absorbed. But even though the percentage is small in heating oil, even though we are talking about six-tenths of one percent even in New England which is a pretty cold area, the price escalation, very frankly, in the last five years, which we expect to continue and which when added to that very small fraction of six-tenths of one percent, suddenly becomes very meaningful in terms of whether you are competitive or not, whether you are viable or not, whether you continue in business or not. So maybe the justification is different. Quite frankly, I don't think I would even be here today if we were still selling wholesale at 12 cents the way we were in 1973. But these changes have occurred, are occurring very rapidly, are occurring both here and abroad, and I think have leant a sense of urgency to it because we are being hurt by it so we are coming to say "help."

QUESTION: But the point is that every marketer is hit with the same situation.

MR. BUCKLEY: No, sir. The major integrated company is not. They get temperature compensation in their company. We do not. That is the difference. The integrated company, at some point which they decide among themselves (they are all affiliates, 100 percent owned) buys erude oil temperature compensated, sells refinery products, heating oil, temperature compensated. They have incorporated that in their system. We buy temperature compensated and don't temperature compensate when we sell. We lose it. So at the wholesale level we are competing with somebody that has an advantage now that is suddenly a significant and meaningful advantage and that is anti-competitive. The lack of government action here, the lack of a unified standard, has created a situation that is unequal between competitors. All we are asking for is that everybody be treated alike and not have one group able to do something and another group not able to do it.

QUESTION: Was consideration given at the consumer level to the reaction particularly in the Northeast where they would switch to natural gas heat rather than have this complication.

MR. BUCKLEY: We are talking about $3 / 10$ ths of a penny on a \$. 62 item so it is not the kind of a thing that is going to precipitate anybody doing anything very dramatic. At tne wholesale level it is a crucial element in the competitive posture. 
QUESTION: But just the reactions put on top of enormous price hikes might just conceivably be the "last straw." MR. BUCKLEY: I guess it is fair to say that in our region of the country, anyway, we are losing some accounts to natural gas, have been for the last few years because it has been price controlled but if you do it on a BTU basis, even today natural gas is no great bargain vis-a-vis heating oil. Just a couple cents a gallon because of the long pipeline it takes to get it up that far and the high transmission cost of getting it up that far. In other parts of the country where natural gas is closer, they have already taken the market. At the same time we have been losing accounts to natural gas we have been picking them up from electricity because electric utilities, of course, burn residual fuel and that is $\$ 20$ a barrel plus now. They have big transmission losses so their costs are higher in New England than gas or oil. So, as of now, we are still getting a good share of the new home market for oil heat. We are losing some conversions to natural gas, but don't forget, it was only two years ago when we had natural gas shortages and run outs. That hasn't really changed. All that has happened is that some of the rules have changed and some of the intra-state gas is now available on the interstate market so we have a few years of so-called "bubble." But, longer term, unless we find some new gas and/or some new oil, the marginal source of gas is going to be importing LNG. Then you are up to $\$ 30$ a barrel oil equivalent. That is a high cost gas, and that is going to be the marginal source. We think we can handle the gas competition and that this $3 / 10$ ths of a penny is not going to be a meaningful consumer item in a $\$ .62$ to $\$ .70$ market.

QUESTION: Will you comment on your feeling as to the lack of uniformity where in your region perhaps only some of the states might go for temperature compensation while others would not.

MR. BUCKLEY: I think it would be far better to have a uniform national standard because an awful lot of companies operate in a lot of states. If you have to go it one way in one state - for example, you take that little state of Massachusetts, the western parts gets supplied out of Albany. Suppose New York allows it and Connecticut doesn't.

Springfield and Holyoke, Massachusetts, get supplied out of New Haven. Worcester gets supplied out of Providence. Cape Cod gets supplied out of Tiverton in Narragansett Bay in Rhode Island. Amesbury gets supplied out of Portsmoutin. New Hampshire. Similarly, stuff coming into Boston zoes to Nashua or Manchester. New Hampshire. I could see a real problem at a rack level ilith oil going into several different states from the same central terminal if the states have different standarda. I think it is important to havea unified standard. QUESTION: I believe you said we import half of our oil 
needs.

MR. BUCKLEY: That is correct.

QUESTION: Do you know how much we export.

MR. BUCKLEY: Of oil? The only oil that we can export is oil that we may get an export license for and it is mostly specialty lubricants. I would guess no more than 50,000 or 60 , Oogbarrels a day out of $20 \mathrm{million}$ that we use.

QUESTION: You are not exporting any crude.

MR. BUCKLEY: Not that I know of. There may be a specialty crude with 50 percent waft yield or something of that sort that goefout in dribs and drabs but not that I know of.

QUESTIDN: You mentioned that some dealers are heating their metal disk plates. What controls are on those and is it conceivable that some of them are heating beyond bo degrees F.?

MR. BUCKLEY: I guess the only control is the cost of buying a boiler and burning up the fuel. That is a significant operating cost. I don't think you can control temperature in a large tank to 60 degrees $F$.; it is going to vary from day-to-day with windchill and so forth. So it is an imprecise way of doing it but as long as you do it over the whole winter and come out somewherefinear bo degrees $F$. you are an awful lot better off than if you don't do it at all in terms of your own pocketbook. But, in termof using energy wastefully and inefficiently, I certainly wouldn't recommend it as a national policy. 


\title{
DESIGN AND OPERATION OF
}

\section{MECHANICAL AUTOMATIC TEMPERATURE COMPENSATORS}

\author{
Emmett Wehmann \\ Assistant Chief Engineer \\ Neptune Measurement Company \\ and \\ Manufacturers Technical Committee
}

On behalf of the meter manufacturer's technical committee and the company I represent, permit me to express our appreciation for the opportunity to offer our contribution to this symposium.

As many of you may realize, the meter manufacturer's technical committee was organized and informally exists for the one purpose of working together with the petroleum industry and weights \& measures on all technical aspects of liquid metering involving our mutual interest.

Today our particular topic is "Temperature comensated Volumes in the Sale of Petroleum Products". The overall concept of modifying volumes of petroleum products certainly is not a new one. The development and use of the petroleum tables for volume correction, as published by the American Society fof Testingalyaterials, also dates back to more years than I care to remember.

My specific topic will cover "The Design and Operation of Mechanical Automatic Temperature Compensators" as they are currently produced for use on terminal and vehicle tank meters.

The other speakers in all probability willmention why measurements are corrected to volumes at 60 degrees $F$. I trust you will excuse the likelihood of slight repetition, or overlap, in this presentation.

I would like to approach this phase of the topic with the question, what is temperature compensation as applied to the metering of 1 iquid fuels? In answering this question, it must first be realized that petroleum products, like othar liquids, increase in volume as the liquid temperature increases. The reverse is true when the product temperature decreases. As we are all aware, liquid fuels are predominantly measured by volume: the barrel, the gallon, the liter and the cubic meter.

The petroleum industry developed "volume reduction" tables which list multiplying factors for modifying the volume of a given liquid, at an observed temperature, to the volume it would have at 60 degrees 5 . This calculated so degree volume is referred to as a "corrected" volume. 
With A. T. C. metering, this modification in volume is being accomplished during the measurement process. The 60 degree volume indicates, and often recorded, is already compensated for the deviation between 80 degrees and the actual product temperature.

I prefer to refer to the bo degree metered volume as "temperature compensated". The term "temperature corrected", in this case, implies that uncompensated metered volumes are incorrect and this is certainly not intended.

Stated more directly, when the liquid volumes, at prevailing product temperatures, are automatically indicated by a meter in terms of 60 degree volume, the conversion is called "temperature compensation". The device on the meter. which automatically provides this volume compensation, is defined as an "automatic temperature compensator" or A. T. C. METHODS OF ACHIEVING 60 DEGREE F VOLUMES

There are fundamentally two methods by which converstion to a 60 degree volume may be accomplished.

The first method is to convert by using simple arithmetic. If we have 5,000 gallons of No. 2 fuel oil at 75 degrees $F$, we can find, by referring to Table 6 of the petroleum tables, a volume reduction factor of 0.9933 (35 degrees API). Multiplying the 5,000 gallons by 0.9933 results in a 60 degree $F$ volume of $4,966.5$ gallons.

The second method is to use the automatic temperature compensator. Please note the word "automatic". This method employs the use of a liquid meter equipped with a device which automatically accomplishes the conversion during the measurement process.

There are two fundamental engineering techniques applied to achieve automatic compensation. namely: mechanical and electronic. Both means of acquiring automatic compensation involve two functions: 1) temperature measurement and 2 ) conversion of the actual, metered volume, to tine so degree volume.

We will consider here the mechanical A.T.C. as applied to LP-Gas and other liquid fuel meters used on vehicle tank trucks.

As many of you are already aware, the positive displacement meter produces a rotational, mechanical drive, to the meter read-out. This read-out is also referred to as thb "register" or "counter". The A. T.C. is a component which is installed between the present measuring unit arid the read-out. The A.T.C. consists of three major components: 1) the temperature sensing unit of system, 2) the mechanical computer or ratio change mechanism and 3 ) the coefficient setting mechanism. 


\section{THE TEMPERATURE SENSOR}

The temperature of the liquid being metered is measured by either of two types of sensing units. The one unit, called a thermostat, consists of a metal bellows built into a sealed, liquid-filled bulb. This thermostat usually is assembled in direct contact with the metered liquid. The second type of sensing unit consists of a small bore (capillary) tubing with a bulb at one end and a metal bellows at the other. This assembly is also liquid-filled and sealed. The sealed liquid in both units has a high rate of expansion to achieve a linear movement of the bellows; in the order of several thousandths of an inch per degree Fahrenheit.

With the bulb and capillary tube design, the bulb is assembled in a thermometer-type well. Also with this type of sensor, a second thermostat is assembled in the A.T.C. package to offset the ambient temperature effect on the liquid in the capillary tubing.

THE COMPUTER OR MECHANICAL RATIO, CHANGE MECHANISM

The mechanical computer is capable of automatically applying the proper conversion factor or drive ratio for the prevailing temperature in the metering system. The ratio being applied by the mechanism is determined and controlled by the temperature sensor. Simply stated, this unit modifies the drive ratio between the meter and its read-out.

THE COEFFICIENT SETTING UNIT

In order for the computer to apply the proper compensation factor at any given temperature, the appropriate coefficient of expansion value must be set on this unit. With a coefficient of 0.0016 (propane) setting, this unit would increase the movement, per degree Fahrenheit, of the calculator to almost four times what it would be if the setting were 0.00045 ( 35 degrees API).

With the aid of several slides, we will be able to achieve a first-hand impression of what an A. T.C. looks like on truck type petroleum meters. For each manufacturer's design you will observe essentially the same meter without and with A.T.C. component in the assembly. In all cases the component is installed between the standard meter and its read-out unit.

With the use of another slide, you will be better able to observe how the volumes of two different petrolaum products vary with temperature. The one product volume/temperature curve is for propane and the other is taken for a 35 degree API product (No. 2 fuel oil).

With the remaining slides, we hope to convey at least an 
impression of the mechanical principle of each of several computers and their associated temperature sensing units.

No. 1 The first schematic indicates use of the sensing bulb, capillary tube and bellows system. Use is made of an opposing ambient bellows for reasons mentioned earlier. The "gravity selector", another term used for the API or coefficient setting, is shown on the left. Adjustment moves the pivot up or down, altering the lever ratio to the computer. The change inratio of the computer is accomplished by changing the shaft angle of the rollers which provide the drive between the lower cone and the upper cone. A "disconnect knob" shown at the bottom is used to deactivate the control of the temperature sensor.

No. 2 The second schematic indicates, at the lower portion, a thermostat type sensor which directly couples through a rod to the lower end of a lever assembly. This lever pivots about an adjustable point for change of coefficient. The upper end of the lever varies the position of a friction roller on a rotating platform. When the roller is closer to the center of the platform the rotation of the roller decreases and vice versa. The planetary gearing system allows for the major portion of the drive to go from input to output and the remaining portion of the drive to be controlled by the friction roller mechanism.

No. 3 The third schematic, at the lower portion, indicates again a thermostat type sensor which is directly coupled to a lever system for control of the computer. The coefficif setting is accomplished by movement of an adjustment which raises or lowers the pivot point. This, in turn, affects the ratio to the computer mechanism. The ratio mechanism of the computer is varied by changing the distance between two points (A) and (B). As center (B) moves away from (A), through a ratchet and pawl mechanism, the output angle is increased over that of the input. In both the No. 2 and No. 3 schematics by withdrawing a pin, the computer is disengaged from the sensor.

A fourth mechanism embraces the elements covered in the above schematics with one exception. The computer in this design, while making use of the planetary gearing approach. the ratio change input to the planet system is provided by two over-riding friction clutches. The stroke of these two cam-operated clutches is varied by the temperature sensor and the coefficient setting. The temperature sensor is again of the bulb, capillary tube and bellows type with compensating ambient thermostat. With this design the sensor is not disengaged from the computer. In the deactivation mode the meter drive is by-passed from the planet drive to directly couple the read-out. 

(SCHEMATIC)
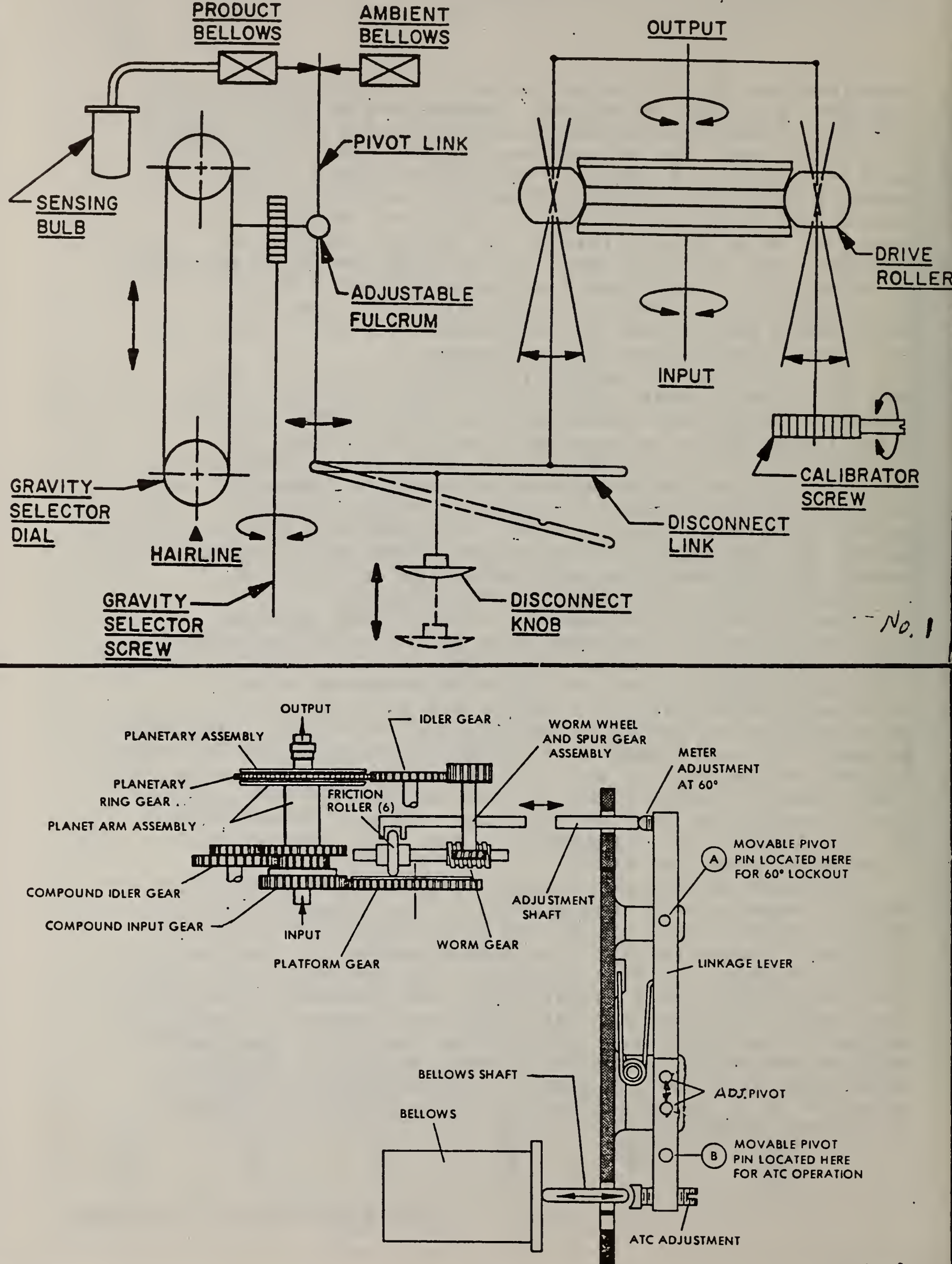


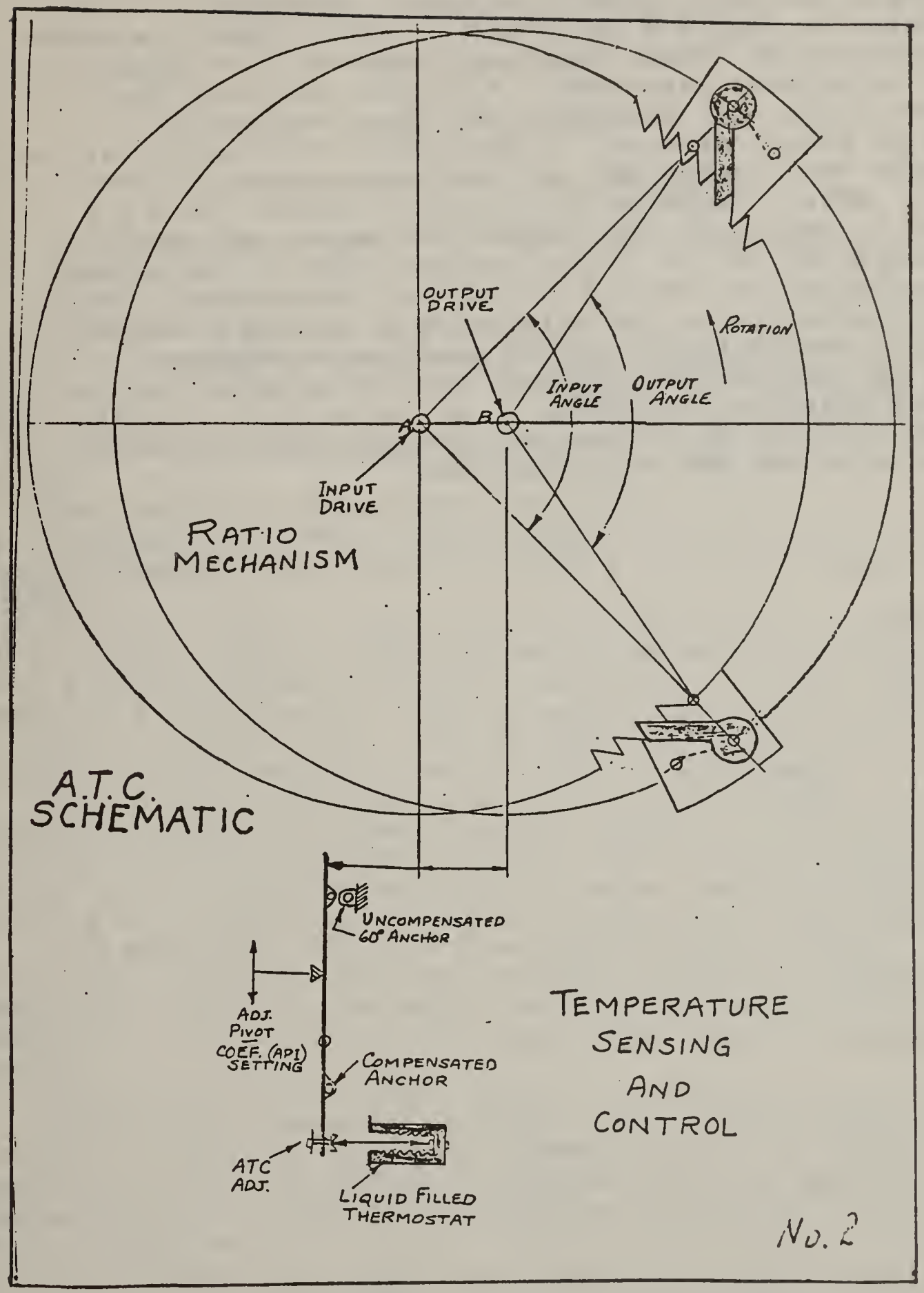




\section{THE DEACTIVATE OR LOCK-OUT FEATURE}

Products delivered by vehicle tank meters are furnished with a single read-out, whether equipped with an A.T.C. or not. In order to test and calibrate an A.T.C. meter, a means must be provided to "deactivate" or "lock-out" the computer function. As already mentioned, in several designs, the temperature sensor is disengaged and the computer is by-passed by direct gearing. In any case, the computer action is nullified for testing and calibration purposes of the meter only. After the meter is routinely tested, an A.T.C. meter test is made with the temperature sensor and computer units engaged. All A. T.C.' 5 are designed with an adjustment feature included, to permit bringing the compensated reading as close as possible to the calculated bo degree $F$ volume.

All A.T.C.'s are designed so that adjustable settings, including the coefficient setting, are sealable by the weights and measures inspector.

Again allow me to express our appreciation for being able to be with you and to participate. 


\title{
PERFORMANCE CHARACTERISTICS OF
}

\author{
MECHANICAL AUTOMATIC TEMPERATURE
}

\section{COMPENSATORS}

\section{Howard Siebold}

\section{Liquid Controls Corporation and \\ Meter Manufacturers Technical Committee}

This discussion is not intended to advocate or to oppose the use of automatic temperature compensation with fuel oil truck meters. We hope to cover one aspect of the subject that might otherwise be ignored. Most of these comments will apply as well to other truck meters measuring other petroleum-based liquids.

Many weights and measures officials are familiar with the Automatic Temperature Compensator, or ATC, particularly those involvedwith the testing of LPG truck meters that are 50 equipped.

The two fields of application are different, however, in one important respect. The LPG Measuring Device Code was set up at a time when many LPG truck meters were fitted with temperature compensators. The tolerances allowed were ample to cover a tolerance for the LPG meter and a tolerance for the ATC. It has seemed to be a workable arrangement.

Now we have a situation where the Liquid Measuring Devices Code has a tolerance established for the meter, and we are considering the addition of a temperature measuring device to it. The tolerance for the meter canrot possibly be expected to include the automatic temperature compensator.

Testing a fuel oil truck meter with ATC is really testing two separate devices with two different standards of comparison. For one, the meter, a known volume prover or test measure. For the other, an accurate temperature indicating device.

As mentioned by others, the ATC is a measuring device. It measures the temperature of the liquid in the meter and changes the ratio of the drive between the meter and the indicating and/or recording element so that the amount displayed is the volume at 60 degrees Fahrenheit of the amount delivered.

Any temperature measuring device must have a tolerance or a factor of uncertainty. We will discuss some of the sources of error that should be given considaration in analyzing this problam. 
Since the performance of the ATC is compared to volumes calculated from the Petroleum Tables, the determination of the actual 1 iquid temperature in the meter is a vital function. This is usually made with a mercury-in-glass thermometer. This is a temperature measuring device that also has a factor of uncertainty.

That uncertainty is a function of: (1) the readability of the thermometer, (2) the time lag, (3) certification by NBS, and (4)

whether it is being used as it was certified - that is, totally immersed or partially immersed.

NBS Handbook 99 recommends that mercury-in-glass thermometers with one degree Fahrenheit graduations be used. Thermometers with better readability are available, but they are difficult to find, they are fragile, and they are expensive.

In testing an ATC, or a meter fitted with an ATC, some human error is possible. The performance of the device is compared to mathematical tables based on the reading of the temperature of the liquid by an operator - or operators. The variation of readings of the same quantity by various operators - or by the same operator at different times was well illustrated by part of the tests reported to the National Conference on Weights and Measures on May 22, 1953 by W. J. Louden and Mac Jensen of NBS. No definite conclusions were reached on this point, but it was established that operator error can be a significant factor in testing a device.

My personal experience has been that it is very difficult to read a thermometer with one degree Fahrenheit graduations closer than one fourth of a degree Fahrenheit and that a one fourth of a degree error is quite possible.

The tolerance for a temperature measuring device of this kind could take a variety of forms. One method would be to express the tolerance in degrees Fahrenheit. This would have the advantage of varying the tolerance as the coefficient of expansion of the liquid varies. In other words, the tolerance would be greater for gasoline than it would be for \#2 fuel oil.

The Canadian weights and measures law recognizes that the response curve for the device and the coefficient curve for the liquid may not be a straight line. The tolerance allowed increases as the temperature difference from 60 degrees increases. The formula for establishing the tolerance is a bit complicated and is probably not suitable for field use.

The tolerance that is established could very well be listed in a table showing temperatures and tolerances especialiy for a limited range of liquids sush as \#1 arid \#2 fuel oils. 
A tolerance established for the ATC must be based on the uncertainty of the temperature determination, the uncertainty of the determination of the coefficient of expansion of the liquid, and an allowance for the mechanical device.

The actual testing of a fuel oil truck meter equipped with the ATC would follow the procedure outlinedin EPO No. in NBS Handbook 112. The basic meter accuracy would be determined first with the ATC "deactivated". This instruction should be added to the "Pre-Test Determination" of EPO No. 23.

This is a good example of a situation where it would be desirable to have the meter error "- - as close to zero etror as practicable". The error noted at the pormal flow rate will be the basis for computing the error of the ATC at bo degrees Fahrenheit or at the operating temperature.

The test is them repeated with the ATC "activated".

The temperature of the 1 iquid in the meter is recorded as 60 degrees Fahrenheit. The temperature of the liquid in the prover is determined and recorded. That is the temperature that is used to calculate the volume of that amount of 1 iquid at bo degreesfahrenheit.

The multiplying factor for the liquid at that temperature can be located in table 24 of the Petroleum Measurement Tables. Locate the column headed with specific gravity of the liquid at 60 degrees Fahrenheit. Follow the column to the temperature observed in the prover. This will show the multiplying factor.

For example, \#2 fuel oil with a specific gravity of .850 at 60 degrees would have a multiplying factor of 1.0000 if the prover temperature of 60 degrees is observed. If the temperature of the fuel oil in the prover is 40 degrees Fahrenheit, the multiplying factor would be 1.0089. If the volume in the prover is 100 gallons, that volume converted to 60 degree volume would be 100.89 gallons.

If the recorded temperature of the fuel oil in the prover is 80 degrees Fahrenheit, the same column in table 24 would show a factor of .9911. This means that the meter should register 99. 11 gallons for 100 gallons in the prover. Obviosuly, the coefficient of expansion used in the calculations must be the same as the coefficient set on the ATC. If it is not, the test results are sure to be in eTror and the error will increase as the temperature differs from 60 degrees Fahrenheit.

In the example above, the \#2 fuel oil has a volume change of. 89 gallons in the 100 gallons for a 20 degree change in temperature. This figures out to be a coefficient of expansion of .00045. It means that the volume of that fuel oil will increase or decrease 0.045 percent for each degrae Fahrentieit.

If tables are used to list tolerances, they could also 
list multiplying factors for fuel and kerosene as is done for LPG in NBS Handbook 99.

The test procedure outlined above is copied from Handbook 99. The instruction to record the temperature of the liquid in the meter as bo degrees Fahrenheit merits some discussion. This is a valid recommendation only if the temperature of the liquid does not change after it leaves the meter and is determined in the prover. The example in H-99 of testing the meter without ATC shows a change from 63.5 degrees to 65 degrees between the meter and the prover.

The meter with ATC will display the volume adjusted to bo degrees from the temperature sensed in the meter or in the line "immediately adjacent to it". If the temperature of the liquid in the prover is different, the volume in the prover must be adjusted to the volume that it would occupy at the meter temperature for calculating the ATC performance.

If our basic intent is to improve the accuracy of measurement of petroleum products, then we should not overlook some of the sources of error that have not been stressed in the past.

One example is failure to determine liquid temperatures in the meter and the prover in ordinary meter proving that does not involve temperature compensation.

Handbook 99 suggests reading the temperatures to the nearest one-half of a degree Fahrenheit. On LPG this could amount to an error of nearly one-tenth of one percent.

If these proceedings should lead to action by the

National Conference on Weights and Measures to permit the use of Automatic Temperature Compensation, the Meter

Manufacturers' Technical Committee offers its assistance in working out Specifications and Tolerances that are fair and equitable. Any state considering the passage of enabling legislation should make sure that it does contain such Specifications and Toleerances.

QUESTION: What is the state of the art in electronic compensation?

MR. SIEBOLD: I am just going to say it can be done, but I don't know that any of the cost figures that you might be hearing would apply at all because it would cost a great deal more to have an electronic device to do the same thing.

QUESTION: Some question of reliability --

MR. SIEBOLD: We could have another meeting on eletronic devices in this business. I really don't know. I don't think anybody has enough experience on them in this application to be able to tell you what the reliability might be. You siould get better. more accurate results but first, let us dacide whether we are going to need it.

QUESTION: Is it not possible to test at delivery temperature compensated and test the delivery with the temperature compensator/and gauge? In other words, take the 
temperature of the product as it is delivered and deliver the known quantity and then relate that to the registered volume? MR. SIEBOLD: You mean do it mathematically. This is one way of doing it. Importantly, and you mentioned it, you must determine the temperature as you delivered it. You would have some of the same problems I just covered. You could be in error there, too.

QUESTION: Would that not then test the unit as a complete unit, a single unit, rather than breaking it into two sections - a temperature pricing unit and a measuring unit?

MR. SIEBOLD: If you were certain that your meter basically was accurate that would be all right, but it might not be. The reason the Handbook 44 specifies that you be able to deactivate it is so that you can determine the basic meter accuracy uncompensated but with the device being operated. Once you establish the accuracy or adjust the meter to be accurate, then you test it with it activated and you get a valid comparison. With your method you are presuming that the delivery without the ATC would be accurate and you would have to establish that anyway.

QUESTION: Don't you also make the presumption that when you test the meter at one particular temperature and find it correct, that it is correct at other temperatures?

MR. SIEBOLD: I didn't say you only needed to test at one temperature. Most Weights and Measures officials test it at whatever temperature happens to be on the truck. I don't know that I blame them for that. However, under a pattern approval plan I would presume as Canada does you would run it through the range of temperatures that it is designed to cover.

QUESTION: What are the ranges of commercial equipment available now?

MR. SIEBOLD: Most manufacturers have a variety of ranges. I would say the standard one is probably -30 to 120 degrees Fahrenheit, or maybe 0 to 150 degrees Fahrenheit. It covers about a 150 degree Fahrenheit range, and you can get one from 200 to 350 degrees Fahrenheit if you are handling heated products. This is simply a matter of convenience.

QUESTION: Has the reliability of the equipment on trucks

been tested given the bouncing a truck takes?

MR. SIEBOLD: Yes, the LPG people have been using them for 20 years, and they bounce just as much as any other truek.

QUESTIDN: Would you care to express an opinion on the two different methods that Mr. Wehmann detailed for

temperature response, or perhaps Mr. Wehmann could respond to that?

MR. SIEBOLD: You will have to ask him berause my answer is no. Mr. Byrd reminded me of something, and it will only take me a minute to comment. Mr. Wehmann reminded me that 
we were testing some heavy bunker fuel meters, and they were heated. We were using scales as the standard of comparison, and in order to establish the weight per gallon I was making hydrometer measurements of the heated bunker fuel. The oil plant man was looking over my shoulder, and he said, "Howard, what would the result be if you misread the hydrometer?" I said. "Walter, nobody around here would be able to prove that I vas wrong."

MR. WEHMANN: That is true. I can remembar our going through some of that experience. When you have heavy fuels and you watch the hydrometer, it takes a long time for the hydrometer to make up its mind to sink, and after it stops sinking into the product then the oil starts creeping up the glass. So, you can never make up your mind which is which.

If I may try to reply to the question regarding response. Essentially. I don't think there is a strong case for either of the two sensing type systems that you are talking about over the other. In the thermostat type, your bellows, sealed liquid and container are all in one package, that is directly exposed to the 1 iquid. Therefore, it would essentially have pretty good response. But this is not to take away from the other type of sensing system where you have a bulb, becauseimost of the designsthere is a material put in the thermometer well to give it thermal conductivity from the shell aver to the bulb.

I think, even considering some of the discussion that took place this morning on the speed of the response aspect and some discussion about electronics, certainly with the thermistor and the platinum type units which have rather low response time, one has to consider that any unit itself has to be put into the fluid and into some hardware which immediately adds a certain lag.

In the practical application on equipment you must consider the fact that in use (let us say we can either go to the bulk rack meters or the truck meters), most of your equipment is essentially at some temperature level. In other words, you hear laboratory examples of taking the product from 90 degrees Fahrenheit and cooling it down to 30 degrees Fahrenheit and see how long it takes to get there. Studies were made by API several years ago on just checking out testing procedure where temperature readings were taken in the field at the meter and at the prover. We put a thermometer, a mercury and glass thermometer, right in the strainer section of the meter on the truck and observed the temperature change that would take place in a wall with some fluid in there to get a good thermal conductivity. It is true that if you have left the pump running you might see the temperature $r i s e$ and then go back down on that thermometer. But, keep in mind that if you were standing there watching that thermometer and allowing for the fact that that 
thermometer had a relatively low inertia, you wouldn't know what to do with the data when you observed it. You would kind of average it out over the whole delivery.

In LP gas the Bureau has decided and in $\mathrm{H}-99$ it is outlined that you take a temperature reading partly into the delivery, and then about two-thirds the way through again to get a pretty good average. But by the same token, for the temperature sensor in the meter, its inertia can stand it in good stead as an advantage rather than a disadvantage berause if you get a slight temperature rise, it is then not going to run up and change and then run back. It probably will average out. Remember that the vehicle tank truck is out in the weather; the piping is in the weather; and the delivery is of longer duration than when we were talking about filling station pumps. So actually, inertia is not a handicap. Certainly, in the testing procedure at the time you test the thermostat you have run your full flow test and maybe you recheck the full flow, you have wet the prover. You run the low flow and then you engage the thermostat to check the ATC reading. Certainly by that time the system has been run long enough that everything is pretty well equalized so you are getting a very fair representation of what the temperature is in the system under test. It isn't very likely that a lag would be an important factor in the testing technique.

QUESTION: One more question. I was told one time that the meter was already temperature corrected. In other words, it was inherently temperature corrected because of the various metals which are used in the meter. Is that right?

MR. WEHMANN: No, that is not correct. Meter materials are not such that they would compensate for change in product

temperature. It is true that the meter would probably be more efficient and tend to register a little higher on a very viscous liquid as opposed to a very thin liquid. If one assumes that a viscous liquid gets thin when it is heated, that really is not temperature compensation. There is some effect, but the effect that you get there is very slight, so you would certainlyhot say that changes in clearances or expansion of the metals in the meter would compensate for a liquid volume change. In other words, let us say roughly that at 90 degrees Fahrenheit, the meter gives you a 231 cubic inch gallon, and at 60 degrees Fahrenheit it will still give you 231 cubic inch gallon. It might be slightly different only because of the slight viscosity change if one wanted to assume, you know, that that was a significant factor.

Certainly that is not really a significant factor.

QUEETION: Could you give an approximate cost per unit to update existing meter and/or the rate of repair versus what would be normal for a regular meter?

MR. WEHMANN: On cost, I can't,Mr. Dugan is in the audience. You bought some, 50 you would probably know how 
much more a meter would cost with than without.

MR. DUGAN: The cost is approximately $\$ 400$ to $\$ 500$

depending on what kind of cabinet modification you have to make in-house. I do it all in-house.

QUESTION: What about rate of your failures? Is it any different?

MR. DUGAN: With due respect to Emmett, after two years of installation on my entire fleet, I have replaced two sets of planetary release. That is on 50 truck users.

MR. WEHMANN: Thank you. We also have another gentleman on the program following who will talk about his experience with compensators. He probably has more firsthand experience. Keep in mind that $I$ am in product line engineering, and $I$ don't usually get involved with prices, but if we get too much maintenance, you know, we do hear about it. 
PRACTICAL EXPERIENCES OF A

RETAIL FUEL OIL MARKETER

Jay L. Dugan

Meenan Oil Co., Inc.

The proper place to begin is to identify Meenan ail. We are one of the largest independent retailers of Number ? heating oil in the country,. We market on Long Island and along the Hudson River in New York State, throughout the state of New Jersey and in southeastern Pennsylvania.

I am responsible as General Manager of our Pennsylvania retail division for a deep-water terminal in Tullytown.

Pennsylvania, which is just north of Philadelphia across the river from Trenton from which we serve approximately 18,000 retail heating oil customers in lower Bucks County. Also, we supply wholesale all or part of the No. 2 fuel oil needs of well over a dozen of our retail competitors.

Dur principal supplier of product is Mobil Oil who classifies us as a cargo/barge buyer. It is and has been for many years the practice of the major oil companies to sell oil in barge and cargo quantities at a standard bo degrees F., using Table $b$ or the more abbreviated Table 7 of the petroleum tables. This ereates a problemfor us, however, when we arrive at the retail sale of this product. Qur storage capacity at Tullytown includes approximately $161 / 2 \mathrm{million}$ gallons of No. 2 heating oil. obviously all above ground. For at least six months of each year this productin the tanks is below bo degrees $F$. and is thas contracted volumetrically from the base 60 degrees $F$. at which we must purchase it.

At Meenan Dil we found that our substantial product loss was due to two unrelated factors. The first was the fact that we purchased our oil from Mobil based on barge measurements which, again, is normally standard in the industry. It is known throughout the industry, however, that barge measurements can be notoriously inaccurate as anyone who has seen an empty barge going down the river can tell with the dents in the side; remember they are only a single hull. On a 12 -month basis this was costing us in excess of 100,000 gallons. To correct this problem we agreed with Mobil to use our shore tank as the measurement point. This is an unusual move in the industry but it is a function of Mobil having resognized the inaccuracy of barges.

The second cause for product loss was ooviously shrinkaga dise to temperature. We conducted daily studies during a period of over two years taking into account the 
daily throughput at out loading racks and the daily temperature measured by immersion thermometers at the loading rafks and comparing this with our purchases at 60 degress which goes into book inventory. When we compared physical versus book inventory the results showed that we were losing on the average of 0.35 percent of all of our product due to its reduced volume alone.

Many years ago retail fuel oil distributors recognized this problem. I have to emphasize that there were very few that took it seriously. They accepted it as a normal business 1055 and the loss at the time wasn't very large since, as John Buckley and others have said, product seven or eight years ago was costing around $\$ .10$ a gallon at wholesale. With today's wholesale cost of over $\$ .47$ per gallon. (I had to update that as I rewrote the speech every week because it went up another cent or two. ) The monetary loss to the distributor

who buys at 60 degress $F$ is significant. We have heard it suggested, not here but in many other places, that there is an easy, no-cost solution to this problem. (When you say "no-cost" I am all ears.) The retail distributor should simply increase the selling price by an amount necessary to recapture this loss due to shrinkage. We recognize at Meenan that increasing margin to compensate forloperating inefficiencies is to sweep the inefficiencies under the rug. This is unacceptable since it only tends to perpetuate an identifiable problem.

We investigated three potential solutions to the problem which have already been spoken to here: installing submersible heaters in our tanks was unacceptable because of the cost involved in the initial capital construction, plus the waste of the fuel oil reeded to fire the boilers.

An additional possibility was installing line heaters, which John had mentioned. Most companies, I think you will find today, that do heat their number two are multi-product terminals who can parallel their product lines with a number six oil line and jointly wrap the two for insulation. There is heat transfer which can raise the product termperature of the number two; however it is slightly less controlable.

The obvious solution was the installation of automatic temperature compensators on our loading racks and our retail trucks. In this way we felt that we had the final solution to controlling our inventory overage in the summer and shortage in the winter, and equaliy important, establish an equitable solution to a serious industry problem.

It has been charged by some opponents of automatic temperature compensation for number two that tha customer loses and the oil company increases what are now rapacious profits. A sustomer, and Meenan has many that are very muri like John Buckley, has a 1,000 or 2,000 gallon tank, and 
historically requests that this tank be filled in late summer or early autumn. Automatic temperature compensation makes him a winner since he is receiving more oil volumetrically than he is being billed for. The majority of our customers, to be sure, have smaller tanks and receive most of their deliveries during the winter months.

Since our average customer consumes 1,100 gallons per year, using ATC to eliminate the 0.35 percent shrinkage loss means that each customer is being billed for less than four additional gallons than he would have were Meenan not to use ATC's. Is this a consumer rip-off? I don't think so. It is an honest attempt on the part of Meenan to establish an orderly and equitable procedure for passing along the true cost of product to our customers. We could just as easily have increased our margin to recoup this loss, but we chose not to operate this way. Such a solution would compound the inequities and perpetuate the fact that current metering methods are inherently inaccurate. We first approached the Pennsylvania Bureau of Standard Weights and Measures in 1976 with the request that we be allowed to install automatic temperature compensators on our retail deliver trucks. On June 15, 1976, Walter Junkins, then Director of the Department of Standard Weights and Measures, approved the installation of ATC's on ten of our delivery trucks, with the proviso that they be tested for a period of six months and that the test results conducted periodically over this time demonstrate an acceptable level of reproducability and accuracy. The test period was later extended to twelve months and during this time period representatives from the Bureau of Standard Weights and Measures in Pennsylvania, the Nepture Measurement Company, and Meenan Dil, continualiy monitored ATC performance. And, after several false starts, as Emmett will remember when he and I along with Ron Roof were fighting about the proper way to set up test procedures, we finally arrived at a standard procedure which we all agreed was accurate and fair.

For its part, Meenan purchased the Cerifine 100 gallon prover, custom built to show 450 cubic inches below zero, to be able to prove and adjust the ATCs in the most extreme product temperature environments.

We subject all trucks to a minimum of two tests per year in addition to the test conducted by the state each summer. After a public hearing held at Harrisburg on August 17, 1977, Type approval for the Neptune Type One, Style Five. Automatic Temperature Compensator was granted on Dctober $27,1977$.

This, I stress, was not a permit specifically given to Meenan Oil to use automatic temperature compensation. This was the State of Pennsylvania saying that tha Neptune Type One, Style Five meets their standards as sperified in the Pennsylvania Weights and Measures Code, and 5 an therefora be 
used by any retail distributor who so desires.

Meehan proceeded to install these units on our entire delivery fleet in the Pennsylvania Retail Division, consisting of 25 trucks, with one exception, and $r$ will defer to Mr. Byrd. We have one truck which about one day a week goes into New Jersey. We have kept that truck at gross. We have not converted it to temperature compensation. If that truck breaks down and we have to make a delivery in Jersey, we will remove the temperature compensator from another truck, make sure the meter is in calibration, and make our New Jersey deliveries.

Dur experience to date has been quite satisfactory. The total product loss through our terminal on a through-put volume of over $60 \mathrm{million}$ gallons had in the past run as high as 300,000 gallons, of which almost 200,000 can be attributed to temperature, and the balance to barge shortages as noted abdue. Last year, and by that I mean the 1977-1978 heating season, or the full 12 months (we are on a July through June fiscal yearl, the first year in which automatic temperatura compensators were being utilized on our entire delivery fleet total product shortage for a like through-put was 8,000 gallons. One must remember that by this time the barge shortage problem had already been solved.

Several people have questioned the maintenanca of the ATC's and I stated earlier that we have replaced two sets of planetary gears, which we felt was a cheap price to pay. For comparision purposes, we use as our printing registers, the Lockheed Computing Register Style 840 . These have required an average of four repairs per truck, per year.

Another objectioh being voiced is that the retail

customer is unaware of the fact that his oil is being sold on a different basis, and this today is true.

We, Meenan, have an agreement with the Pennsylvania Bureau of Standard Weights and Measures that as soon as our present stock of pre-printed delivery tickets have expired, we will have new tickets printed specifying that it has adjusted volume to 60 degrees $F$. We have too many of these present ticketsictiree weeks we are going to have them overprinted with a statement clearly stating, right above the gallons printed, that this volume is adjusted to bo degrees F.

It is not, nor has it ever been our intention to mislead our customers, and using this notification I hope to demonstrate that we are adhering not only to the letter but to the spirit of the agreement reached between Meenan 0 il and the Pennsylvania Bureau of Standard Weights and Measures.

Meenan recommends to the National Conference on Weights and Measures that they propose to NBS that automatic temperauire compensation for retail fuel oil distribution be spoken to in Handbook 44 in the same fashion as the current 
approval for the use of ATC's on LP gas, that is, that permission be granted for measuring number two fuel oil as a standard gallon. subject to the approval of the individual states or municipalities, but only at the request of the heating oil dealer, as it is now done with the LP industry.

Fair and consistent test procedures should be established and adhered to rigorously. I recognize that the major oil companies are concerned that if ATC for retail number two is approved the next logical product would be gasoline. Since virtually all gasoline statóns store their inventory underground, where it has an ambient temperature not too different from 60 degrees $F$. , the advantage to the motoring public would be insignificant. In most cases the capital investment required of the major oil companies would be staggering.

It is my understanding that Harold Harris, of Exxon, will speak to this subject in more detail tomorrow.

In conclusion. I would like to state Meenan Dil's position regarding the use of automatic temperature compensation for the retail delivery of number two heating o i l:

Number one: We are opposed to making its use mandatory. We believe mandating its use would work economic hardship on small distributors whose storage is underground and whose inventory in these underground storages rather quickly reaches an ambient temperature not too different from bo degrees F.

Number two: We are opposed to its use, even on a voluntary basis, by distributors who would use it for unjust enrichment. Its use should be limited to those distributors who purchase their oil on a temperature-corrected basis. since this use would only be for recouping product loss due to shrinkage.

Number three: Where the use of automatic temperature compensators are approved they must be used twelve months a year. An economic advantage can be gained by disconnecting the ATCs when the product temperature is above bo degrees, and that is the case at least five to six, sometimes seven months a year. This would only tend to give another black eye to an industry which God knows already has its share.

Hankboak 44 currently permits, and the operative word here is "permits," the use of ATC for wholesale transactions. The Liquid Measuring Device Code specification S.-2.6, states that ATC may be used at wholesale racks, as long as it meets certain design criteria, such as a lockout device.

The retail ATC units have such a lockout device.

Specification $5-4.3$ requires tickets to be marked to show that the transaction occurred at 60 degrees F. Equity would demand that the Vehicle Tank Meter Code be brought into conformity with the Liquid Measuring Device code, and that it 
would permit the use of ATC.

Referring to a report issued by the Conference Committee on Specifications and Tolerances, in 1977, we find the

following quote:

"NBS Handbook 44 'Specifications, Tolerances and Other

Technical Requirements for Commercial Weighing and Measuring Devices' provides for the application and use of both the unit gallon with respect to the design and performance of some measuring devices in commerce, such as a gas pump, and to a standard gallon with respect to other devices, such as LPG liquid meter. State and local laws and regulations dictate whether a unit or a standard gallon of measurement will be applicable to a particular measuring device or practice in the marketplace."

There is a basic inconsistency here which does not seem to be in keeping with the aims of the National Bureau of STandards, and we ask that this inconstency be corrected.

Thank you very much for your attention. If I can answer any questions I will be more than happy to.

QUESTION: I would like to clarify one thing. In New Jersey it is not that we object to ATC's because we have them on all LPG meters; we have no problems but our law requires that liquid fuel, that is heating fuel, at retail be sold at the ambient temperature. That is a problem that we have.

I also have a question. You say, that it should not be mandated that ATC's be used, but in my own personal opinion. if one group uses ATC or a temperature compensated gallon. that could be a competitive factor over somebody else who does not. In my opinion right now I think that if the agency that has the business of telling people they can go with ATC does so, everybody in that particular should do it so that there is no competitive advantage. For example, do you get a payback after a certain length of time when the ATC's are paid for, and do you have a competitive advantage on the other marketers?

MR. DUGAN: We1l, it depends on what you mean by "competitive advantage." I have a payback. There is no question about that. I wouldn't make the capital investment, which as I said was approximately $\$ 550$ installed, unless I can demonstrate an economic payback. After that point, after the units are amortized. I am. making net slightly more per gallon, but what I am basically doing is recouping a historical loss. As John talked about earlier, the last person in the produet chain who buys at bo degrees $F$. and selis at a lower ambient is the loser in any product chain. In the past we have been delivering oil to our customers in smaller units than we have been paying for it. We are doing no more now than passing the burden which has been passed to us by tha major oil companies down to the final consumer, so that they are now buying a standard gallon. 
Admittedly, someone who buys on this basis during the summer gets a small advantage and someone who buys during the winter gats slightly less, but, as I said it is less than four gallons, and at today's resell price it costs about $\$ 2.00$. We have a fairly decent margin. You can't compare the margins of one oil company and another.

QUESTION: I take it you feel that it would cost the consumer four gallons per year?

MR. DUGAN: Slightly less.

QUESTION: I figure out, for example, on average, 200 gallon deliveries.

MR. DUGAN: Yes.

QUESTION: If that was delivered at 20 of ; which would not be unusual.

MR. DUGAN: That would be very unusual in my case.

QUESTION: 20 degrees?

MR. DUGAN: Yes, the coldest that I have recorded a temperature going out of my meters, is 28 degrees. That was January of a year ago. But remember, I am talking about a 12 month basis. I am talking about 0.35 percent of the total delivered in 12 months. Seven months of the year it is higher than 60 degrees.

QUESTION: We11, he is using that factor of 20 degrees.

MR. DUGAN: I don't think that is a fair temperature to use, because now you are down to about two percent shrinkage, and we don't experience that in point of fact, or in practice.

QUESTION: I was just wondering, it may have come close to 40 .

MR. DUGAN: Yes, but again, we don't do it like that. Number two: each of our customers gets on the average of $5 i x$ deliveriea year, two of which happen at times when temperatures are about to degrees. As a further example, product was very tight in February. We were on top of Mobil every single day to get every drop of product we could out of them. One day they said, "Okay, we have a batch coming off the still today. Do you want it?" We said "Put it on the barge. "It went from the still to the barge, came up to our terminal at 85 degrees, in the middle of February. It went in one side of the tank and out the other. That is how short we were of product

It is not at all unusual during summer fill, where you will find temperatures coming up at 100 degrees. There is $a$ very short distance between ourselves and the refinery. You have to speak on a twelve month average.

QUESTION: Is there any consideration in the printing of your tickets that instead of saying, which might be a little contusinglolume at 60 of, say that the delivery was made in terms of United States petroleum gallons?

MR. DUGAN: That is not the definition of United States 
petroleum gallons, though.

QUESTION: What is it?

MR. DUGAN: As I understand it, U. S. petroleum gallons are not a function of temperature, at least in number two heating oil.

QUESTION: Yes they are.

MR. DUGAN: It is at 60 degrees?

QUESTION: That is your definition.

MR. DUGAN: Okay, here we have a problem because NBS does not recognize that the reason we came up with the wording "adjusted to 60 "F " is that this is the wording that the Pennsylvania Department of Standard Weights and Measures suggested to us, and we will do exactly what they say.

QUESTION: I was just curious: when you implemented the temperature adjustmentfid you reduce the price to the consumer a compensating. amount?

MR DUGAN: No, but by the same token we haven't increased our margin more than 20 points this past year. We have passed it along cost for cost. We are just barely making up the effect of increased union costs.

QUESTION: You wholesale at ATC also?

MR. DUGAN: That is correct.

QUESTION: Given any independent the desire to put an ATC on his own vehicle, a one or two truck operation would certainly show a loss.

MR. DUGAN: That is true. Three of our competitors whom we supply have installed ATC's on their trueks. Unfortunately, when they do it, it is no more than to recoup the loss which all of a sudden we have shown them, or they have shown themselves.

QUESTION: In other words, if it was mandatory that all wholesalers went ATC, then it would follow that 90 percent of the retailers would do it in self-defense?

MR. DUGAN: I would think over a period of years, yes. rou really have to look ahead in years. As John Buckley was quoting number of vehicles on the road and numbers of racks and, quite frankly, as the gentlemen from the hardware industry who are here today would say, they could not possibly handle that type of demand for immediate rack and truek conversions.

QUESTION: What effect is the Pennsylvania moratorium on the ATC units having?

MR. DUGAN: We are going along with the latter of the law. My company owns two subsidiaries in Pennsylvania, one of which had ATC's installed on about half of their fleet before the moratoriumi actually, more precisely, before the winter started and we ran out of time. The other one only has one ATC installed on a fleet of five trucks. We will wait until the morator ium is lifted, and then continue.

QUESTION: Is tax applied in Pennsylvania? 
MR. DUGAN: No it is not. There is no tax on Pennsylvania fuel oil. Okey, if there are no other questions, I thank you very much. 


\section{DISCUSSION OF OPTIONS AVAILABLE FOR RESOLVING COMPUTATION LIMITATIONS OF MOTOR FUEL DISPENSERS}

MR. SIMILA: We have covered the subjects that were listed in the program for today. I don't want to cut short any discussion. If anyone has any questions they would like to address to any of the participants, we would entertain those at this time. If not, we would entertain discussion on the issue of retail motor fuel dispensors, and particularly the issue of computation limitations imposted by the 99.9 unit price.

To introduce discussion on that subject, I think it would be appropriate if the Chairman of the $S$ \& $T$ Committee might indicate the status of that issue before the 5 \& $T$ Committee, since the Committee met in late January here at the Bureau, and was aware of this, but perhaps not of the rapidity with which it might be coming at us. However, it was discussed. Jim, if you and your Committee might assemble up in the front, and if you would care to describe what the Committe has discussed, and get further information from those in attendance, we would like to do that at this time. Would the $S$ \& $T$ Committee members join Jim up in front? MR. BIRD: Thank you, Ken. At the interim meetings fo the $S$ \& $T$ Committee, we espoused a policy, as I indicated this morning here, that we would try to project and offer solutions to problems before they happen. or try to foresee these things, and offer corrective procedures for them.

This is one of the things that we talked about at the interim meeting, and here is what we have in our tentative report for the National Conference, and I will read it to you verbatim.

Code for liquid measuring devices. Impact of rapidly escalating petroleum product prices. The committee reviewed the events which took place several years ago when the retail price of gasoline exceeded 49.9 cents per gallon.

The interim measure recommendation was to set the variator at the pricea per one-half gallon, require the prica per gallon to be separately posted, and to multiply the total price by two. So inoicate on the face of the dispensor. I $i$ would hava a label saying that.

At the time the 49.9 cents per gallon capability existed on only 200,000 of the one and half million dispensors in the United States. It is the Committee's view that this would not be considared an appropriate solution when the price of gasoline exceeds a dollar per gallon, if the industry does not take immediate steps to prepare itself for this apparent eventuality. The Committee recommends to the industry tnat all new pumps installed at this time should be equiped with a unit price capability greater than 99.9 cents per gajlon, and shou?d also have convenient and immediate means to convert to 
metrie.

The Committee recommends to weights and measures officals that careful attention should be given to new equipment being installed and to communicate to any organization not following these guidelines. Based on that. we in New Jersey put a

bulletin out to our local superintendents dated February 14 th, on the subject of fuel measuring devices. NBSH-44. GUR-11 suitability of equipment and liquid measuring devices S-144 money value computations.

And we state: it is possible that the retail cost of motor fuel and heating fuels may exceed a dollar per gallon. The oil embargo several years ago caused sudden price changes in the market that had not been foreseeable. Much of the then-existing equipment was not capable of calculating over 49. 9 cents per gallon.

We now have warning of future prices exceeding a bollar per gallon, and it is necessary to (1) survey existing equipment for devices not capable of computing over a dollar a galloni and, (2) warn operators that theg must either replace these devices which cannot calculate at the expected prices, or have existing units modified to do so. Since that date I have had several phone calls from different organizations asking about feelings on metric marketing. In weights and measures we follow what the laws say and what the politicians tell us to do.

Many of our state laws demand that motor fuels and heating fuels, as I indicated earlier, be sold on a gallonage basis. That is the unit of measure. Now it is my understanding that California recently had some work done on this, and they found that there was a cost-benefit value to go metric. Darrell Guensler could speak to thati I think he arrived.

As I have indicated to some of the people tho have called in our office, what has to be done, not only in New Jersey but other states, is to get the marketers involved, to get the laws changed so that you can market on the ilter basis.

We can't go to the legislature and say "This is the way to go, "because we are a small organization, as in man's states, and we really don't have the political clout to nove it and gay "Well, this is the way it has to ie done."

We enforce the rules and laws that are laid down to us to enforee. We hope to do it in a judicious manner. For the benefit of all of those people here today and tomorrow, we are having this ad hoc meeting to try to find ways and means of arriving at a solution with this particular problem, 三s we are with this temperature compensation problam

At this polnt I wosld lixe to introduce Dartell Guensier from California, and let hin soeak to the issua of 
cost-benefit based on their findings out there.

MR. GUENSLER: Maybe it would be most appropriate if I brought you up to date on where we are in California with this particularkituation, and what we are proposing at this point. Last Friday we made a presentation to the California Metric Council, which is the State of California's version of the U.S. Metric Board, only with state responsibilities. We pointed out to them the problem that we are all aware of: of the computers not being able of going over 99.9 cents per gallon and outlined some of the alternatives that may be available, such as doing nothing, and half-pricing;

converting to $\$ 1.99$ capabilityi going metrici dropping the tenth of a cent and computing to the nearest dime; computing in quarts; computing in half gallons.

There are a number of alternatives. It boiled down to really only two that we feel are practical, and that is either to convert to the $\$ 1.99$ capability at a cost somewhere around $\$ 200$ per unit; we are estimating, and that is as close as we can come with the information that has been supplied to us by the manufacturer of that type of product. Dr you could convert to metric, at a cost of somewhere around $\$ 50$. 00, we are estimating. That is borne out fairly accurately with what they found in Canada. I think it cost them $\$ 60$. 00 a unit there.

Those are not set in concrete. There are variations to that caused by three-wheel computers that can't be converted, and things like that. It gives sort of an indication.

The Metric Council in California went on record as stating that in the long run they felt that the least confusing and also the least expensive methos of handing the problem is to convert to metric, and that if the industry chooses to do that the Council would fulfill its obligation to assist them in coordinating the conversion to metric.

In addition to that, we have sent telegrams to major oil companies, service station representatives, associations, oil and gas marketers, etc., requesting them to attend a meeting in Sacramento April 10th to discuss this situation, with the goal of cominglout of that meeting with a decision as to what is going to be done in Californidat least: to convert either to the $\$ 1.99$ or to the metric.

That is where we are right now. We figure that the difference in total cost to the California marketers would be about $\$ 15 \mathrm{millioni}$ i.e. between converting to metric, which we estimate at around $\$ 5 \mathrm{million}$, and converting to 1.99 per gallon, which we estimate at around $\$ 20$ million. 
In the discussion that followed these points were developed:

(1) Converting dispensers to metric at retail would not necessarily introduce change at the wholesale level.

(2) Public education would be a prerequisite for public acceptance of metric.

(3) Conversion to liters should preferably be on a nationwide basis or at leaston a statewide basis.

(4) Lack of availability of conversion equipment and of manpower to install it makes infeasible early enough

conversion to meet the $\$ 1.00$ plus price per gallon.

(5) A short-range plan for coping with the problem is to sell by half-gallons with appropriate information posted at gas stations.

(6) Any solution to the problem will involve dealing with certain state laws that do not allow the solution.

(Whereupon, the first day of the symposium concluded.) 


\title{
EVENTUALLY -- WHY NOT NOW?
}

\author{
George Mattimoe \\ Division of Weights and Measures
}

State of Hawai

Chairman Simila, Chief Tholen, and all of you very important people who have taken your valuable time to participate in this symposium:

Let me say that in all honesty, I have mixed emotions about being here, and contrary to accepted format, I plan to defer the expression of my feelings until such time as I see some positive action taken as a result of the symposium.

That is not to be construed asprecluding the expression of my viewpoint in the absence of such action. However, it seems illogical that this symposium would ever have been called in the first place if remedial action as relates to the inequities and discriminatory inconsistencies in the liquid measuring device and vehicle tank meter codes were not up for considered correction.

Don't misunderstand me. The renewing of old friendships and the establishing of some new ones is always a worthwhile endeavorand that accomplishment is always enjoyed by me -and I trust by you.

I merely take this opportunity to express the point that, if a "preconceived concept to do nothing about that which is causingmore and more concern prevails", then this symposium will go down in history as a tantalus -- to both those of us who recognize the need and to the open-minded progressive leaders and members of the National Conference on Weights and Measures who reject, or should reject, the pragmatic concept that if it wasn't included before, then it shouldn't be included now in Handbook 44.

The implied perspicacity in such a concept clearly indicates that there would be no longer any need for this conference; that is, the National Conference on Weights and Measures.

I, for one, reject that concept. To the contrary, I believe that we need more involvement with and from this conference, including the regional election and designation of the members of the Standing Committees, the vica Chairmen, and the ereation of four Regional Executive Secretaries. who. while residing in their respective regions, would meet with the National Executive Sesretaril at least four times a year, to assure adequate regional dialogue at the national level, whish dialogue wouid 
be representative of the national interesti and a restructuring of the voting to allow those, who will be regulated, a vote in the formulation of such regulations. That, hosever, while a major contributory factor to our being here today, is a subject for a different time and place.

I also reject the concept that our predecessors in the National Conference on Weights and Measures, and the Office of Weights and Measures, were omnipotent and al knowledgeablei thus their concepts and publications represented technological finality - - irreproachable and unrefinable. That is pure bunk!

At the 14th National Conference on Weights and Measures, held in 1921 or 58 years ago, the present-day, existing tolerance, or limits of acceptable inaccuracy was established for retail gasoline dispensers. This sacrosanct "specification" has survivedevery rewrite of the Specifications Handbook and the LMD code since that time. It is nothing short of hypocrisy to contend thatfour present-day technology cannot improve upon a tolerance of 102 cubic inches per 100 gallons delivered at retail.

Through Pono Industries. Incorporated's IECOM Mark IV

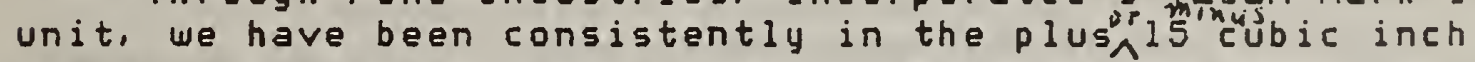
range on 100-galion deliveries in Hawail, and that is with the temperature compensator both connected and disconnected.

In 1923, 56 years ago, at the l6th National Conference on Weights and Meausres, a gentleman named Howard R. Estes, Sealer of Weights and Measures. Flint. Michigan. cited what may well become the basis of Secretary Schlesinger's Gasoline Rationing Plan. when he identified the estimated gasoline consumption per motorist at two gallons a day.

of equal importance was that portion of Mr. Estes' presentation devoted to temperature correction. wherein he cited Circular 57. relating to the temperature compensation of petroleum products, which was actually the first compilation of the results of the experiments carried out by the National Bureau of Standards between July 1912 and December 1914, which was published as Technologic Paper 77 by Doctors Bearce and Peffer. 26 August, 1916.

Circular 57, titled "United States Standard Tables for Petroleum Dils", was published 11 May 1916, or some four months before the supporting data in T-77 was published.

Mr. Estes quite succinctly stated,

"When a refiner sells a tank car of gasoline, it is the custom to allow for the change of volume due to the variation of temperature from the standard. This applies, at least, to those shipments that have been investigated. It should be stated that the specific gravity of gasoline is corrected to so degreas Fahrenheit. One concern bills a carload of gasoline in this fashion: Shell Capacity, Gallons, 8050; Temperature, Degrees, 78; Change, Gallons, 37; Net, Gailons, 
7963

"This means that a car having an 8050 gal? on capacity was filled with gasoline having a temperature of 78 degrees Fahrenheit. This was 18 degrees higher than the recognized standard temperature for gasoline. Therefore, because this gasoline was expandedpue to the higher temperature, we are deducting 87 gallons from the total, because when the gasoline gets to the temperature of bo degrees Fahrenheit, it will have shrumken by 87 gallons."

"Thus, you see the refiner recognizes the principle, and the jobber takes these same figures. He, therefore, recognizas it. The wholesaler who buys the gasoline accepts the figures. Therefore, he recognizes it. And there it stoos."

"The specific gravity, a density measurement of petroleum oils, among which is gasoline, is referred, as mentioned before, to the standard temperature of 60 degrees Fahrenheit, as stated in Circular No. 57 of the Bureau of standards. For convenience, and in order to make it clearer, let us say that one gallon of gasoline occupies a space of 100 units. According to the table in Circular 57, 100 units of petroleum oil at 80 degrees Fahrenheit, with an observed specific gravity of 0.620 , would, at 60 degrees Fahrenheit, a change of 20 degrees Fahrenheit, occupy a volume of only 98.2 units. With an oil of a specific gravity of 0.750 , which approximates ordinary present-day gasoline, the 100 units at 80 degrees Fahrenheit would shrink to 98 . 8 units at 60 dezrees Fahrenheit."

"Now let's see the effect the above change in volume has on ordinary commercial practice. The wholesaler, esperially if he iffoing only a nominal business, has two or more storage tanks holding about 15,000 gallons each. These, you will find, are ordinarily placed above the ground, probably to detect any leaks which might occur, probably to use the fores of gravity in filling vagons, and possibly to conform to loral ordinances and laws. Many times you will see these storage tanks painted black.Tha color black is the greatest light absorbing color, and consequently the greatest neat absorbing color. Therefore, in hot weather, it ought not to surptise us to know that gasoline in such containers frequentily reashes the temperature of 85 degrees fahrenheit In the case of tank-sar shipments from the Oklahoma field, it is doubtful if gasoline shipped to southern points ever reaches a temparature much below 75 to 30 degreas Fahrenhait in uarm weather."

"Let us look no:ע at tíe retailer or filling station

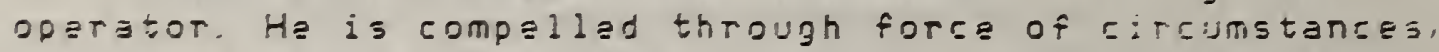
insurance rezulations, state laws and eity ordinaneas, to put his $3 a \equiv 0$ i:n storage tank at least four faet jelow the surfase of the ground. What is the result? The temperatise at 
which he sells his product is rarely over 70 degrees

Fahrenheit, and, from tests that have been mode, averages nearer 65 degrees Fahrenheit. For convenience, let us assume there is a difference of 20 degrees between his buying temperature and his selling temperature, the latter being the lower, and let us base our example upon the product of 0.620 specific gravity (about 96. 5 degrees API). This, it snould be explained, is probably a greater variation of temparature than occurs ordinarily, and a lighter oil that is now commor. but the assumed conditions are used to make the illustration more clear. With such a temperature change there will de a change of volume from 100 units to 98.2 units, or the filling station operator could recover only 98.2 gallons out of every 100 gallons which he bought under those conditions. Similarly, with a gasoline of 0.750 specific gravity labout 57 degrees API), he would recover only 98.8 gallons..."

"It is up to us who stand for a square deal for all concerned, to see that some definite data are obtained wich will show us whether contraction and expansion play a part important enough to be taken into consideration in the sai of gasoline."

"Let us consider this a minute in our own terms. The tolerance on 100 gallons of gasoline as adopted for pumps by this body at the l4th annual conference is 102 cubic inches The shortage due to a 20 degree fall in temperature (on the 0.620 specifie gravity product) is 415.8 cubic inches, more than four times the tolerance; or 277 . a cubic inches (on the 0.750 specific gravity product) almost three times the tolerance, in the two examples given above." (Notes in parentheses added.)

"It is easy to understand that only a small amount of gasoline sold will have a variation in temperature as grest as 20 degrees, yet in the southern seitions oi the country this would be the rule rather than the exception in warm weather."

"The principle of volume change is as old as the hills. But its effect is going to be noticed more and more in the gasoline business because of the increasing volume and of the eventful (sic) rise in price of the commodity. It is well that we are beginning to investigate it."

So spoke an enlightened Mr. Howard Estes, Sealer of Weights and Measures, Flint, Michigan, on May ż, i?:3. So years ago

Mr. Estes' presentation, coming seven shert years aiter the puolication of $\mathrm{C}-57$, represented commendabie foresight and an honest desire to see the National Conference serve everyone equitably. It does not detract from has presentazion unen he cites that a change of 20 degrees faniennelt resilis in a given change in volume, for that is factul.

There tends to be, however, an implied connovatzon that 
a change in product temperature must occur far an inequity to prevail, which, of course, is simply not true. There is nothing equitable about buying 231 cubic inches at 80 degrees Fahrenhełps a gallon of petroleum, even if this inequity is compounded by selling those 231 cubic inches at 80 degrees Fahrenheit as a gallon. Such a transaction simply will not meet the test of either the existing tables or the proposed modifications thereto.

Utilizing Estes' 57 degree API gasoline at 80 degrees Fahrenheit would entail the delivery of 233 . 8 cubic inches at 80 degreesfahrenheit to meet the definitions established by the tables developed by the National Bureau of Standards, and this is true irrespective of whether the transaction is at retail, wholesale, conducted by pipeline or put-up in one-gallon containers.

In order to meet the test of Table Eight and Table Six, either 231 cubic inches at 60 degrees Fahrenheit must be delivered as a gallon, or the equivalent thereto at any other temperature must be delivered. This means, very simply, that if the temperaturefincreases, the volume increases (the weight remains constant), and, conversely, if the temperature decreases, the volume decreases (the weight remains (constant).

I am sure that most of you are familiar with the situation prevailing in Pennsylvania, where the dealers are buying at 60 degrees Fahrenheit and selling at 38 degrees Fahrenheit, without any compensation allowed for contraction of the produet. Such a transaction simply fails to meet the test of Table $S i x$ and Table Eight, and is therefore inequitable.

No one should suffer simply because a hydrocarbon expands and contracts; particularly since the means exist to automatically prevent either party suffering.

Many of you, here, may remember the presentation made in 1974 by Mr. Harold Harris of Exxon to the 59th National Conference on Weights and Measures, wherein he cited the fact that, "This subject has arisen in the past, however,

primarily with regard to potential dealer losses relativa to amount delivered versus the amount sold ta the consumer."

Let me point out that that is not a study relating to temperature compensation but merely a throughput study.

Harold also cited one of the most prominent as being that conducted in the state of Texas in 1954-55, wherein the results ivere documented in the Congressional Record, and he concluded that. "It was proven that the bo degree Fahrenieit basewas entirely equitable."

I have, here, a copy of the report cited, and it is indeed imprassively titled"A Report on Losses of Gasolina at Retail Service Statians Through Shrinkage: Evaporation and Other Causesi Submitted to the ways and Means, U.S. Housa of comm. His on 
Representativesfy the Department of the Treasury, July 19b2." The cover carries the following note:

"This document has been printed for information purposes only. It has not been considered or approved by the committee or anupinember thereof."

Furthermore, the cited studies were not temperature correction studies but, rather, throughput reconciliation studies, and while I have no quarrel with Hal Harris' claim that "It was proven that the so degree Fahrenheit base was entirely equitable", the cited study did not accomplish that fact.

We once again recognize the great insight that Mr. Estes enjoyed of the petroleum marketing hierarchy. In his identification of underground tank temperatures, 'way back in 1923, which he indicated averaged 65 degrees Fahrenheit: whereas, 53 years later, the Radian Corporation in their report RC \#200-127 titled, "Summary and Analysis of Data from Gasoline Temperature Survey Conducted at Service Station by American Petroleum Institute", indicated that Mr. Estes inight have been in error as relates to today's conditions, since their data reflected an average dispensed product temperature of 66.8 degrees Fahrenheit, or 1.8 degrees higher than Mr.

Estes" figure.

It is interesting to note that the Radian figure is 10.6 degrees higher than the figure cited by Hal Harris in his 1974 presentation; all of which indicates to this observer that the only temperature of concern, aside from that contained in the definition of a U.S. petroleum gallon, a.g. 231 cubic inches at 60 degrees Fahrenheit, is the temperature of the product at the time of quantity determination.

An interesting aspect of our present debacle, regarding temperature correction at wholesale but not at retail, is the fact that all of these documents, excluding the original

"United States Standard Tables for Petroleum Oils", C-5T, and of course the supporting data contained in T-77, were

published after the original and currentiy existing

tolerances for gasoline dispensers were established, and, in fact, after Mr. Howard R. Estes made his presentation to the National Conference on Weights and Measures on May 23. 1923.

There can be no question that the leadership of the National Conference on Weights and Measures, in harmony with the Director of the Office of Weights and Measures, simply chose to ignore the technical data being generated by a different arm of the very same National Buraau of Standards.

Perhaps, at this point, it should be stated that ( 1 ) the technology was lacking to temperature compensate at retail and ( 2 ) the plentiful supply and low cost of gasoline did not focus attention on the associated accuracies involvad.

Further, there were those who, in spite of the voluminous data to the contrary, became emotionally confusad 
over the definition of a U. S. gallon of 231 cubic inches. There should not have been any confusion for, indeed, 231 cubic inches is the definition of a U.S. gallon. However, what has happened to the basic definition is that certain temperatures have been appenday/to it to recognize the physical phenomena introduced by temperature change, such as in the case of alcohol, proof gallons, which is 60 degrees Fahrenheit, and refrigerated products, which is 40 degrees Fahrenheit; and frozen-state products, which is that the temperature at which the product freezes; and for all other 1 iquids is 68 degrees Fahrenheit, excepting, of course, petroleum, which is 60 degrees Fahrenheit.

There are many who argue that 60 degrees Fahrenheit, as relates to petroleum. is applicable only to packaged consumer commodities, while being totally cognizant that such temperature is appended to the definition of petroleum gallons in the National Bureau of Standards publication, Handbook 44, relating to bulk of wholesale liquid measuring devices.

Such definition is conspicuously absent as relates to retail sales of petroleum to the consumer.

It hardly seems necessary to mention to this group that every NBS document, herein contained, starting with $T-77$, C-57, $C-154, C-154$ supplement, $C-154$ revised supplement, MP-97, RP-393, C-410; each carry the message that the "standard unit used most extensively in this country for determining quantities of gasoline and other petroleum products in commerce is the gallon definedas 231 cubic inches of liquid at 60 degrees Fahrenheit. " (Source: RP-393, P, 1133)

And, "The weight per gallon of oil is the apparent weight of a volume of 231 cubic inches of oil at 60 degrees Fahrenheit when weighed in the air. "And, "Columns of multipliers which are actually:

$$
M=\frac{\text { VOLUME a } 60^{\circ} F}{\text { VOLUWE } T^{\circ}}
$$

(Source: C-154 Supplement, Revised Edition, P. 1)

Thus, when the: $\quad \frac{\text { VOLUME a } 60^{\circ} \mathrm{F}}{\text { VOLUME a T }}=\frac{231 \text { CUBIC INCHES }}{231 \text { CUBIC INCHES }}=1.000$

or we have the definition again confirmed that, for petroleum, a gallon is 231 cubic inches at 60 degrees

Fahrenheit.

To those who would attempt to convince others that any temperature would have sufficed, and that there is nothing magical about 60 degrees Fahrenheit, we couldn't agree more! However, we did not select any other temperature. We selected so degrees Fahrenheit and all of the tables are predicted on 60 degrees Fahrenheit, including Table Eight, which remains unaffected by either the recent NBS study or tha API formula manipulation just completed in San Diego.

Let's look at the bulk versus the parkaged consumer 
commodities quart can of oil concept but, before we do, I'd like to go over the weight-volume relationship expressed in Table Eight, by the following formula:

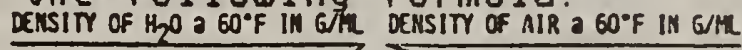

$$
\frac{N}{V_{60}}-\left[\frac{(0.9990405050-0.0012170)}{1-(0.0012170 \div 8.393185)}\right] F \quad \begin{aligned}
& \text { FACTOR FOR. } \\
& \text { CONVERTIRG } \\
& \text { G/PRT TO GALLONS }
\end{aligned}
$$

DENSIT OF AIR a $60^{\circ} F$ IN G/R DENSITY of BRASS a $60^{\circ} F$ IN G/M

By observation, the only variable in the tormula is the density of the product, the weight per unit volume of which is being determined, and that density must by definition be at 60 degrees Fahrenheit.

From Table Eight, we determine that a petroleum product with an API gravity of 64 degrees weighs 6.025 pounds per gallon, or per 231 cubic inches at 60 degrees Fahrenheit.

Let's determine if this is 50 .

We determine that:

$$
F=\frac{0.0022046223}{0.00026417762}=8.345227 ; D 60=\frac{141.5}{A P I+131.5}
$$

Then, by manipulation of the above formula, we find:

$$
\begin{aligned}
\frac{W}{V_{60}} & =\left[\frac{\left(0.9990405 D_{60}-0.0012170\right)}{1-(0.0012170 \div 8.393185)}\right] \mathrm{F} \\
& =(0.9991854 \mathrm{D60}-0.0012172) \mathrm{F} \\
\frac{W}{V_{60}} & =\left[\frac{141.3847}{\mathrm{API}+131.5}-0.0012172\right] 8.345227 \\
& =\left[\frac{141.3847}{64+131.5}-0.0012172\right] 8.345227 \\
& =\left[\frac{141.3847}{195.50}-0.0012172\right] 8.345227 \\
& =[0.723195-0.0012172] 8.345227 \\
& =[0.721978] 8.345227 \\
\frac{H}{V_{60}} & =6.025072 \text { POUNDS PER GALLON, }
\end{aligned}
$$

And this relationship is not altered by temperature change. The 231 cubic inches will, of course, expand and contract generally in accord with Table Six but irrespective of the volume occupied, the weight will remain constant.

The corresponding specific volume, that is the volume of oil per unit weight, is the reciprocal of the weight oer unit volume. To illustrate:

$$
\frac{1.000000}{6.025072}=0.165973
$$

And may be found under the heading "galions par Found" in Table Eight. 
Now, regarding that bulk-versus-quart argument. From whence came the National Standard Petroleum Oil Tables? And, before that, the data from which the tables were generated?

Are we to assume that Bearce and Peffer had bulk quantities of petroleum samples with which to experiment? Say 100,000 gallons? Or even 1,000? Dr 10? Would you settle for a quart?

How about Dr. Jim Whetstone? Did he have bulk

quantities, say, of $1,000,000$ gallons? Or 100,000? Or 10? Or even one with which to experiment and determine the amount of expansion and contraction? Not according to the sampling instructions containedin. Appendix One, page one section $B$ of the recently published NBS study, which called for:

"Sample - Definition

A sample shall consist of two (2) one-quart samples taken so that they are substantially equivalent."

This leads one to conclude that all data relating to the thermal characteristics of bulk petroleum products was determined from one quart or one-half gallon samples - which were not alone representative of themselves, but of the lot from whish they originated.

One could extend this logic one mare step and conclude that the definition of bulk ranges from one quart to infinity.

Such as being the case, there appears no justification for not applying this expensive information fromiend of the spectrum to the other, thereby ending the existence of a double standard and the elimination of this discriminatory practice.

QUESTION: In terms of economics, what would be the incremental costs for this pump?

MR. MATTIMOE: Would that I could answer that. I am fundamentally an engineer, not an economist. I turned the unit over to a local organization known as Adtech back when we were working on it, and their original projections were less than $\$ 700$.00. This was four years ago. The analogy that I would draw would be to compare the cost of your digital watch, although the degree of complexity is certainly different. My watch with liquid crystal displays cost about $\$ 22.00$. It originally came out under its lapanese name for somewhere around $\$ 100.00$. I would anticipate, particularly dropping the 8080 and replacing it with an 8020 which is a single voltage chip requiring only five volts DC, I would anticipate a considerable reduction in the cost of manufacturing, mainly because we had a great heat sink. An $80 s 0$ requires three different DC voltages: as most of you know. This required an input fan to dissipate tis heat. All of which was added to the cost. These are being taken out bif the people who ara packaging it now. It is baing put into 
what I would call an engineering prototype. It certainly is not yet a production prototype. The first units that we put together were merely proof of concept. Would it work? Would it do the job? We feel that it did.

QUESTION: To your knowledge, are any otiners developing such a device as this?

MR. MATTIMOE: We have no knowledge that anyone else is, but certainly it is not a problem. The hardware exists. The approach is relatively straightforward. If wa accept the philosophy that we could tighten up, for instance, on tolerances and derive a benefit from doing 50 , this unit may be one way to do that. What I should do is go back and. rewrite the regulations and promulgate them into law and call for something like a tolerance of plus or minus two cubic inches, and this unit would meet that. I am sure there are others that do or that would. I don't know anybody else that is building one at this moment in time.

QUESTION: What possible economic benefit would using this unit demonstrate? Who needs it primarily, the consumer or the dealer? The dealer can justify a capital investment of $\$ 2,500.00$, let's say. It seems that the consumer would derive very slight benefit.

MR. MATTIMOE: We looked at equity in metering; that was the concept behind the development of the pump. If indeed 231 cubic inches at 60 degrees was what we wanted to deliver as a gallon, then we had to find a means to get there. Getting there has been accomplished, now reducing the cost so that it becomes an acceptable or a marketable device is ahead of us QUESTION: Do the dealers want this equipment?

MR. MATTIMOE: We have a very unique dealer association in Hawaii. Their feeling is, "Get the thing out so that we don't have to make this manual adjustment. "The dealers do feel that it is worthwhile. They also want to go metric. We would like to do the two of them at one time, but that is farsighted.

QUESTION: I anticipate that the dealer would determine the API gravity?

MR. MATTIMOE: No. You don't change your API gravity that often. The API gravity is required by law to be listed on the delivery slip. If you change it, you are delivaring a product that the retailer dion't buy. Besides, our gravities are relatively close in Hawaii. I don't know whether that exists elsewhere. But if it becomes a problem you could get yourself a hydrometer and determine what the density is and go anead and set it for your input. It isn't that big a probiem.

QUESTION: With this elaborate attempt to measure $y$ product, is it delivered at a constant bo degrees?

MR. MATTIMOE: I may have conveyed an improper impression. The unit does not deliver at $s 0$ jegrees. It displays 60-degree gallons, even if the product that is golng 
into the prover is 80 degrees, $81,82,83$ degrees. We are not attempting to deliver 60-degree gallons. We merely tell you the number of bo-degree gallons that have been delivered and price them accordingly. I don't have a refrigeration unit in the pump and don't attempt to control temperature.

QUESTION: What would the temperature range be?

MR. MATTIMOE: It was designed to meet a range of about

\section{0 degrees.}

QUESTION: I have a comment. It seems that we are trying to separate absolute truths from economic truths. What is the best percent? The problem is the economic cost to maintain the precision at retail that we can have at a wholesale or larger bulk. I want you to understand that we are doing the best we can with what we have. All of us have many hats to wear, and few, if any, of us can allocate time and research staff as you have. We appreciate your contribution, but I know you won't feel slighted if we come out with different decisions than you would expect us to.

MR. MATTIMDE: Since that was a comment, I suspect it deserves a comment in return. The feelings that I expressed for the first 13 pages of my presentations were those of Mr. Estes who back in 1923 suggested we should look at this. 1923 until now is a good long period of time to be looking. I would think that if indeed temperature compensation is a permissible end at wholesale, it should be permissible at retail.

QUESTION: If I understand the type of equipment you described, in test mode this dispenser, when the button you described was pushed, might show a 92. 5 degree Fahrenheit temperature. The inspector, after delivering five gallons, would be looking at 92. 5 in the temperature indicator and there would be an indication of the number of cubic inches, 1155 plus 20 or whatever cubic inches. Well, this gives plus 20 above the zero on the five gallon test meter. What provision is there for verifying that temperature?

ANSWER: A thermometer calibrated exactly the way Jackie described yesterday. I did get here in time to hear her presentation. It was sort of a fascinating approach. I use a slush-ice bath and I use a tempertaure bath at the upper range. I swizzled this platinum probe around in the vat and also used the NBS calibrated quartz thermometer as our backup standard, or as the standard against which we calibrated the straight line device. It tracked quite well. It reads to a tenth of a degree, which is something I don't think is necessary but might be. If the pump had stood idle for a period of time and you observed the temperature of the product, you would be reading the temperature of the product in the pump. You would want to get that out of there by making a delivery, wetting your prover with tiat one and than proceed in the same manner that you would test any other 
pump. Then you would take your calibration reading.

QUESTION: If the inspector is testing the device with the assumption that it is going to continue to operate accurately for a period of time, say a year, it is reasonable to assume that the temperature might vary quite a bit over that year's time. Shouldn't he look at the dispenser at more than one temperature? At wholesale we remove the probe and put it into a simulated product.

ANSWER: Okay, you set the input density to double zero or triple zero on your API selector and you knock out the temperature compensating capabilities and you have a regular gasoline dispenser.

QUESTION: You test your compensator at one point without putting it in an ice bath or something like that to look at it at another point on the scale. My question is do you feel it is important to test it in that manner and is it possible to test it in that manner? Is the probe removable so it can be put into a bath?

MR. MATTIMOE: Yes, it is a consideration that we really didn't pay a whale of a lot of attention to. It certainly is not that difficult to do.

QUESTION: Would not the inspector have to determine specific gravity and temperature?

MR. MATTIMOE: You have to know the density of the product, just like you have to know the temperature. All of our people incidentally carry hydrometers, so it doesn't present a problem to us.

involved?

QUESTION: Are any of the Hawailan based oil companies

MR. MATTIMOE: No, the Hawaiian based oil companies are not yet involved with the unit. The unit actually belongs to the Hawaiian Gasoline Retail Dealers Association and testing is being done for them at this time. We have a peculiar mix in Hawaii as to ownership of pumps. There are no vits installed except the one that has been installed on the pay tank. It is the only operable one in existenre, in fact. QUEESTION: George, you indicated that this dispensor is under control of the Association. I am confusad because we get communications from Kono, Inc. What is their involvement? MR. MATTIMOE: The State of Hawaii has an Ethics

Commission, just like many states do. When an attempt yas made to purchase a certified compensated retail gasoline dispenser, it was an unsuccessful attempt. You may recall that I made some comment facetiously that Hawaii should be able to develop one of these things in time for the San Diego National Conference on Weights and Measures which was a year away, and somebody suggested that if I was so damned smart. why didn't I do it? To do this, when I went home, required an arm's length arrangement, and I went to the Ethics Commission and inquired whether, in my present position, I could put. 
together something that might be a commercial or commercially available unit. They advised me the methodology would be to form a corporation. That corporation, Kono, Inc., has caused a lot of interesting comments. I doubt that you have received any communications from me over a period of the last two years on Kono stationary because I have not been affiliated with them. You may read the name, Mattimoe, on the bottom Iine. That is my son who is President of Kono Corporation and that is a very short arm's length arrangement, but, nevertheless, it is the one that exists at this time. Kono owns the packing rights on this device. The Hawaii Gasoline Retail Dealers Association, as part of my commitment to them when I developed this three or four years ago, has had surrendered to it the rights from the State of Hawai. That is a little involved but that is the ethical understanding that I made with the State, and, in fact, tha State said that I could even recouplny investment. They were very optimistic. QUESTIDN: Do they have calibration seals?

MR. MATTIMOE: We don't have calibration seals in Hawail. The Attorney General said that we can't require them, that to cite źman for adjusting his own pump to make it more accurate is ridiculous, and so they are not there.

QUESTION: What about diesel fuel?

MR. MATTIMOE: Diesel fuel would be sold in a similar manner. 
EVENTUALLY - WHY NOT NOW?

THE STORY OF THE U.S. PETROLEUM GALLON

- A FABLE -

C. G. Bockus

Division of Weights and Measuras

State of Hawaii

Once upon a time...possibly during the time the First World War was fought, a standard of measure for liquid petroleum products (including gasoline) was created. Its godfathers were Drs Bearce and Peffer and it was named $U .5$. Petroleum Gallon.

This was to differentiate this gallon from gallons of water, gallons of snake oil and gallons of milk.

Unlike these gallons, but similar to his alcoholic cousins, this U.S. Petrumgallon contained 231 cu in of volume only at soof.

It couldn't help it; it was created that way. And for good reason.

It seemed that the world of liquid petroleum measurement needed an accurate and uniform method for measuring, and thus accounting for, all liquid petroleum gallons be they crude oil, fuel oil, automobile gasoline, diesel fuel, av gas, jet fuel, or three in one oil.

It was plain to USPG's creators that because of the different thermal volumetric reactions of the above listed liquid petroleums that all of these gallons would be the 231 cu in size only at the $60 \mathrm{~F}$ base reference point but would change size (volume) at different rates wherheated or cooled to temperatures other than $60 \mathrm{~F}$. However, it was noted that any particular products, such as 58 degree APi gasoline. would not change its weight when heated or coolad from its so F definition point.

Thusly, godfathers Bearce \& Peffer of the Bureau of Standards, after delivering their baby, set about constructing a set of tables for him so that no matter what size USPG appeared to be (at temperatures other than $50=$ ) he could alyays be recognized and properly and correctly messured. These tables were known as the "Density and Thermal Expansion of American Petroleum Dils," or NBS Technologie Paper NBR 77.

Truly, these volume correction tables, as they became known, were absolute works of art, admirable for thelr time The USPG used them wherever it went so ha and is tis tilions of brother USP gallons could always be aceurately accountad 
for. In fact, it was quite self evident that the tables, and their use, tended to assure all parties to a petroleum product transaction. (measure) at all levels in the distribution hierarchy, and particularly the ultimate consumer, were dealing in and uniformly measuring the same amount of product irrespective of apparent volume.

Use of the tables, in other words, helped to assure equity of measurement. This was especially true of liquid petroleum because except for a few places on the earth at infrequent times, the USPG could never find a place to stay, be stored, be piped, be pumped or be measured at $60 \mathrm{~F}$. Even as a finished product as motor fuel, the USPG found himself being dispensed in the continentayunited States at anywhere from $49 F$ to $83 F$ as was found true by various API studies. But I am getting ahead of my story.

Accordingly, USPG found himself being used synonmously with the term temperature correction or volume correction. This was just peachy with USPG because he knew that because of his thermal condition, Ae could swell or shrink in volume and cause all sorts of mistakes for the unknowing or those uninitiated in the black/lost art of liquid

petroleumfasurement. He had unintentionally fooled many a weights and measures inspector when it was assumed that his apparent 231 cubic inch size at $80 \mathrm{~F}$ or some temperature other than his true 60 F definitiorpoint, was a USPG.

Certainly, he had cause to wonder at the problems caused in trade by those unwitting souls who tried to measure him without consulting the TC tables. Not only were incorrect taxes being collected by inept measuring of USPG, but related government regulations such as FEA petroleum ceiling prices and EPA mileage figures became somewhat meaningless when temperature correction tables were not used.

This problem became quite apparent to a weights and measures inspector from Michigan in 1923 when he advised the NCWM of the causes of 1 iquid petroleum measurement error. The cause, of course, being due to the thermal sansitivity of liquid petroleum. The measurement error was due, basically, berause liquid petroleum dispensers of the day, used for retail measurement, did not take this thermal sensitivity of USFG into account.

To give you an idea of just how sensitive our USPG is, when he is at an AFI gravity of 58 and at a temperature of 80 degrees $F$, if metered through an existing non-temperatura correction "pump" not even 19 and three-fourths of him will flow into the motorist's tank by the time 20 gallons is displayed on that dispenser!

Well, 1923 came and went. . and although tha Weights and Measures community had been forewarned and advised of tine inherent limitations of retail gasoline pumps. . . tie cumulative atrors bezan to add up, but only inhere Temparature 
Correction was not recognized or not used.

Therefore, USPG didn't have many worries elsewhere, sueh as at the Wellhead, at OPEC, at the refinery, or at Temperature Correction rack meters, or as Temperature Corrected packaged products or in Hawaij or in California when delivered/measured to the Government, or to farmers, or to purchasers of 5,000 gallons or more, or in the pipaline or when being exchanged or transferred amongst the Oil Inoustry, or at US Customs points for that matter or with the airlines.

But he did cause enough problems when not Temperature Corrected that the State of Virginia in 1961 and the Treasury Department in 1962 attempted to figure out what caused the unaccountability of gasoline at service stations. Amazingly, both governmental bodies either largely overlooked or forzot about USPG's thermal sensitivities or the Temperature Correction tables. If that wasn't amazing enough, the state of Montana had the temerity to try to legally deny USFG's sensitivity by passing a law forbidding the temperature correcting of gasoline. This was akin to trying to repeal the laws of nature

The chaos in liquid petroleum measurement at retail pretty well went unnoticed, unrecognized or unsolved for year after year after year. There were complaints such as at Dan $k^{3}$ Whits Store in Vermont which noted that due to iemperature changes of its stored gasoline, it was losing thousanos of dollars in taxes and profits. But the Weights and Measuras community didn't really appear concerned; no waves were made Al1, perhaps because the means had not yet baen invented to economically and automatically temperature cortect liquid petroleum measurement.

This changed in 1973 when NBS was advisad that not only did the long standing problem of the inability to account for liquid petroleum at retail exist, but that practical solution was at hand.

In 1974, the problem and the solution was prasented to NCWM. At that time, the API, while admitting the correct definition of the USPG, ie. 231 at $60 \mathrm{~F}$, had the audacity to claim, not only an annual over delivery of 228 million gallons of motor fuel to the American motorist, but that overages and underages all balanced out!

Not one peep of outrage was heard from the assemoled Weights and Measures officials. Surely, some of them mus: have thought that if it all balanced out, then why were ye all spending millions of dollars annually in saiaries and equipment inspecting retail gasoline pumps. Why indeec? And if 1 iquid petroleum measuring devices all balanced out, then why not all scales, taxi meters and packaged produst

quantities, too????

And if that were true, why have a national helahts anj Mezsures program at al1? But no one asxed. Nor seemed 
concerned.

Later on. Hawai asked the API the logical question of what it was doing to correct the ees million gallon giveaway it had touted. Was it going to avail itself of the latest in automatic Temperature Correction equipment? No answer was received from the API. Hawaii, therefore, was forced to conclude that someone was either equivocating or did not know what he was talking about. About this time, the then chief of Dffice of Weights and Measures denied any knowledge of a problem having to do with retail measurement of 1 iquid petroleum products and continued to plead for cooperation in adhering to National Conference codes. This person promised to continue to study the matter, but to USPG's knowledge, nothing on Dffice of Weights and Measure's part was done. It would have been simple for office of Weights and Measures to ask each state and local Weights and Measures juridiction for 12 months of voluntary dispensed fuel temperatures on which to base a valid study. Still seeking cooperation, office of Weights and Measures refused to publish in its Tech Memo 1976 a treatise on incomplete testing of retail pumps.

However, in this same year, the Radian Corporation correlated and completed the API study of retail fuel temperatures. It showed, among other things, that not only was $60 \mathrm{~F}$ fuel a rarity at retail, but that the dispensed fuel temperatures for the 56 test stations scattered nationwide averaged well over $60 \mathrm{~F}$. In fact, the figure pinted was 66.8 F. This figure, combined with the 1974 Exxon/API data showed that out of the over 100 billion gallons of motor fuel annualiy delivered at retail, the underdelivery, repeat, underdelivery of over $400 \mathrm{million} g a l l o n s$ of motor fuel was not only possible, it was probable! No wonder the USPG was not wanted by the Dil Companies at retail! Heck, with a little deliberate heating of the fuel, even more gallons could be "legally" underdelivered. No wonder the Dil

Companies do not see the cost benefit to themselves in being required to, by definition, honestly and correctly measure their fuel, not only throughout the entire distribution hierarchy, but at retail stations as well matter:

Therefore, we come to the final questions of this

1. Why should there exist one standard of measure (tne USPG for industry but another standard for the consuming motorist? Why, in effect, the condoning of a double standard?

2. Dr, if the Temperature Correction tables are used to assure uniformity and equity of liquid petroleum trade, why ar a not the tables translated into ALL shannels of industry and trada?? ?

3. Why mandate ria Congrass a National iniform Measurement system only to condone fifty or mare loral 
systems?

Thank you.

QUESTION: What is the average temperature in Hawaid?

MR. BoCkus: Product temperature? Average, oh I could say 80 degrees Fahrenheit.

QUESTION: I wonder if you were experiencing the same temperatures we have in Montana if you would be willing to temperature compensate. The average temperature in Montana over a three-year period averaged 43 degrees. It is pretty hard to sell the so degree correction to consumers.

MR. BOCKUS: Yes, it definitely would be

SPEAKER: I would also like to state that whether we are right or wrong, we are uniform.

MR. BOCKUS: Measuring is being done all the same. My only answer to that is that it is being done uniformly incorrectly. I recognize the fact that in many cases your fuels do average less than 60 degrees $F$; for instance, in the Meenan oil case, the customers were receiving more because of the colder than 60 degrees $F$ product temperatures.

But in a transaction having to do with equity, somebody loses somewhere. It has been stated to me somewhere along the line that the dealers and the sellers are people, too. They are public. I keep hearing the word equity. Certainly a person who gets more fuel than he pays for gets a great deal, but I dan't know how that would be reconciled with equity. It would be something different for everyone, but it certainly isn't equitable to buyer and seller.

QUESTION: I would like to bring up Kono Industries. We have quite a few communications between us, and I have noticed your name on carbon copies that are about the komo. Could you tell me what your relationship is with this?

MR. BOCKUS: I am a good friend of Craig Mattimoe. He is copying me on these particular letters because I do want to keep abreast of what he is doing and saying in representing Kono and temperature correction simply. to keep informed:. As for the financial relationship, we don't have anything on paper regarding my ownership or any proprietary ownership. I have simply donated my own time and energy and money to do something that I feel is inherently correct to do. I did a study showing that in California, if your fuels were averaging 75 degrees, your consumers aren't getting what thay paid for.

I just feel it is a worthwhile project. Again, on tie time and money to get here and back, I am on my own. I am on vacation right now. I don't particularly represent the state of Hawaii here at this symposium. I had to fly here via Canada because of the strike, and that was $\$ 200.00$ extra. I am on my own time and money on this. 
BY

AMERICAN PETROLEUM INSTITUTE

WEIGHTS AND MEASURES TECHNICAL TASK FORCE

H.E. HARRIS, CHAIRMAN APRIL 4, 1979

- Today we would like to share with you what we have learned about temperature effects on gasoline marketing operations.

- This presentation will cover work undertaken by API member companies and by Radian Corporation, a consultant contracted to perform analytical studies.

- We will look at the subject in four parts: First, the background concerning previous temperature studies; then proceed to explore the API gasoline temperature survey, the consultant analysis of survey data and finally, we will provide conclusions for your consideration.

- In July, 1974 results of two gasoline temperature studies were presented to the 59th National Conference on Weights and Measures; one by the State of Hawaii and the other by the Arrerican Petroleum Institute.

- Both had assumed that the average retail dispensed gasoline temperature was equivalent to underground tank and in turn to average ambient temperature. The assumption was questioned; however, no viable alternative existed due to the limited technical data then available.

- In order to correct this technological deficiency, the API initiated a one-year survey to measure actual gasoline temperatures at a cross section of representative service stations.

- Scope of the API survey was to gather and analyze various data at service stations relevant to the temperature of motor gasoline and develop a data base for study of temperature correction, both wholesale and retail.

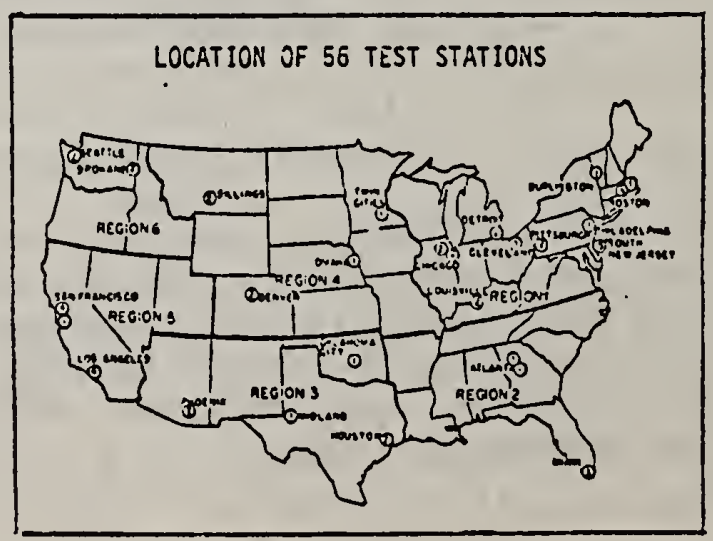

- The survey was conducted at fifty-six service stations located throughout the continguous United States as shown on this slide. 
- Representative sites were chosen and the 13 participating oil companfes were responsible for obtaining, installing, calibrating, and operating the necessary instrumentation. Test stations were selected to represent typical retail outlets, considering volume thruput, hours of operation, location, and climatic conditions. The locations were chosen to insure complete coverage utilizing cities having National Weather Service data avallable to allow study of the effect of climatic conditions on gasoline temperatures.

Characteristics of each test station as to physical features and operational procedures were recorded to be included in the data base: Such items as weather exposure - altitude - hours of station operation - size and amount of cover for U.G. tanks and piping - dispenser flow rate and station volume thruput.

- Meteorological data were compiled for the cities where participating stations were located allowing various parameters to be inciuded; maximum, minimum and daily average ambient temperatures - prectpitation cloud conditions and average wind velocity.

- Gasoline temperatures were monitored and data collected at two primary points in the service station system; underground storage tank and gasoline dispensing unit.

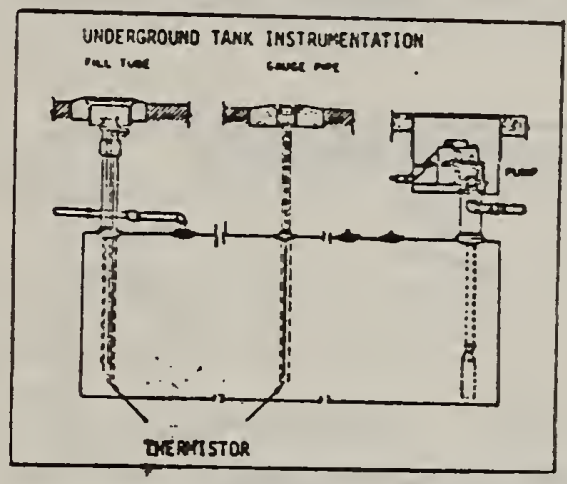

- This slide, U.G. Tank instrumentation. shows the location of the temperature thermistor prote near the bottom of the tank which was placed in either the ffil tube or gage pipe access port.

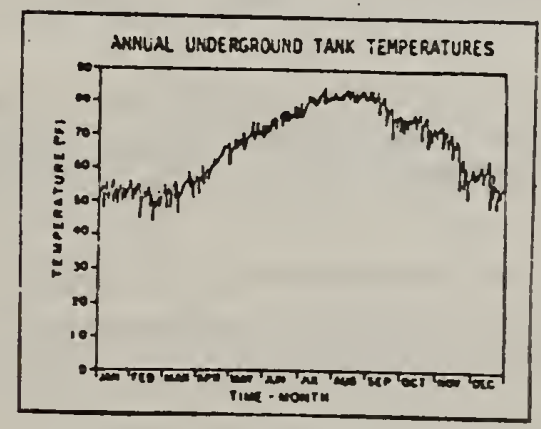

- Underground tank temperatures were collected by analog strip charts recorders which due to the relatively slow variation in U.G. tank temperatures were run continuoujly.

- An example of an U.G. tank temcerature recording over a year's time is shown here. The "spikes" reflect gasoline delfveries to the station. Their magnitude varies in direct relation to the amount of product delivered and temperature differential of the U.G. tank and delivery tank truck. 


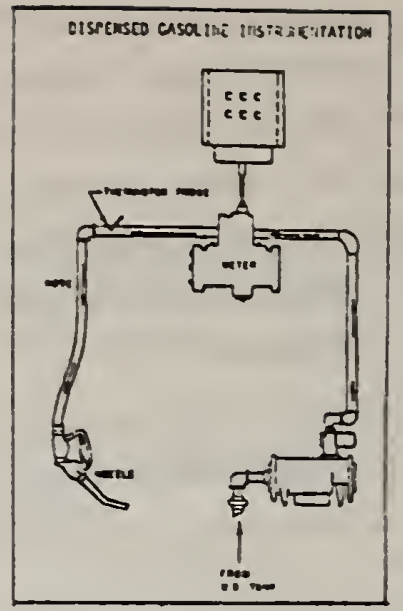

- This slide shows the location of the themistor probe in the dispenser just upstream of the discharge hose. Dispensed gasoline temperatures were collected on strip chart recorders which were energized only when the dispensing pump was activated.

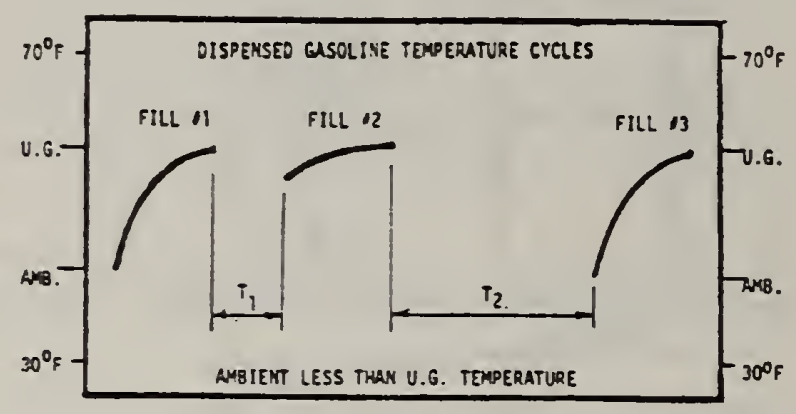

- here we see three typical fills under conditions where ambient temperatures are less than U.G. tank gasoline temperatures.

- The first filling operation is shown on the left. The dispensed gasoline temperature starts at rear ambient, i.e., the temperature of gasoline in the dispenser. It then rises toward that of the U.G. tank temperature, refiecting gasoline temperature in the U.G. line. End of fill is essentialiy at U.G. temperature.

- Fill 22 as shown here is started quite soon after completion of the first $f 111$, as shown by the time interval $T_{i}$. Cue to this short time lag between fills, the gasoline in the dispenser and U.G. piping did not have time to cool off significantly and was jispensed at a temperature almost equivalent to that of the L.G. tank temperature.

- Looking at still a different possibility; the configuration of fill 3 is a result of a much ionger time lag. snown as $T_{2}$, and is similar to fill ili starting at near ambient and ending at about U.G. tank temp.

- Uncerstanding of this complex interaction is of great importance to the study of dispensed gasoline temperature.

- On the next cnart we will see typical cycle plots taken from the survey data. 


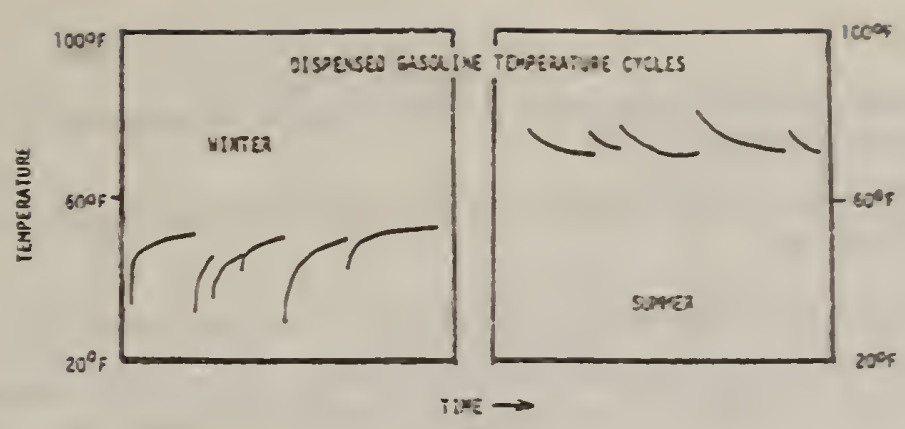

- Again, each individuai curve represents one vehicle fill of gasoline.

- On the left we see temperature cycles during the winter seasen with arotent heiry less than U.6. ใ2nd cemperature. A temperature spread of up to $150=$ is snju betwear. start and end of f\{11, jue is :Pe effect of arbient on the underground jiping and the abjve ground dispenser.

- Juring sumer wo see the sane type of temserature cycles excapt since ambient is risw greater than underground the dispensed temperature at start of fill is warter than at the end of fill, i.a., near ambient at star: and near U.G. tenperature at end.

- After collection of survey data over a year's tize, a consulting fim, Radian Corporatisn, was ccntracted by API to create a data base ane perform statisticai stucy. This slide provides an cutlire of the rajor work activities bhat were involved.

- Completeress and validity of the suriey data was to be verified.

o Relaticnshios anong gascline temperatures, anjient tempratures and service sta:ian charaztaristics needed to te detemined.

- An estirate of the naticnwlde average dispensed gasoline temperature was to be nade and firaliy.

0 Temperature adjustzent parameters and costs were to be provided.

- A poll of survey participants was uncertaken by the consultant in order co assess tre vaitijity o: sha reporting data. Questions asked of the survey zarticipan:s centeres on problems they experiences ir ootaining the data and on their confidence in the datz's valicity. Specifications and operatirg ramzas for ali the equipment used during the survej were also examined.

- Survey data were jetenmined to be idequate to provide a reliable teans of statisticaiiy larelazie: arenaç temperatures for the paraneters tes:ed. Fichough all stations did no: repcrt aii or ihe pa-ss:et data, it was juciged that the survey provided an adequate gevgrapaical and metecrologica? s3mpling at: the contiguous United States.

- Oatu collected at fiftysix stations inciuded nany hours of strip chart recordings/azproxialaieiy '\$j, unc hours of underground tank product terperatures, and 105,000 hours of dispensed prosuc: ie-geratures.

- Due to the maçnitude of data and the number of variables involved it was determired that a cxes..er technique should be used to anaiyze the data.

- This slide outlines the relationship anong gascline temperzures, anbient tenceratures ard $5: 10: 00$ characieristics.

- Dispensed gasoline temperature was found to have the hignest relationshto factor with atcient of ald the variables identifled. [Sore 35 : of the variance in discensed tercerature can te expiaines in ierts of ambient terperature variation.]

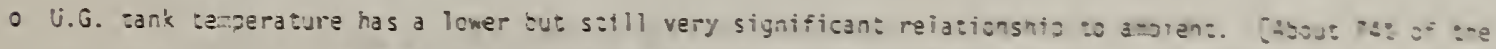
variance in dispensed temperature can te exalained in terms of v.u. esoprasure variatlor.

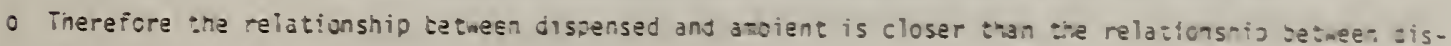
pensed and undergrcund. 
- Also, the relaticnship of service station characteristics .. such as weather exposure and U.G. tank ccver .. to gasoline temperature was found ts be mininal.

- All of the various relationships were then used to assess the effect of the current practice of no teriperature adjustrent at the service stotion.

- First, the data base was used to statistically detemine the effect on the service station operator.

- Temperature variations do cause apparent gasoline inventory changes which can vary monthly by 0.5 : among stations; however, it was found that any gain or loss tends to balance out overall on an annual oasis.

- An analysis was performed to investigate the effect on station inventory in geographical areas the size of large cities. It was indicated that the delivery to sale variation is very small among competing stations.

- A study of the effect on the retail gasoline consumer was then undertaken and this slide shows the primary results that were obtained.

- $61.6^{\circ} \mathrm{F}$ was statisticaily calculated as the average annual nationwide volure weighted dispensed gasoline teriperature. Tnis average was derived by aggregating the average dispensed product temperatures in over 3,000 counties and weighting by county gasoline consumption.

- However, it was found that individual dispensed fill cycle temperature precision can vary by as ruch as plus or minus $15^{\circ} \mathrm{F}$ from the average.

- As a result of this rather significant texperature range for individual fills, a precision versus cost study was performed analyzing different methods of temperature adjustrent.

\begin{tabular}{|c|c|c|}
\hline \multicolumn{3}{|c|}{ 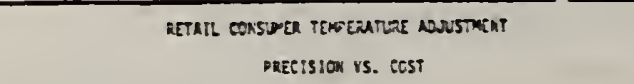 } \\
\hline coperanition ronoss & 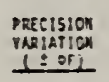 & 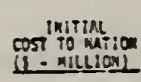 \\
\hline \multicolumn{3}{|l|}{ use ase } \\
\hline NO NUUSTMET & 15.0 & 0 \\
\hline \multicolumn{3}{|l|}{ NTERMtives } \\
\hline The IINE Netea & 12.5 & 11 \\
\hline 2WTERS KETER & 9.0 & 420 \\
\hline elcetronic expexshita & 1.0 & 675 - 1,225 \\
\hline paecisicu corstoere & PECERrL of & inceushetes \\
\hline
\end{tabular}

- This slide compares three alternative methods of retail consurier temperature adjustirent to the iase case of no adjustiment.

- is prevlously stated, a precision variation of up to $\pm 15^{\circ} \mathrm{F}$ can occur during an individual fill cycle with no temperature adjustment - shcwn for the base case.

- A one time meter adjustrant, i.e., change in, meter calibration, provides a small average improvement to a variation of $\pm 2.2^{\circ} \mathrm{F}$, at an estimated initial cost of some $\$ 11$ million.

- A quarzerly meter adjuszitent would decrease the variation to $9.0^{\circ} \mathrm{F}$ with an initial cosi of $\$ 420$ milition.

- These timo elternatives, ore-time and quarterly adjustment have one discrepancy in comicn; while an improvement is roted, there is still a large variation in individual fill cycles.

- Let's look back briefiy at the slide which shows dispensed gasoline temcerature eycles. 


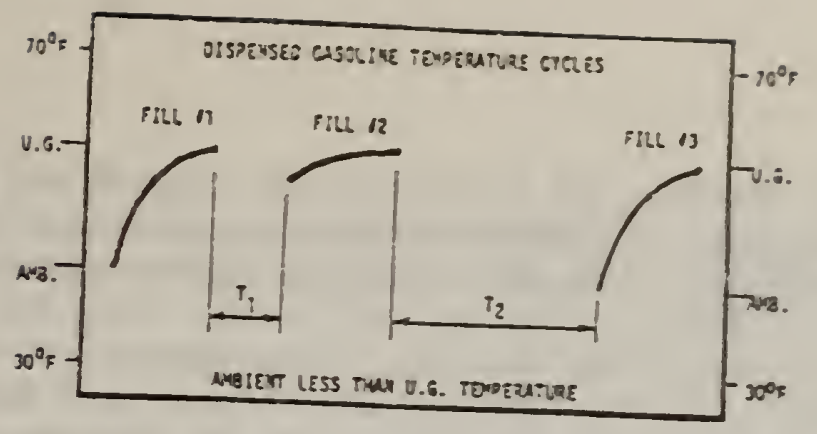

- Again, as we look at individual fill cycles, a conplex interaction can be noted and it is evident that only sensing of each fill will provide highly accurate incividual measurement precision.

\begin{tabular}{|c|c|c|}
\hline \multicolumn{3}{|c|}{ 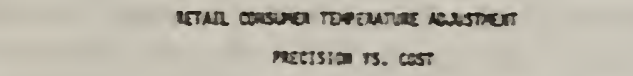 } \\
\hline 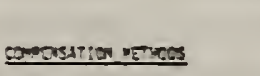 & 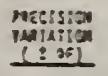 & 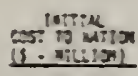 \\
\hline \multicolumn{3}{|l|}{ cust ast } \\
\hline a wivgen & 15.2 & - \\
\hline \multicolumn{3}{|l|}{ KTERTives } \\
\hline ore bix राया & 12.5 & 18 \\
\hline 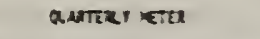 & 9.0 & w \\
\hline Crtmenic comasnish & 1.8 & $37 \cdot 1.235$ \\
\hline
\end{tabular}

- Consequently, the electronic concensator with a $\$ 1^{\circ}$ F yartation end initial cost of up :0 $\$ 1.2$ billion is the on?y alternative that was identified as being viable to accurately canpensate on a fill by fill basis.

- Aiso, it should be noted that for ali methods studied presision was sunsiderec indapentent of matering inaccuracies.

- The data shown here as well as that previousiy discussed provided a base for the study conclusions we rould like to present for your consideration.

- The study indicates that the service station operator buys and sells çscline at essentially the sare temperatura.

- Total dispensed gasoline sales are eurrently equitable on a nationwide basis with the overail :emoerature cemonstrated to be very close to $60^{\circ} \mathrm{F}$.

- The electronic compensator is the only known method that would provide accurate tercerature concensaticn for the Retail Consumer.

- Excessive cost of temperature compensation outweighs any potential consuser gain: \$1.2 jillivo exaenciture without any overall benefit.

- In survary, the study results identify that the current fractice is the cost favorable alternative for both the service station operator and the consuner. 
QUESTION: Mr. Harris, the costs that you quoted for the varfous alternatives, do those include governmental costs for improving vessels' electronic equipment, that additional decisions may be necessary to improve the accuracy of $1 t$ ?

MR. HARRIS: No, sir, they did not. Those costs are strictly the initial cost to provide the equipment. Just that, just the initial investment. They are not an annualized cost, they do not include maintenance, they do not include any administrative impact, any follow up costs. Strictly the inftial costs.

QUESTION: Those were estimated at $\$ 1.2$ billion dollars? Has there been an evaluation of the cost/benefit ratio?

MR. HARRIS: The only way you can really come up with a cost benefit/cost loss analysis would be to take into account all of the costs, Including taking into account the cost of money over a period of time to actually annualize it. It is hard to do on this particular subject, harder than on what most of us are used to where there is some specific benefit that is gained. In this case, if you work it out for the individual consumer, it is a gain for one versus a loss for the other. That makes it rather difficult to come up with what we typically know as a standard cost effectiveness.

QUESTION: Do you have any information on the reliability of the computer that you are talking about, the BCT computers and data electronfcs? I am looking at reliability and breakdown time, because more sophistication many times results in more breakdown time when the device cannot be used. Was that figured in, or do you have any information on it?

MR. HARRIS: No, it was not figured in. Perhaps to answer your question, the best way would be to tell you how we arrived at the electronic compensator concept, if you will, and also the cost of it.

Radian Corporation interviewed, I believe, something like 20 different companies that work in this field, in both electronic and mechantcal compensation as well as working in the area of producing dispensers. They took all of that information, and all of the data they could get relative to research that these companies had done, and estimated what they felt would be a good cost per unit to go into this initially.

The rellability factor that you are talking about is again one that should go into any cost benefit effective study. But there is nothing in this study that would help in that area.

sensor?

QUESTION: Was consideration given to the response time of the

MR. HARRIS: Response time of the sensor in an electronic unit poses no problem. This was looked at: how quickly should you sense, and how often should you sense? With electronic equipment and thermisterprobe that is no problem.

If you look at it from the view of a mechanical compensator, then it becomes very important, and we found in this study that the only way we could really do it with existing mechanical compensator techmology would be 
to limit flow rates to about three gallons per minute. As you know, we are dispensing elght, ten, twelve gallons per minute.

MR. SIMILA: One of the critical items here, of course, is the economics. That is being spoken to, and whether you pick $\$ 1.2$ billion or whatever, and you are comparing that to a payback to the motorist or whoever, it depends on the difference of temperature from $60^{\circ} \mathrm{F}$.

The difference between 60 and 61.6 is substantialiy different than between 60 and 66.8. I was wondering on thet weighting, maybe you or some individual with Radian could speak to it, how that weighting on throughput was done. There are many areas of the country, for example, my state, I see there were no stations at all included. How was the throughput in the counties and the stations that were used related to get a good weighted average in terms of population and demographics or whatever. Also related to that, I thinik the data is now going on about four years old. We have seen in the recent past quite a trend of population shift toward the Sunbelt areas, which is obviously going to increase the consumption in the higher-temperature side of the United States. How was that weighted?

MR. HARRIS: I will answer the last part of your question first. The shifting that you speak of was not taken into account, was not considered in this particular study. In a state such as Oregon which did not have test stations in it (there were other states that did not also), the welghting or the calculation of average dispensed gasoline temperature in those particular states was jone knowing the relationship of ambient. It was done, as I mentioned before, on a county to county basis, including the counties in states that we did not have test stations in. But we did have the daily, monthly : yearly ambient temperatures. We also had stations that could have been located in Oregon from a climatalogical and ambient temperature standpoint. So that was all weighted in with 3,000 counties. We lised the counties in that if we could not obtain a gasoline consumption figure in the county, then we used the population figure. We thought that by having 3,000 county state points any random errors that might be in it would tend to balance out because of the large sample. 


\title{
AUTOMATIC TEMPERATURE COMPENSATION VOLUME
}

\section{OF LP-GAS MEASUREMENT}

\author{
LeRoy Lindbloom
}

Northern Propane Gas Company and

National LP-Gas Association

I am pleased to present data and the experience of the LP Gas industry with temperature compensation of liquefied petroleum gases. The LP Gas industry has been using automatic temperature compensators with LP Gas liquid meters and vapor meters for over 20 years. Provisions for automatic temperature compensators are contained in the Code for LPG Liquid-Measuring Devices and Code for LPG Vapor-Measuring devices in National Bureau of Standards Handbook 44 . These provisions have been followed at the local level through compliance with state codes based on Handbook 44.

In presenting this information. I am representing my company, the Northern Propane Gas Company headquartered in Omaha, Nebraska and the National Trade Association of the LP Gas industry, the National LP Gas Association. The NLPGA represents all segments of the liquefied petroleum gas industry including retail marketers who distribute some 10 billion gallons of LP gas annually to consumers throughout the U.S. that are equipped with automatic temperature compensators.

Northern Propane Gas Company has 150 retail outlets operating some 413 bulk delivery trucks in 22 states, all of which are equipped with meters having automatic temperature compensators.

Provisions in the LPG Liquid Meter Code in NBS Handbook 44 relating to automatic temperature compensators are as follows:

SECTION $S .2$ DESIGN OF MEASURING ELEMENTS

5. 2. 6. Automatic Temperature Compensation - A device may be equipped with an adjustable automatic means for adjusting the indication and registration of the measured volume of produce to the volume atto degrees F.

S.2.6. 1. Provision for Deactivating - On a devica equipped with an automatic temperature compansating mechanism that will indicate or record only in terms of gallons compensatad toto degrees $F$, provision shall be made to facilitate the deactivation of the automatic temperature compensating mechanism so that the meter may indicate, and record if it is equipped to record, in terms of tha 
uncompensated volume. (Amended 1972)

S.2.6.2. Provision for Sealing-Provision sriall be made for applying security seals in such a manner that an automatic temperature-compensating system cannot be disconnected and that no adjustment may be made to the system.

\section{SECTION N. 4 TESTING PROCEDURES}

N. 4. I Normal Tests - The "normal" test of a device shall be made at the maximum discharge rate that may be antipated under the conditions of installation. If the device is equipped with an automatic temperature compensator, thas test should be conducted with the compensator deactivated.

N. 4. 1. I Automatis: Temperature Compensation - If a device is equipped with an automatic temperature compensator. the compensator shall be tested by comparing the volume indicated or recorded by the device with the compensator connected and operating, with the actual delivered volume corrected to $60{ }^{\circ} \mathrm{F}$.

N. 5. Temperature Correction - Corrections shall be made for any changes in valume resulting from the differences in liquid temperatures between time of passage through the meter and time of volumetric determination in the test measure.

SECTION T. 1. TOLERANCE APPLICATION

T. 1. 1. To Underregistration and to Overregistration The tolerances hereinafter prescribed shall be applied to errors of underregistration and errors of overregistration, whether or not a device is equipped with an alitomatic temperature compensator.

SECTION UR. 2. 4. TEMPERATURE COMPENSATION

UR. 2. 4 Use of Automatic Temperature Compensators - If a device is equipped with an automatic temperature compensator, this shall be connected, operable, and in use at all times. Such automatic temperature compensator may not be removed. nor may a compensated device be replaced with an uncompensated device, without the written approval of the weights and measures authority having jurisdiction over tine device.

UR. 2. 4.2. Written Invoices - Any wititen invoice based on a reading of a device that is equipoed with an automatic temperature compensator shall have shown thereon that tha volume delivered has been adjusted to the volume at oc of In summary, these provisions as they relate to LP Gas marketing operations provide the following:

1. "permissive" and not "mandatory" use of temperature compensators.

2. If ATC's are used they must be used on a year around basis.

3. Written invoices must show that the viume delivared has been adjusted to the volume at/6o degrees F.

Similar concepts appear in the Vapor Meter Code. These 
provisions for liquid meters have been in Handbook 44 since 1965 and since 1972 for vapor meters. To my knowledge, these codes have presented no difficulty to the consumer, the weights and measures officials and the LP Gas industry. Also, there have been no difficulties encountered in the testing of LP Gas liquid meters

with automatic temperature compensators. NBS Handbook 44 and 99 properly address the subject of LP Gas temperatuire compensation.

The compelling force to use automatic temperature compensations with liquid measurement of LP Gas is attributed to their comparatively high coefficient of expansion. Propane has a 1.6\% volumetric expansion per $100^{\circ} \mathrm{F}$. This is almost triple of gasoline and almost four times that of fuel oils. We receive our product from the producers of LP Gas compensated to apo degrees $F$ basis. It is therefore necessary to also compensate our sales to our customers on this same basis, particularly in colder areas. Without temperature compensation, the price to the customer would have to reflect this loss, but in the latter case there would not be any automatic way or means to do so. Quite naturally, in the early days of.our use of ATC!s, the narthernitier of states: either required or had no objection to the use of temperature compensation. The following was the situation in 1960:

1. A majority of state weights and measures legislation or regulations having to do with temperature compensation. specified that automatic temperature compensation devices must be used. Legislationgenerally specifies that temperature compensation may be used.

2. The following states by law or regulation required liquid LP Gas temperature compensation: South Dakota, North Dakota, Kansas, Nebraska, Wisconsin and Minnesota.

3. The States of Colorado and Nevada had gone on record as saying that liquid LP Gas temperature compensation is not legal.

4. The following states had indicated that they have no objection to automatic temperature compensating devices:

Dhio, kentucky, Arizona

California, Michigan, Wyoming

Missouri, New York, Texas

Iowa Oklahoma, Tennessee

I 11 inois, Oregon

Today, practically all states recognize the use of automatic temperature compensation in accordance with Handbook 44 provisions. Approximately six have mandatory requirements for temperature compensation.

Although there were some objections, at first in some of the southern states, these objections have sincz been resolved. The reasons for this are:

i. The most eritical situation involved the heating loaj in the northern states where volumes and temperature differences are substantial. 
2. Prices to consumers in the colder climates would have to reflect any loss attributed to not compensating the volume topo degrees $F$.

3. The most consistent and accurate method of compensating for temperature is through the use of ATC's.

4. The heating load in the south is not as critical a fastor and the ultimate cost to the consumer therefore does not reflect any appreciable change in volume attributed to temperatures. This averages out for the most part throughout the year.

Sinse the advent of the automatic temperature compensator with all the considerations involved two decades ago, another very important factor has appeared on the scene which emphasizes the need for ATC's; particularly in areas where volumes and temperature differences are substantial. This is the need for more precise inventory control. This need is attributed to costs per gallon at the wholesale level which have escalated about 5 times what they were 20 years ago. Also, LP Gases are under price control and al location regulations of the Department of Energy. Thus, LP Gas marketers have been forced tc utilize every means at their disposal to maintain a good accounting of their inventories. Automatic temperature compensation is a useful tool in this respect.

The following is in response to some of the questions posed in the report of the Committee on Specifications and Tolerances during the 1978 National Conference on Weights and Measures:

1. Can anyone use temperature compensation for a given product at his own pleasure?

Relating to the manner in which the question is phrased, we concur with the Committee's reaction in stating this should not be permitted. There are very definite controls that should be placed on temperature compensation. These are incorporaied in the two LP Gas meter codes in Handbook 44, namely, if used they should be used the year around and the customer should be made aware that he is receiving a temperature compensated volume.

2. Should all companies within a given state be required to use automatic compensators if they are recognized in the code?

We feel the use of automatic temperature compensators should not be made mandatory, but rather permissive. Unfair competition and consumer misunderstanding has never resulted with respect to the sala of LP Gas where temperature compensation is used. As a matter of practica, most companias in the northern cilimates do use ATC's.

Furthermore, the subject of mandatory use must ba derided upon at the individual state level rathar than 1 ? Handbook 44. Handbook 44 should go mo further than 
recognizing their use with appropriate controls.

We would be pleased to assist with providing any further data needed for this study.

QUESTION: You said that you thought automatic temperature compensators should be permitted, yet the question comes to my mind is that if it is not a problem, why not make it mandatory?

MR. LINDBLOOM: We believe the mandatory requirements should be left up to the states, and not make it mandatory in Handbook 44. The states can then apply it on a mandatory basis, if they so desire.

QUESTION: You sell much more liquid, as we heard yesterday with fuel oil, in the winter time than in the warmer months? I suppose that would be true, wouldn't it? MR. LINDBLOOM: That would be true, yes.

QUESTION: Consumers, when they are charged for 100 gallons, are getting a lot less than 100 gallons, aren't they at 1.6 percent expansion per $10 \%$ and with temperatures down around 40 and 50 degrees?

MR. LINDBLOOM: They are geting a hundred 231 cubic inch gallons compensated to bo degrees $F$. 


\title{
VIEWPOINTS FROM THE FIELD OF
}

\section{WEIGHTS AND MEASURES}

\author{
Darrell A. Guensler
}

Division of Measurement Standards

\section{State of California}

It is a pleasure to be here today to present the

viewpoint of the California Department of Food and Agriculture on the subject of the "Temperature Compensation." The Director of this Department is responsible for the enforcement of weights and measures laws in California.

Dur state, which has a population of approximately 22 milion people, experiences gasoline sales in the neighborhood of a billion gallons a month. I think it is safe to say that competition is as keen in California as it is elsewhere.

First of all, I'd like to attempt to set the record straight on a few points.

We do not question the contention that temperature correction provides the most uniformly accurate gallon of gasoline. The same is true for any liquid.

We also agree that there are inconsistencies in the method of sale of petroleum products.

We do, however, question the motives of some of those who so strongly advorate temperature correction at retail.

Be that as it may, we have attempted to evaluate the topic in a purely scientific and economic manner as it relates to what we believe our mission or role to be. We have attempted to define our role with the following statement: 
"To preserve and maintain the standards of measurement essential in providing a basis of value comparison for consumers and fair competition for industry.

Practically every technical decision we make is evaluated with regard to this role statement.

On the general subject of temperature compensation, we have the following conditions present in California:

By law, all sales of gasoline in quantities of 5000 gallons or more must be offered on a temperature compensated basis.

All packaged 1 iquid petroleum products must represent their volumes at 60 degrees $F$.

There is no law against compensating for temperature change at either wholesale or retail.

Specifications have been developed which recognize whole deliveries of gasoline, diesel and LPG as well as LPG by vehicle tank meters on a temperature compensated basis.

Temperature compensation actually takes place on many sales of LPG and on most wholesale deliveries of gasoline.

Retail sales of fuel oil by vehicle tank meter is not a particularly significant business in California, at least when compared to the northeast section of the nation. To my knowledge, there is no temperature compensation taking place on these types of sales.

Some Possible Problems in the areas just mentioned are:

On LPG sales by vehicle tank meter, there is a tendency to temperature compensate in the northern part of the state where the temperatures are generally below 60 degrees $F$. and to not compensate in the southern part. Dur requirements are only that once started, compensation must continue throughout the year. Possibly, there is a need to require all dealers in a given marketing area ("Marketing Area" would have to be defined) to either compensate or not. We believe that this should be addressed in the "Model State Method of Sale of Commodities Regulation".

On wholesale deliveries of gasoline (over 5000 gallons) there are some practices such as temperature averaging which are questionable from the standpoint of individual accuracy and which are difficult to verify. Because of this, legislation has been introduced in California to provide more accountability on the part of the Seller. 
Specifically with regard to retail sales of gasoline, the current situation in California is:

It is reasonable to assume that more gasoline is solo at retail above 60 degrees $F$. than below. There is no temperature compensation taking place now.

We have heard of only one supplier of retail temperature compensation equipment. We have not evaluated such equipment

(Our Department did not participate in the tests mentioned by George Mattimoe.)

We have received no complaints regarding temperature compensation at retail except for those obviously generated by the advocate group.

It is our understanding $t$ hat at least one of the strongest advocates of retail temperature compensation has at least an arm's length financial interest in this equipment.

There seems to be no question that sales of gasoline at retail would be more uniformly accurate if they were temperature compensated.

The questions are:

Is it necessary to temperature compensate in order to preserve and maintain the standards of measurement essential in providing a basis of value comparison for consumers ard fair competition for industry?

Is mandatory temperature compensation worth the cost?

If we attempt to answer these questions with a simple yes or no, we believe that the answer, in both sases, would have to be no. However, such a simple answer does not really do justice to such a complex subject.

In order for value comparison and fair competition to function properly, it is necessary that:

The galion be the same size throughout the competitive marketing area, and

The quantity represented must be verifigble. 
Even though it is fact that in the summer the gasoline sold in the desert is warmer thath that sold in the high mountains;

when a person attempts to value compare or a business person attempts to compete, generally, the conditions are the same within their particular area of interest. Provided no one is artificially controlling the temperature of the product, everyone gets a fair shot.

Obviously, if we were to require temperature compensation at retail gasoline outlets, there would be costs involved. Obviously, the ultimate consumers of the gasoline would absorb such costs. Phasing in equipment on a normal replacement cycle would minimize costs but would create a non-uniform, chaotic condition which could last in excess of 10 years. Since

that is not realistic, change would have to be accelerated to some reasonable period which would then require retro-fit or premature replacement resulting in high costs. Maintenance and inspection costs would also increase.

If you assume a conservative cost of $\$ 500.00$ per dispenser, the cost to the consumers in California alone would be equal to $\$ 70 \mathrm{million}$. This does not include maintenance and administrative costs.

In our opinion, the result is simply not worth the cost.

Dur eyes and minds remain open.

Thank you.

\section{VIEWPOINTS FROM THE FIELD OF}

\section{WEIGHTS AND MEASURES}

MR. SIMILA: We have about 10 minutas before we need to break for lunch. I would like to have the S\&T Committee come on up to the front and maybe we could open up a little discussion for those who can't stay after the lunch period. We will reconvene at $1: 30$ to discuss same of the weights and measures issues or get weights and measures.viewpoints on any or all of the subjects we have discussed here, particularly the information developed here in the past day and a half. This information is going to be fad into the deliberations of the Specifications and Tolerances Committee of the NCWM. It is that group that is going to have to wrestle with, at least initially, any recommendations.

We have heard quite a bit now from representatives of industry. We do have some Weights and Measures people here to 
be heard from. Jim Bird, would you want to lead off? The Committee may have areas in which they would like to challenge the people here to provide further information; maybe you would open it up that way.

MR. BIRD: Ken, the only response that I can make at this time is that in the past two days all of us have heard a great deal offiformation which may have been available for a long period of time, but has not focused at one time and place. We have a mountain of information that the Committee is going to have to digest and make recommendations upon.

As I said in my opening remarks yesterday, there are many impacts to the problem. It has long been established that we want to maintain equity in the marketplace. It involves all of this. It also involves other committees in the NCWM. It also involves everybody that attends the NCWM Defining what "equity" is, is our responsibility and also whether a certain precision of measurement is economically defensible. Even though everyone of us in the room and in the conference, and on this Committee, have certain personal biases, if we put things together, we hope that the biases are balanced out so that when the Committee makes its final recommendatins, we have a good balance of proper and equitable positions to offer the conference.

As I indicated yesterday morning, not only do we have inequities in some states, we have regional inequities. As Darrall mentioned this morning, California, in a way, is unique. They have a population island in which they can make decisions that are effective state-wide and that do not impact upon other states in a tremendous manner; in the Northeast, anything that Massachusetts decides affects Neul York, Pennsylvania, New Jersey many times, and what we decide affects them. In the 14 states in the Northeastern

Conference, what each one decides impacts on the others because we have cross-overs. We are not unique; it is a large marketing region, and this is one of the things that we have to get together on so as to set a standard for the whole area.

Dick here indicated this morning that as soon as a requirement, if I understand it correctly, appears in NBS H-44, it automatically becomes required in Maryland. That is not quite the case in New Jersey because certain laws say that you must sell in a certain way. In New Jersey all of the LPG meters, no matter what they are for, whether it is for industrial purposes or for retail, they all have temperature compensators on them. If one has it ithey all have to have it, so that they have a uniform basis of competition.

We have several states represented here who have viewpoints to be brought forward and at this time.I would like to invite those who have viewpoints, from either their state or region or other associations to give those. I 
believe Bob Probst from Wisconsin will be the first.

MR. PROBST: I think that the confensus of the Northwest Weights and Measures Association was that they would not favor temperature compensation of fuel oil. That would be my observation of their position.

On some states I may not be speaking on too firm a ground but with regard to our friends in Minnesota, I was admonished to come down here and tell you that is the way they feel for sure.

As Director of Weights and Measures in Wisconsin, I can give you a little background as far as we are concerned. From the gasoline side, we have about 5900 gas stations, 'and we figure we have about 31,000 pumps. I will extend my invitation to the Shell Oil Company to come and open up as many metric stations as they want to in the state of Wisconsin. The Speedway Company, the consolidated Speedway, opened and operated a metric station in the State of Wisconsin for two years and I asked them why they quit operating. They said they did not get any competition so they went back to gallons.

In the State of Wisconsin, the sale of retail gasoline by the liter is legal, the only requirement being a price posting requirement which would quote the gallon and the liter price in the approximate same size out on their street signs. The liter price would show on the pumps without any question.

We have about 1,500 bulk fuel dealers in the state of Wisconsin. 1,500 of them and most of them are dealing in both - probably have two meters on their trucks. We figure that our last count was around 4,400 BTMs in the state of Wisconsin.

With regard to Handbook 44, our state does accept Handbook 44, but in the case of temperature compensation of fuel oil we have been advised by our Attorneys General that we would have to have a law change. They cite the incident where we had a change in our law to permit temperature compensation of LP and I think that law has been on the books since the early 60's and we are listed as one of the states that have required temperature compensation for LP. So the same logic would apply to temperature compensation of fuel oil. It would have to be a legislative matter.

The Retail Gasoline Dealers Association came to the Department at the beginning of the first energy crunch in 173. They came to us and asked us of the possibility of temperature compensation. They were just beginning to receive shipments temperature compensated to their station. They came and asked us for some relief and at that time we advised them that it souldprobabl:y be a legislative matter. They have not been back to us since.

One large fuel oil dealer in the State of Wisconsin who 
was represented at the Northwest Weights and Measures Meeting last month in Madison, also petitioned us for temperature compensation and the reason that they gave related to their trying to balance their books and also to the matter of tax collection. Tax collection in Wisconsin is done at the terminal level. The tax auditors are terribly suspicious during the heavy sale months if you have a one percent loss of their taxes. That was their reason for trying to make the books come out as well as possible.

Look at the consumer side. I guess we all like the idea of getting 101 gallons of fuel oil when we only buy 100 . I heat my house with fuel oil and to be honest with youf avoid buying fuel oil in the summer even though there is a price break.

Another area that I think should be mentioned is we are probably premature as far as the research and development, the availability, the installation, the cost of maintenance are concerned and it boils down to the question of who is going to pay the cost. I think that we recognize a better technology but I doubt that the conference can mandate this better technology.

SPEAKER: Thank you Bob for those comments. I balieve there is at least one other jurisdiction that had a statement. Pennsylvania?

SPEAKER: Thank you. My name is Ron Roof with the Pennsylvania Bureau of Weights and Measures. I am one of the lab men with the bureau there.

There is currently a very popular song that you hear on the radio called "Stumbling In" and, when it comes to automatis temperature compensators of fuel meters in Pennsylvania, we have really stumbledfinto it and we are about up to our neck with it.

It all started back about March 5, 1976. We had a request from a major oil dealer in the suburban Philadelphia area along with his equipment installer of petroleum type measuring devices to install these automatic temperature compensators on fuel meters. Nothaving any experience with it , we on the following month called a meeting in our Director's office to meet with the representative of the fuel company as well as a representative from the meter installer as well as the meter compensator manufacturer. At that time when I was involved in it, I wanted to make sure we had a firm understanding and be sure my superiors had a thorough understanding of what they were getting into. Basically, the only criteria that we had to work with were the conference statements of 1976 and 1977 by the $S$ and $T$ Committee 3 iving three reasons why you should not have automatic compensators on fuel meters, (1) there is 231 cubic inches to a gallon at the prevailing temperature; ( 2 ) that it would be unfair competition and ( 3 ) that the handbook does not address itself 
to compensators so therefore it should not be permitted.

We discussed in the meeting that we had a very serious public relations problem if it would get out to the public that these compensators were being installed and that we could not make a commitment on these compensators because the National Conference on Weights and Measures still had this under consideration.

So, the head of the bureau, with the cooperation of the companies, decided that we would run a test on a trial basis for approximately six months to a year on these devices and they were installed in October of 1976 and we conducted tests through February 1977. By that time, the company felt that they had cooperated fully with the Bureau of Weights and Measures on this and they wanted some type of decision made on whether they could keep them on or put more on or what they should do.

It was a great deal of expense to this company to install these devices. I still did not think there was enough information to the public on this so in August of 1977 we formulated a public hearing which was held in the Department of Agriculture Building in Harrisburg and we had representatives of the major oil companies, independent oil dealers, the device manufacturers, and Weights and Measures personnel, including representatives from the National Bureau of standards. What happened there was about as much as what we have covered here. The situation was still cloudy but noboidy who attended the meeting could say that there wasn't a full public hearing on this and that they did not understand what was going on.

During this whole time I was assured by quite a few people that this was sort of a dead issue, that most of the oil dealers would not want to put them on anyway because thermal expansion of fuel was not that appreciable, and the compensation was not that great. However, I have found that this is not the case. From 1977 to 197.8, we really did not have much going on. We still had the compensator at the one company. They had then installed a full 25 on their trucks. In June of 1978, we had another company contact us, another device manufacturer along with a fuel oil dealer in suburban Philadelphia requesting that they be able to go through the same testing procedure that the other company had gone through. So, again we started to go through the procedure with that company on about a six to eight month basis and that started in November of 1978 and continued on into this year.

Dating back to November 15 of 1979, I started having inquiries of the Bureau's Vehicle Tank Meter Inspector in this area telling me that more of these automatic temperature compensators had been installed at other places without our knowledge. I did a survey and as of November 15, 1978, which 
was this past winter, we have now 11 companies that have these compensators installed on their trueks with a total of 75 compensators in the Philadelphia area. I estimate that each truck is delivering about 400,000 gallons throughout a year's period of time so you can see that is the amount of oil that is being compensated right now.

There is a great problem on our hands. We issued a directive to the companies that they not put any more compensators on the trucks until we had had somedirection from the National Conference on Weights and Measures of what to do.

A couple of the problems that I encountered is that you cannot get a uniform thermal expansion rate in which to test the compensators. When we were testing them the company knew every day what their fuel was and what the API number on it was and you could make that correction when setting the compensator and their API's were down around 36 or 37 . When we went to the second company and dealt with another manufacturer, they wanted to use an absolute API number of 44 which would give them the maximum amount of expansion permitted or realized for number two fuel which would be triple R5. I felt that they might be taking advantage of the compensation because I did check with the major oil companies in the area and most of their API numbers were down around 37 or 38 so this was a problem that you run into. I understand there is a device now that you can check the API with right there.

With 11 companies that have compensators in use now, we have no statutory authority to require them to put a note on their bill or their invoice that the temperature is compensated to 60 degrees. If these devices stay in operation there is going to have to be some type of regulation enacted to make them put the statement on their bill or ticket.

Another interesting question is if a company is not buying fuel temperature compensated would they have the right to sell it temperature compensated? That is about where we stand.

SPEAKER: Ron, before jyou get away, are those 75 meters all one make now?

MR. RDOF: All but about 10 of them would be Neptune Automatic Temperature Compensators and the other 10 are Brooks. When we did this we required that the manufacturer be involved in the testing process. So far, the only two that have contacted us and have been able to line up fuel companies to purchase them and put them on their trucks and have the hassle of dealing with weights and measures on an every two or three month basis has been Neptune and Brooks. SPEAKER: Thank you. Jimmy Stewart.

MR. STEWART: Mr. Chairman. I come in two ways today. First, I am the 1979 Chairman of the S\%T Committee for the 
Southern Weights and Measurers Association which is the so-called sun belt. We go through Texas across the Gulf of Mexico and up the Eastern Seaboard to Delaware. We have already had our annual meeting and will not be able to give you any assistance until conference time. If the issue is not resolved to any degree in July, then the southern committee will be very active in developing some additional data for the 1980 conference.

Speaking as the representative from the Commonuealth of Virginia, our position, and I have it discussed with Mr.

Lyles who is Director of Weights and Measures for the state, is that if the conference permits the use of temperature compensators on vehicle type meters and leaves it as permissive, we can live with it. We are not for it or against it.

We are in a position to say that we do not favor automatic temperature compensators for retailed motor fuel dispensors. There are several factors that we have looked at. One is the cost to the industry. Another is the cost to the state government due to the time involved in the inspections. Manpower is just as meaningful to us in dollars as cubic inches are to gasoline dealers. So, Virginia's position at this time is as was stated yesterday. The percent of change today is the same at 50 cents a gallon as it was at 12 cents a gallon. Dealers made a living then and they can make a living now. So, we are not in favor of ATC at the retailed dispensors. Thank you.

SPEAKER: Thank you. Are there any other weights and measures jurisdictions that are represented here today that would like to add their comments?

SPEAKER: Before you get away, Darrell, I would like to ask you, what is the situation in California on propane? Is that permissive compensation?

SPEAKER: Yes, for propane measurement, it is --the requirement is that, once you start temperature compensating, you must continue to do it for the entire year. You can't indiscriminantly put it back and forth but there is no requirement for or against temperature compensation. It is permissive.

SPEAKER: Mr. ThOmpSON?

MR. THOMPSON: Mr. Chairman, all of the things that we have heard here the last day-and-a-half, I think probably down deep. many of us knew portions of that. I see some very troublesome aspects and I think Darrell covered probably most of what many of us feel.

Dne item that has not been touched on and it is not a technical itemi it tends to be an emotional one at this stage of the game and in this day and time when the cost of fuel has gone quite high. I understand what some of the speakers have said, that the increased cost has resulted in some 
difficult situations for them; where they could absorb losses before, now they no longer feel they can afford these losses.

But, like it or not -and I am basing this comment on complaints we have received and the tone of those complaints - we must consider the suspicions of the public. A reporter recently said to me, "Now, tell me, Dick, where is it that the gas stations are really ripping off the public?" He has already made his mind up; he already believes that. I heard on the news not long ago the Energy official for the State of New lersey say he does not believe that there is a fuel shortaga. There are other people that say that. Now, I think, down deep, the American public right now, along with this concern. has a deep-rooted suspicion that things are maybe not what they appear to be.

With all of this in mind, when we say now, "We1l, we can't absorb the difference," I wonder if the consumer, the purchaser of the fuel in its final form, isn't going to turn around and say, "Yeah, well, if it is so good now, why did you not do it way back when it would have been insignificant to me? Now, you are going to suggest to me that we are going to compensate --" let's just talk about fuel oil for a moment --"going to compensate when, during the time fiame of the year, when I buy most of my fuel (because most people don't have a thousand gallon tank, and I am not likely to put one in) you are going to ask me to take less than I have been accustomed to getting, with prices as high as they are nou. "

I 1 istened to Ron a moment ago wilen he talked about this hearing he had --and I am not knocking the state of

Pennsylvania in this comment at all--I know how difficult it is sometimes when you think you have covered all bets but you find out you didn't. There was one group he did not mention that attended that hearing and those were the people who buy the fuel. I did not hear any mention of home economists or consumer groups, or what have you. I wonder really if any of us did notrely upon Handbook 44 right now and we went before our respective legislators, our general assemblies, and said, in effect. "We want to give less fuel, " what their reaction would be. And, I can't argue with the intent and what we are really striving to do, but I think we do have to keep in mind this emotional consideration. This is really a new slant for me because I don't often feel this way. I wonder, at this time, if this is really the right thing to do? I am not suggesting it is not. I am just suggesting that maybe the problem is even bigger than we thought two days ago. Thank you.

MR. CHAIRMAN: Any ofhter comments? From jurisdictions or anyone else, for the benefit of the Committee.

MR. STADOLNIK: I have some very brief comments. I would just like to commend Darrell Guensler and Diek Thompsor ror some very excellent observations. 
I did submit to the Committee what I termed to be a comparison rough statistical breakdown relating to volume of \#2 fuel oil and gasoline on an uncompensated and compensated basis in the Commonwealth of Massachusetts.

I will address myself specifically to \#2 fuel oil which is a rather significant fuel in Massachusetts. The statistics that I presented are not based on any actual measurement of product. I obtained actual monthly deliveries of \#2 fuel oil in the State of Massachusetts for 1977 and 1978 and used a monthly mean temperature that we obtained from the US Weather Bureau - we obtained only an approximation of the degree of change due to compensation to 60 degrees.

Now, on \#2 fuel oil, we found that in both 1977 and 1978, on a compensated basis, the consumers would be charged for an additional $17 \mathrm{million}$ gallons, approximately. With the present day market of roughly 60 cents a gallon for heating oil in Massachusetts, you are talking about an added cost of about \$10 million on an annual basis.

Now, we talk about gasoline going up to \$1 a gallon and I think it is only fair to assume that the price of \#2 fuel oil will not be far behind, so that this cost factor will continue to change.

I think there are several points that have to be considered and I think Dick brought one of them out with regard to, if such a concept was to be adopted in a particular jurisdiction or region, what would be the best type of approach? I think merely by changing handbook 44, we really are not going to solve very fundamental issues with regard to temperature compensation. If we adopt our regulation in Massachusetts now, not only are we entering into an area of legislative review of regulation, but there is also a significant interest in the economic impact of changes by adoption of new regulations.

I think the comment was also made that there should be some consideration by the $L$ and $R$ Committee towards drawing up a draft of a model regulation for the method ofsale of commodities. To the best of my knowledge, I don't believe that most of the states, or the great majority of states, have adopted the method of sale in its total form. I know many states have extracted certain portions of that particular model and have passed legislation.

Food and fuelit the two most significant necessities of life and there would be a great deal of legislative interest in such a matter. I think that the course for those that seek temperature compensation to followinitialiy legislative remedy and if that was approved then, through the technology adopted in handbook 44, address the technical aspects of it. Thank yos very much.

SPEAKER: In your comment you suggested that if lagislative people approve such an approash, then we should 
have the appropriate requirements in handbook 44 . I guess we are back to that chicken and egg dilemma of what needs to be done first. Is there need for some changes to the handbook so that it can guide legislative policy or should we wait till there is legislation on the books before the committee needs to propose what changes should be adopted? I am just tossing that out as a possible dilemma we are now facing.

SPEAKER: I wish I had an answer. I think we have had one di lemma in Handbook 44 to begin with; it is the provision for allowing temperature compensation in wholesale metering systems. I really do not know how that developed and why it developedi whether this was a regional problem or an isolated state problem. But you have that in there. Now what happened seven or eight years ago all of a sudden becomes a different type of a look-see at this particular section of handbook 44. I want to make one other comment that I didn't have an opportunity to make before. We heard several remarks made by previous speakers about artificially heating the product. And again this is an area that would have to be addressed in any type of legislation as to what type of restriction, what type of policy, would have to be adhered to with regard to that type of situation.

I understand that in some areas that sell number 2 , they claim that in certain periods of the year, they may have to heat number 2, particularly when temperatures fall to subzero level. But when you get to heating to around bo, how much control do they have to heating to 60 ? And if you can heat it to 60. why not to 70? And if not to 70, why not to 80? These factors are not really outlined that definitively in many of our laws and regulations. And as tanks and customs and trade practices change, I think we have to change along with them to recognize these particular aspects of either potential fraud or possible mistakes in heating.

SPEAKER: A thought that has occurred to me and maybe some of you: we have an interesting paradox in some of the states that are represented here now, even those that only have a recognition of temperature compensation on a permissive basis in liquified petroleum. I can see in a state where number two fuel oil might be, at least, on a limited basis, allowed to be compensated now. It might even be more paradoxical there where you can have the same category of user treated differently depending on which fuel they are purchasing even though they are purchasing it in the same amounts.

Take for example motor fuel applications. Granted, there is very little carboration for motor fuel purposes of propane. But we have a truck stop and I am sure others have where this is the case, you can buy propane for motor fuel temperature compensated. You could also in the state ef oragon or California, perhaps, buy propane that is not 
temperature compensated for motor fuel. Similarly, in the area of diesel or the near cousin to number two, you might be buying motor fuel in 150 or 200 gallon quantities, diesel uncompensated. You might be buying number two fuel oil for home heating in 100 gallon quantity temperature compensated An so even though the amounts might be comparable and even in some cases the application is comparable, we may now be treating the same group differently depending on the fuel and so forth.

So we have some inconsistencies even where we have done nothing really to deliberately distinguish between the same type of use. The committee has been sitting rather solemnly drinking all of this in. Some of them have spoken. I might at this point ask if Jim or the committee have additional comments they would like to make.

SPEAKER: I am Bob Kelley, New York City Weights and Measures. I have a question for the committee. I think based on what we have heard here, putting aside any possible equities involved in temperature compensation, the next question would be is it feasible in the field?

can you test it and if such a law is enacted, can it be enforced? An unenforceable law is worse than no law at all. I just have to leave that hanging.

SPEAKER: We have covered considerable ground in this day and a half. Primarily it was convened as indicated for the purpose of the discussion of the temperature compensation issue although two other subjects have been brought up. At this point, if anyone has anything additional they would like to bring out in those other areas which include the price computation problem resulting frombver 99.9 cents per gallon and the corollary to that, metric conversion which is one of the options in the

pricing issue. We would entertain any additional comments anyone would like to address to that subject at this time.

SPEAKER: Mr. Chairman, Jim Crowley from wild, wonderful and almost heaven. West Virginia. My director, Mr. Griffith, asked me if we could in the state of West Virginia, and probably some other states have the same question, if we could come away from this meeting with some kind of an idea or a suggested guideline as to what and how lye are going to attack this problem.

After thinking about the discussion yesterday, it looks to me like there is a possibility we can go ust here in the field to states individually and attack this: possibly 50 different ways. This kind of reminds me of some of the comments that have been made. You go across a crossroad somewhere where two highways intersect and you have four gasoline Etations, one on each corner. One is selling by the gallon where they have converted over possibly going from 
\$1.00 to \$1.99. Across the street another is selling by quarts. Another corner they have used the half price method. Then the fourth one, he is selling by the liter, metric conversion. When you are driving down there what station are you going to choose?

SPEAKER: Any additional comments? I think we are back to another dilemma that we have all recognized at least in the weights and measures area for sometime; we want to provide leadership particularly through the conference so that people know what they can do andwhat is acceptable and which route to $g 0$.

On the other hand, it has been brought out here in several parts of the discussion that if we exert too much leadership we are usurping - taking over the perogatives of our legislative bodies and they get a little uniappy. In some cases we are content to be followers and let them take the leadership. In this kind of an issue it is kind of difficult to see where to draw the line. Certainly in terms of the metric option.

However, I certainly sympathize with and would like to use this forum of the national conference if at all possible in providing whatever leadership is practical, possible and politicallylacceptable at this point. So the purpose of the symposium has been to develop information, to dialogue on it, to get additional information to the standing committee on specifications and tolerances.

The information we have received here during the past two days will be digested and considered by the committee and certainly spoken to in some form at the national conference in July, whether it will simply be a report or concrete recommendations. It is past the interim meeting stage and the tentative report of the committee is ready to go to press.

The issues involved certainly can be spoken to and we do have the perogative, I guess, in areas where there is some sort of urgency or emergency to bring up new material. However, that has been used very sparingly in the past. Certainly some of the topics we have discussed here today and developments that have brought them about may be in the category that we will have to take extra-ordinary steps in trying to bring some of the issues to a decision-making point by July.

On behalf of myself I would like to thank the speakers and those of you who took the time out of your busy schedules to be with us. At this point, I will ask AlTholen if he has any comments and closing remarked on behalf of the office or Weights and Measures, the co-sponsor of our symposium being the National Bureau of Standards.

MR. TALEN: For the Office of Weights and leasures I also want to thank the close to 100 folks who took the time to come and share their opinions, their knowledge and their 
facts with us.

I want to commend the committee, the S\&T committee, for appearing in 100 percent force.

I want to thank Ken for moderating the meetings and handling everything in a very even-handed manner.

I would be remiss if I didn't commend atto Wornloff who was the prime mover in putting the program together. I think we have had a very outstanding couple of days.

I would like to put a personal piece of what I consider urgent business. I do believe this question of the price at the pump going over 99.9 cents is one that ought to be addressed by the committee with a recommendation to the conference.

If they have a consensus on the committee, considering everything they know, of what the best way to go is, I think it would be helpful if this could be sent out to the states. We certainly would be willing and happy to special mail that sort of advice whether it is unofficial, a general opinion, or what.

An addendum to the Tentative Report of the NCWM Committee on Specifications and Tolerances is on the following page.

MR. THOLEN: I just want to thank everybody for a very fine meeting. I think the manners displayed and the willingness to share have been exemplary.

MR. SIMILA: In conclusion, I hope to see as many of you as can make it out to Portland, the rose city, in July for the 64th Conference where with decisive leadership - -inhat is it our friend, Gary, has described - we, the unwilling, led by the unknowing are doing the impossible for the ungrateful and we have become so used to doing everything with nothing that we can now do the impossible with nothing --or something like that.

Thank yoú.

(Whereupon, the symposium concluded.) 
ADOENOUM

TO THE TENTATIVE REPORT OF THE

COMMITTEE ON SPECIFICATIONS AND TOLERANCES

This addendum results from information obtained during the Temperature Compensation Symposium which is referenced in Item 307-l of this report.

Since automatic temperature compensators that interface with vehicletank meters are apparently readily available from several manufacturers, it is the view of the committee that this technology should be recognized in the Code for Vehicle-Tank Meters. It is also the committee's view and intent that this action neither requires this equipment to be used, nor does it make its use entirely voluntary. It merely removes an obstacle if, in the sale of any product measured by a vehicle-tank meter, it is considered appropriate and legal to compensate for temperature variations.

In order to provide for the sale of products at a reference temperature, further changes to weights and measures laws and/or regulations will be required. The committee offers the following as a guide when this action is to be taken.

The gallon is defined as being equal to 231 cubic inches. Providing for the measurement of volume at specified temperatures can be done in a manner similar to that followed in the Model State Packaging and Labeling Regulation which specifies reference temperatures for various kinds of commodities. An example of a suggested regulation is:

TERMS: LIQUIO MEASURE, HOME HEATING OILS.--Whenever home heating oil is sold or delivered to a consumer by liquid measure, the volume sold and delivered shall be in terms of the United States gallon of 231 cubic inches and the volume shall be expressed at $60^{\circ} \mathrm{F}$. This may be accomplished through the use of an approved meter equipped with an automatic temperature compensating mechanism, or the use of an appropriate volume correction table.

This regulation will result in equitable, efficient and uniform marketing of fuel oil in that all buyers and sellers will be on the same basis at all times.

The specific changes that would need to be made to the Code for Vehicle-Tank Meters cannot all be conveniently presented herein. The numerical designations of those code paragraphs which are presently in the liquid-measuring device code that the committee recommends be included in the vehicle-tank meter code are as follows:

Paragraphs from Code for Liquid-Measuring Devices Recommended for Incorporation in the Code for Vehicle-Tank Meters:
5.2.6.
S.2.6.1.
5.2.6.2.
5.2.6.3.
S.2.6.4.
S.4.3.2.
iv. 4.1 .
N. 4.1.1.
N. 5 .
UR. 3.5 .
UR. 3.5.1.
UR. 3.5.2.
UR. 3.5.3. 
NBS. $114 A$ Q $E$. 9.78

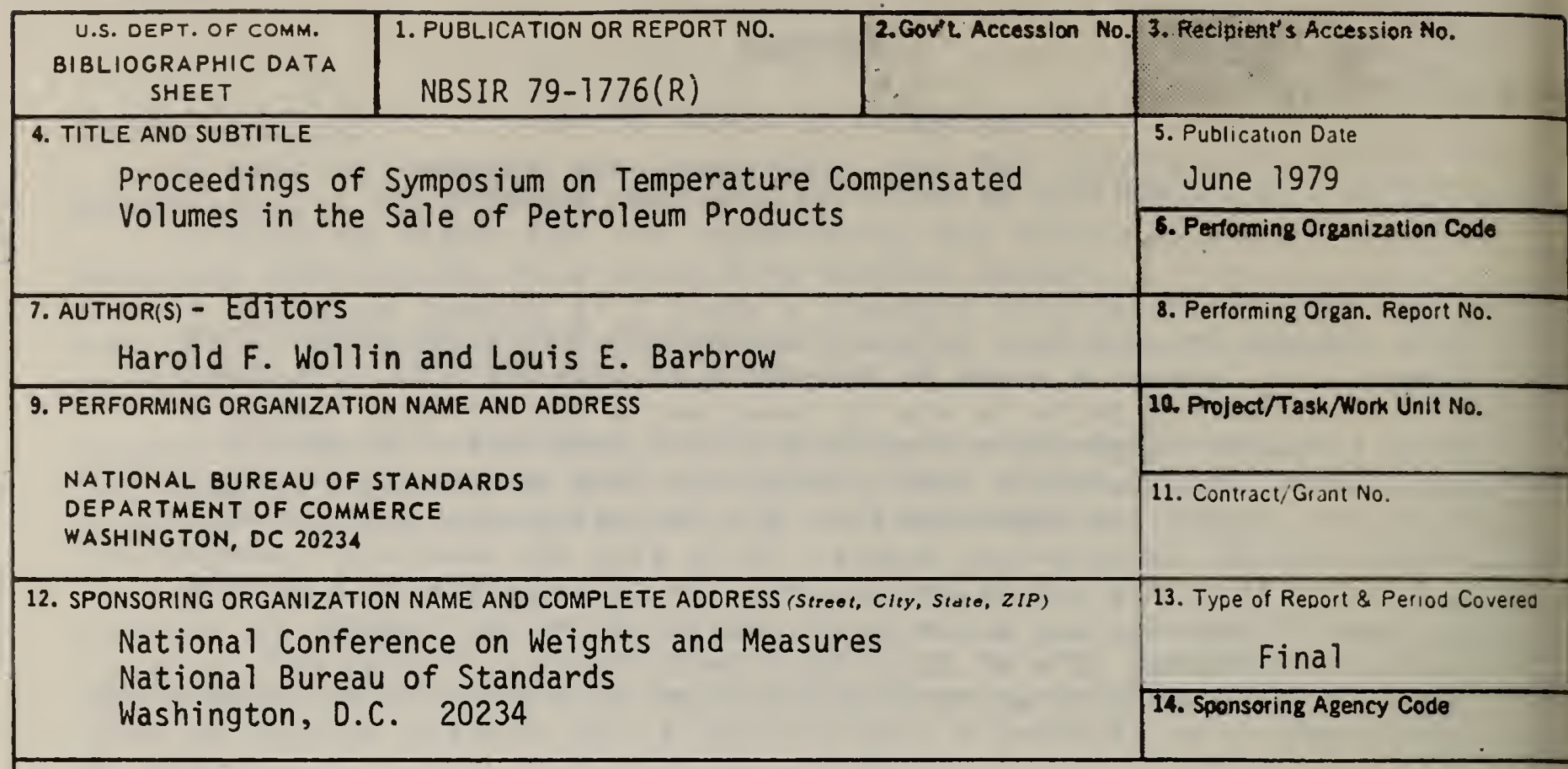

15. SUPPLEMENTARY NOTES

Document describes a computer program; SF-185, FIPS Software Summary, is attached.

16. ABSTRACT (A 200-word or less factual summary of most significant infomation. If document incfudes a significant bibliography or literature survey, mention it here.)

This is a report of the proceedings (edited) of a Symposium held at the National Bureau of Standards on April 3-4, 1979.

The central matter discussed was the delivery of petroleum products over a wide range of temperatures and procedures for (1) automatically compensating, or (2) correcting deliveries to what they would have been under standard temperature conditions $\left(60^{\circ} \mathrm{F}\right)$.

17. KEY WORDS (six to twelve entries; alphabettcat order; capitalize only the first fetter of the first key word unless a proper name; separated by semicolons)

Automatic temperature compensation; computed temperature compensation;

neasurement assurance; temperature coefficient; temperature compensation; volume (all of petroleum)

18. AVAILABILITY Unlimited

X-For Official Distribution. Do Ifot Release to NTIS

Order From Sup. of Doc., U.S. Government Printing Office, Wasinıngton, DC 20402, SD Stock No. SNÓO3-003-

- Order From National Technical Information Service (NTIS), Springfield, VA. 22161

\begin{tabular}{|l|l|}
\hline $\begin{array}{l}\text { 19. SECURITY CLASS } \\
\text { (THIS REPORT) } \\
\text { UNCLASSIFIED }\end{array}$ & $\begin{array}{c}\text { 21. NO. OF } \\
\text { PRINTED PAGES } \\
123\end{array}$ \\
\hline $\begin{array}{l}\text { 20. SECURITY CLASS } \\
\text { (THIS PAGE) }\end{array}$ & 22. PIICE \\
UNCLASSIFIED & 282 \\
\hline
\end{tabular}


